Jairo Paes Cavalcante Filho

\title{
PARAMETRIC OPTIMIZATION OF A SUPERSONIC SWIRLING SEPARATOR
}

\author{
Dissertation submitted to the Poly- \\ technic School of the University of São \\ Paulo for the Master in Science degree \\ in Mechanical Engineering.
}


Jairo Paes Cavalcante Filho

\section{PARAmetric Optimization of A SUPERSONIC SWIRLING SEPARATOR}

Versão Corrigida

Dissertation submitted to the Polytechnic School of the University of São Paulo for the Master Degree in Mechanical Engineering. 
Autorizo a reprodução e divulgação total ou parcial deste trabalho, por qualquer meio convencional ou eletrônico, para fins de estudo e pesquisa, desde que citada a fonte.

Este exemplar foi revisado e corrigido em relação à versão original, sob responsabilidade única do autor e com a anuência de seu orientador.

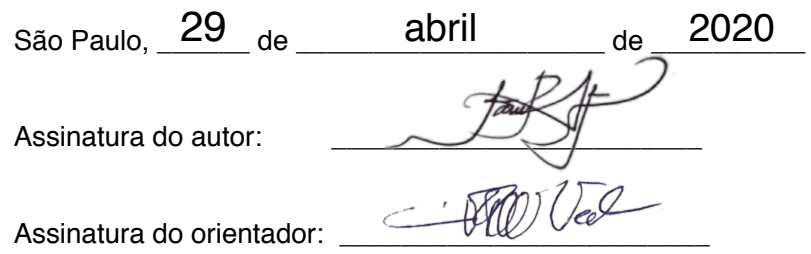

\section{Catalogação-na-publicação}

Cavalcante, Jairo

Parametric Optimization of a Supersonic Swirling Separator / J.

Cavalcante -- versão corr. -- São Paulo, 2020.

$65 \mathrm{p}$.

Dissertação (Mestrado) - Escola Politécnica da Universidade de São Paulo. Departamento de Engenharia Mecânica.

1.Mecânica dos Fluidos 2.Gás natural 3.Adjoint Method 4.Parametric Optimization 5.Supersonic Swirling Separator I.Universidade de São Paulo. Escola Politécnica. Departamento de Engenharia Mecânica II.t. 


\section{DEDICATORY}

To my parents, Jairo and Acyris;

sisters, Berenice and Marília;

and son, Davi;

who have cooperated in this journey with their prayers, incentive and love. 


\section{ACKNOWLEDGEMENT}

First of all, I want to acknowledge and praise Jesus Christ for allowed myself to complete this journey, with the words of Apocalypse, 1.5-6:

Unto him that loveth us, and loosed us from our sins in his blood, and hath made us kingdom, priests unto God and his Father; to him be the glory and the power unto the ages of the ages. Amen.

\section{-literal translation}

To Professor Ernani Vitillo Volpe, my advisor, I am grateful for his accurate guidance in all phases of this work, for he has introduced me to the use of Adjoint Method for aeronautical applications, whose challenges force us to improve our knowledge of the physics and mathematics of the flow problem. We have shared many fruitful ideas on how to face the swirling flow, and the opportunity to get a deep learning on those disciplines. I am thankful to the members of my dissertation committee, Professor Carlos Roberto Ilário da Silva and Professor José Luis de Paiva: Their rich commentaries and contributions have been a new opportunity in my learning career. I thank to Professor Marcelo Tanaka Hayashi for many clarifying discussions on numerical methods and his mentoring as well. Professor Fábio Saltara has contributed with his large experience in turbulence models. Professor João Luis Azevedo, has shared his vast CFD experience and advices. Professor Marcos de Mattos Pimenta has also shared advices from a long academic career. Professor João de Sá Brasil Lima and Professor Bruno Galelli Chieregatti have shared their enthusiasm and many edifying commentaries: Marcelo, João and Bruno have once been part of the NDF2 laboratory, where this research has been developed: The collaborative environment there has given opportunity to several useful discussion with colleagues Ulisses Adonis Silva Costa, Luccas Koji Kavabara, Arthur Cato and Murillo Souza dos Santos Pereira Neto. The support provided by our Information Technology collaborators, Claudenor Rocha and Paulo Faggioni Filho has been instrumental. The administrative support to this project has been managed by our secretaries Marisa Lara and Regianne Amaral. I want to thank to STI-USP (Superintendência de Tecnologia da Informação da Universidade de São Paulo) for the HPC environment and support 
and to FUSP (Fundação de Apoio à Universidade de São Paulo) for the funding throughout this project.

Finally, I want to thank to my family for the unconditional support to this challenge. 
Remember that thou magnify his work, whereof men have sung. All men have looked thereon; man beholdeth it afar off. Job 36.24-25, American Standard Version. 


\section{ABSTRACT}

Supersonic separators of carbon dioxide $\left(\mathrm{CO}_{2}\right)$ consist in a relatively new technology which addresses two key factors in the Natural Gas processing: Firstly, as a carbon abatement tool, it efficiently removes most of the $\mathrm{CO}_{2}$ present in the natural gas composition, especially when there are large concentrations of carbon dioxide - this is the case in several production units in the Brazilian pre-salt basin; and secondly, due to its compact size, it can fit in the reduced space available on the Floating Production Storage and Offloading (FPSOs) units. This project objective is to optimize the overall performance of the supersonic separator, but keeping the original footprint, allowing more room to the phase change processes that take place within its body, by delaying the position of shock waves and by increasing the swirl intensity as well. Owing to their strong dependence on both the occurrence of shock waves and the system geometry, this class of applications could greatly benefit from parametric optimization techniques. That is precisely the rationale behind the choice of the adjoint method, which can, in principle, serve both purposes. In that regard, it should be added that, although the physics of supersonic processes has received significant attention in the literature, there are few references that consider their optimization for supersonic swirling separators. The supersonic separator here studied, has two main components, a static swirl generator, which is responsible for the swirling flow; and a convergent-divergent nozzle, where the phase change processes take place. A hub which sustains the swirler goes across the entire length of the separator. The working fluid is methane $\left(\mathrm{CH}_{4}\right)$ with ideal gas behavior. For this project, the open software SU2 (formerly meaning Stanford University Unstructured) has been selected, which brings opportunity for the University of São Paulo (USP) to contribute in this field, and allows communities around the globe to benefit from the innovation provided by this project. A first contribution of this project in the SU2 community has appeared in the 6.20 release of the code, concerning Discrete Adjoint formulation and nozzle flows. Continuous Adjoint, thought, has been used in this project, owing to memory constraints in laboratory computers.

Key words: Parametric Optimization, Adjoint Method, Flow Solver, Supersonic Swirling Separator, Swirler, Natural Gas, Carbon Abatement. 


\section{RESUMO}

Separadores supersônicos de gás carbônico $\left(\mathrm{CO}_{2}\right)$ constituem uma tecnologia relativamente nova que trata dois fatores-chave no processamento de gás natural: Em primeiro lugar, como ferramentas para a redução da emissão de gases de efeito estufa, removem eficientemente a maior parte do $\mathrm{CO}_{2}$ presente na composição do gás natural, notadamente quando sua concentração é elevada - este é o caso em diversas unidades de produção nas camadas de pré-sal brasileiras; e em segundo lugar, devido ao formato compacto, é possível empregá-los em plataformas flutuantes de produção (Floating Production Storage and Offloading - FPSOs). O objetivo deste projeto é optimizar o desempenho geral do separador, mantendo seu espaço ocupado original, permitindo mais volume para os processos de mudança de fase, ao atrasar a posição da onda de choque, bem como aumentando a intensidade do turbilhonamento (swirl). Graças à sua forte dependência da presença de ondas de choque, bem como da geometria do sistema, esta classe de aplicação pode beneficiar-se grandemente das técnicas da optimização paramétrica. Este é precisamente o raciocínio por trás da escolha do método adjunto, que, em princípio, serve aos dois propósitos. A este respeito, deve-se acrescentar que, apesar de a física dos processos supersônicos ter recebido significativa atenção na literatura, poucas referências consideram sua optimização para separadores supersônicos dotados de turbilhonamento. O separador aqui estudado possui dois componentes principais: um gerador estático que provoca o turbilhonamento (swirler), que é responsável pelo escoamento turbilhonar; e um bocal convergente-divergente, no qual ocorre a mudança de fase. Um eixo central sustenta o swirler e acopanha todo o comprimento do separador. Metano $\left(\mathrm{CH}_{4}\right)$ é o fluido de trabalho, com comportamento de gás ideal. Para este projeto, a ferramenta de código aberto SU2 (nos primeiros tempos significando Stanford University Unstructured) foi selecionada, o que traz a oportunidade para a Universidade de São Paulo (USP), de contribuir neste campo, e permite que comunidades ao redor do globo beneficiem-se da inovação provida neste trabalho. Uma primeira contribuição deste projeto na comunidade SU2 apareceu no release 6.20 do código, concernente à formulação do modo Adjunto Discreto e a escoamentos em bocal. Adjunto Contínuo, porém, foi usado neste projeto, devido a restrições de memória nos computadores do laboratório.

Palavras-chave: Optimização Paramétrica, Método Adjunto , Solver de Escoamento, Separador Supersônico com Turbilhonamento, Swirler, Gás Natural, Redução na Emissão de Dióxido de Carbono. 


\section{CONTENTS}

List of Figures vi v vi vis

List of Tables $\quad \mathrm{x}$

Acronyms

$\begin{array}{lr}\text { List of Symbols } & 1\end{array}$

1 Introduction 1

1.1 Separation Tecnologies . . . . . . . . . . . . . . . 1

1.2 Supersonic Separator . . . . . . . . . . . . . . . . . . . 3

1.3 Scope and Objectives . . . . . . . . . . . . . . 5

1.4 Why Adjoint Method has been chosen . . . . . . . . . . . . 9

2 Adjoint Method 13

2.1 Adjoint Overview . . . . . . . . . . . . . . . . . 13

3 Arina Nozzle Optimization $\quad 20$

3.1 Closing remarks . . . . . . . . . . . . . . . . 26

4 Integrated Separator Optimization 33

4.1 Swirler . . . . . . . . . . . . . . . . . . . 33

4.2 The 3 D Euler approach . . . . . . . . . . . . . . . 35

4.3 The Swirling Flow . . . . . . . . . . . . . . . . . . . 39

4.4 Navier-Stokes approach . . . . . . . . . . . . . . . 46

4.5 Supersonic swirling separator optimization . . . . . . . . . . . 48 
Appendices

Governing equations . . . . . . . . . . . . . . . . . 69

Compressible Euler . . . . . . . . . . . . . . . . . . . 69

Compressible Navier-Stokes . . . . . . . . . . . . . . 70

Menter's Shear-Stress Transport Model . . . . . . . . . . . 71 


\section{List OF FiguRES}

1.1 Pre-Salt carbon dioxide percentage . . . . . . . . . . 2

1.2 A Supersonic Separator scheme according to (YANG et al., 2014) . 4

1.3 Schematic cut of the ENGO 3S supersonic separator, according to

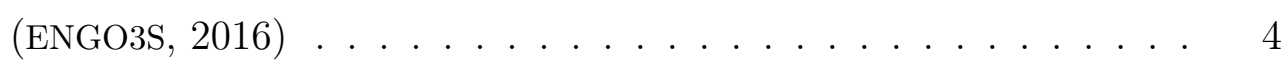

1.4 Schematic cut of the Twister Mark II supersonic separator, according to $($ TWISTERBV, 2016$) \ldots \ldots \ldots \ldots$

1.5 Schematic cut of the Orbital ATK ICES supersonic separator, according to $($ ORBITALATK, 2015) . . . . . . . . . 5

1.6 Schematic cut of a supersonic separator for gas developed in the RCGI (University of São Paulo), showing the ocurrence of nucleation of $\mathrm{CO}_{2}$ according to (RESTREPO, 2019) . . . . . . . 6

1.7 An Arina nozzle profile with maximum length of 100 units, according to $($ WEN et al., 2012) $\ldots \ldots \ldots \ldots$

1.8 External aspect of the Supersonic Swirling Separator . . . . . . . 7

1.9 Schematic aspect of the Supersonic Swirling Separator . . . . . 8

1.10 Diagram of optimization loop using the Adjoint Method . . . . . . 12

3.1 Stagnation Temperature (Non-dimensional) in an Arina nozzle $2 \mathrm{D}$ Euler . . . . . . . . . . . . . . . . . . 21

3.2 Stagnation Pressure (Non-dimensional) in an Arina nozzle - 2D

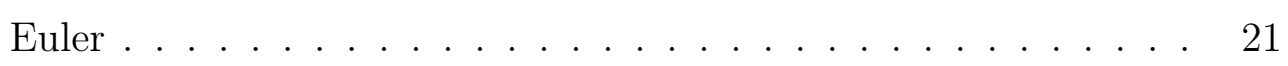

3.3 Stagnation Enthalpy (Non-dimensional) in an Arina nozzle - 2D Euler ............................ 22

3.4 Entropy (Non-dimensional) in an Arina nozzle - 2D Euler . . . . 23

3.5 Comparison of the pressure coefficient values obtained as the original, optimized and target ones - 2D Euler . . . . . . . . . 24 
3.6 Comparison of the Mach number values obtained as the original, optimized and target ones - 2D Euler . . . . . . . . . . . 25

3.7 Comparison of the geometry: The Original Geometry versus the Optimized Geometry - 2D Euler . . . . . . . . . . . 26

3.8 Residual history for the flow solution in the 17th cycle - 2D Euler

3.9 Adjoint density distribution in the Arina nozzle after the first optimization cycle - 2D Euler . . . . . . . . . . . . . . . 27

3.10 Adjoint density distribution in the Arina nozzle after the final optimization cycle - 2D Euler . . . . . . . . . . . . 28

3.11 Adjoint energy distribution in the Arina nozzle after the first optimization cycle - 2D Euler . . . . . . . . . . . . . 28

3.12 Adjoint energy distribution in the Arina nozzle after the last optimization cycle $-2 \mathrm{D}$ Euler . . . . . . . . . . . .

3.13 Adjoint density residual distribution in the Arina nozzle after the first optimization cycle $-2 \mathrm{D}$ Euler . . . . . . . . . . .

3.14 Adjoint density residual distribution in the Arina nozzle after the last optimization cycle - 2D Euler . . . . . . . . . . . . 30

3.15 Adjoint energy residual distribution in the Arina nozzle after the first optimization cycle - 2D Euler . . . . . . . . . . 30

3.16 Adjoint energy residual distribution in the Arina nozzle after the last optimization cycle - 2D Euler . . . . . . . . . . 31

3.17 Original 2D grid for the Arina Nozzle at the inlet portion . . . . . 31

3.18 Comparison of original Arina profile with the optimized profile using inverse design pressure with 2D Euler equations . . . . . 32

4.1 The 3D Fluid domain . . . . . . . . . . . . . . . 33

4.2 Fluid domain in a FFD box . . . . . . . . . . . . . 34

4.3 Longitudinal cut of the fluid domain . . . . . . . . . . . . . 34

4.4 Coarse mesh of the fluid domain . . . . . . . . . . . . . . . 35

4.5 Stagnation Temperature - 3D Euler . . . . . . . . . . . 36

4.6 Stagnation Pressure - 3D Euler . . . . . . . . . . . . 36

4.7 Streamlines and non-dimensional temperature - 3D Euler . . . . 37 
4.8 Vector representation of Mach distribution - 3D Navier-Stokes . . 37

4.9 Mach distribution - 3D Euler . . . . . . . . . . . . . . 38

4.10 Longitudinal cut with Mach distribution - 3D Euler . . . . . . . 38

4.11 Circular section showing vanes with Mach Distrution - 3D Euler . 39

4.12 Detail of vanes profile near hub . . . . . . . . . . . . . . . 39

4.13 Recirculation after swirler, according to Gupta et alii . . . . . . . 40

4.14 Radial distribution of axial, tangential and radial velocity components, according Beér and Chigier . . . . . . . . . . . . . . 42

4.15 Relationship between Swirl number and G, according to Gupta et alii ............................ 44

4.16 Transparent view of the Supersonic Swirling Separator, showing the disc region where the axial flux of the tangential momentum $(S W 1)$ and axial flux of the axial momentum $(S W 2)$ are calculated - 3D Navier-Stokes . . . . . . . . . . . . . . . . . . 45

4.17 Stagnation Temperature - 3D Navier-Stokes . . . . . . . . . . . . 49

4.18 Stagnation Pressure - 3D Navier-Stokes . . . . . . . . . . . . . . . 49

4.19 Outlet Stagnation Pressure - 3D Navier-Stokes . . . . . . . . . . . 50

4.20 Original surface with Mach distribution of one vane and nozzle, on a coarse mesh - 3D Euler . . . . . . . . . . . . . . . . 50

4.21 Optimized surface with Mach distribution done with the inverse design pressure, showing one vane and nozzle - 3D Euler . . . . . 51

4.22 Original versus Optimized geometry on a coarse mesh done with the inverse design pressure -3 D Euler . . . . . . . . . . . . 53

4.23 Magnified view of Original versus Optimized geometry on a coarse mesh done with the inverse design pressure - 3D Euler . . . . . 53

4.24 Detailed Original versus Optimized geometry on a coarse mesh done with the inverse design pressure - 3D Euler . . . . . . . . 53

4.25 Original pressure coefficient distribution on a vane using a fine mesh - 3D Navier-Stokes . . . . . . . . . . . . . . 54

4.26 Original non-dimensional temperature distribution on a vane using a fine mesh - 3D Navier-Stokes . . . . . . . . . . . . . . . 54 
4.27 Optimized pressure coefficient distribution on a vane using a fine mesh, with MOMENT-X as a measure of merit - 3D Navier-Stokes 54

4.28 Optimized non-dimensional temperature distribution on a vane using a fine mesh, with MOMENT-X as a measure of merit - 3D Navier-Stokes . . . . . . . . . . . . . . . . . 55

4.29 Cut showing the Momentum in the axial direction obtained in the Cycle 31 with a fine mesh, using MOMENT-X as a measure of merit - 3D Navier-Stokes . . . . . . . . . . . . . . . . . 55

4.30 Cut showing the Momentum in the axial direction obtained in the Cycle 32 with a fine mesh, using MOMENT-X as a measure of merit - 3D Navier-Stokes . . . . . . . . . . . . . . . . . 55

4.31 Non-dimensional temperature distribution on nozzle and vanes surfaces with a fine mesh, using MOMENT-X as a measure of merit - 3D Navier-Stokes . . . . . . . . . . . . . . . . . . 56 


\section{LIST OF TABLES}

4.1 Swirl numbers per optimization cycle, calculated for abscissa $x=$ 0.155. Cycle 1 represents the original geometry. Cycle 32 is the last realizable cycle. . . . . . . . . . . . . . . . . 52 


\section{ACRONYMS}

CFD Computational Fluid Dynamics

CST Class function/Shape function Transformation

EOS Equation Of State

FFD Free Form Deformation

FPSO Floating Production Storage and Offloading

FUSP Fundação de Apoio à Universidade de São Paulo

HPC High Performance Computing

NDF2 Núcleo de Dinâmica e Fluidos, Laboratory 2, Universidade de São Paulo PDE Partial Differential Equation

SST Shear Stress Transport in the Menter turbulence model

STI Superintendência de Tecnologia da Informação da Universidade de São Paulo (STI-USP)

SU2 Formerly, Stanford University Unstructured, today, just SU2: an open flow and adjoint solver 


\section{LIST OF SYMBOLS}

\section{Number Sets}

$\mathbb{R} \quad$ Real Numbers

\section{Latin Symbols}

$\overline{\bar{I}} \quad$ Identity matrix

$\bar{F}^{c} \quad$ Convective flux

$\bar{F}^{v} \quad$ Viscous flux

$\bar{u} \quad$ Flow velocity using Cartesian reference

$\langle\mathbf{f}, \mathbf{g}\rangle$ Inner product

a Lagrange multiplier (in Adjoint introduction)

B* Adjoint operator to B

B Set of boundary and initial conditions

L* Adjoint operator to $\mathrm{L}$

L Linearized form of the governing equations

$\mathbf{N}$ Set of $K$ nonlinear PDEs which govern the system

Q State vector, comprising density, linear momentum and total energy

$\mathbf{R}(\chi, \alpha)$ Source term of the equations which govern the flow

S Linearized form of the governing equations which gathers all control parameter variations

$\mathcal{D} \quad$ Flow domain

$\mathcal{R}(U)$ Compressible Euler or Navier-Stokes equations in differential form

$\mathcal{R}(U)$ Compressible Euler or Navier-Stokes equations in differential form

$A(x)$ Cross sectional area of the Arina nozzle as a function of $\mathrm{x}$ 
$B \quad$ Body surface

$C_{p t a r}$ Target pressure coefficient

$C_{p} \quad$ Pressure coefficient, Specific heat at constant pressure

$C_{v} \quad$ Specific heat at constant volume

E Total energy per unit mass

$G(\mathbf{Q}, \alpha, \phi, \beta, \mathbf{a})$ Augmented functional representing the constrained variational problem

$G_{\varphi} \quad$ Axial flux of the tangential (or angular) momentum

$G_{x} \quad$ Axial flux of the axial momentum (or thrust)

$G_{v \varphi} \quad$ Momentum of tangential velocity component

$G_{v x} \quad$ Momentum of axial velocity component

I Measure of merit: mean square error of a pressure distribution

$I_{o}[\mathbf{Q}, \alpha]$ Generic measure of merit for Euler compressible flows

$k=\mu C_{p} / \operatorname{Pr}$ Thermal conductivity, where $\operatorname{Pr}$ is the Prandtl number

$M \quad$ Mach number

$M_{\infty} \quad$ Mach number in the freestream

$p \quad$ Static pressure

$P[\phi, \delta \mathbf{Q}]_{s}$ Bilinear concomitant

$p_{\infty} \quad$ Absolute pressure in the freestream

Pr Prandtl number

$\mathrm{Pr}_{t} \quad$ Turbulent Prandtl number

$r \quad$ Radius

$R_{\text {gas }}$ Gas constant

$S \quad$ Swirl number; Vector of conservative variables in compressible Euler or Navier-Stokes governing equations

$U \quad$ Axial velocity component 
$U \quad$ Vector of conservative variables

W Tangential velocity component

$x \quad$ Cartesian coordinate

y Cartesian coordinate

z $\quad$ Cartesian coordinate

$R_{s i} \quad$ Radius of the Swirler Internal wall

$R_{s o} \quad$ Radius of the Swirler Outer wall (annulus)

$R_{s w} \quad$ Radius of the Swirler Internal wall (Hub)

\section{Greek Symbols}

$\alpha \quad \alpha$ represents the set of parameters that control the system, $\left(\alpha \in \mathbb{R}^{N}\right)$

$\overline{\bar{\tau}} \quad$ Viscous stress tensor

$\beta \quad$ Lagrange multiplier (in Adjoint introduction)

$\beta_{1} \quad \kappa-\omega$ closure coefficient, $\beta_{1}=3 / 40,($ WILCOX, 1988)

$\chi \quad$ State vector, coordinates of the domain $\mathcal{D}$ in physical space $\left(\mathcal{D} \subset \mathbb{R}^{J}\right)$

$\delta G \quad$ First variation of the augmented functional

$\delta I_{o_{\alpha}} \quad$ Parametric part of the total variation

$\delta I_{o_{Q}} \quad$ Physical part of the total variation

$\delta I_{o} \quad$ First variation of a generic (objective) functional

$\Delta d_{1} \quad$ Distance to the next point away from the wall

$\gamma \quad$ Ratio of specific heats $\left(\gamma=C_{p} / C_{v}\right)$, Blended $\gamma$ constant in the Menter SST turbulence model

$\kappa \quad$ Turbulent kinetic energy in the Menter SST model

$\mu \quad$ Dynamic viscosity

$\mu_{t} \quad$ Turbulent viscosity

$\nu \quad$ Kinematic viscosity

$\nu_{t} \quad$ Eddy viscosity 
$\omega \quad$ Rate of dissipation of turbulence per unit energy in the Menter SST model

$\partial \mathcal{D} \quad$ Domain boundaries

$\phi \quad$ Lagrange multiplier (in Adjoint introduction), Blended generic constant in Menter SST turbulence model

$\rho \quad$ Density

$\rho_{\infty} \quad$ Density in the freestream 


\section{INTRODUCTION}

\subsection{Separation Technologies}

The increasing worldwide demand for energy in the recent decades, has brought a grave drawback for the environment: the corresponding increase in greenhouse gas emissions. Carbon dioxide $\left(\mathrm{CO}_{2}\right)$ and methane $\left(\mathrm{CH}_{4}\right)$ are among the major greenhouse sources (EPAREPORT, 2017). The combustion of methane produces a lesser amount of carbon dioxide than heavier hydrocarbons thus making it an important transition fuel in the energy market. At the same time, recent regulations are constraining more and more the release of carbon dioxide into the atmosphere. The Natural Gas industry faces important challenges with both gases: while methane with high purity degree should be sold as fuel, most of the carbon dioxide present in the natural gas ought to be re-injected into the wells. In the majority of countries, the energy matrices are undergoing progressive changes, aiming at adapting them to the more stringent environmental laws and to the global economy instabilities.

The separation of natural gas components is crucial due to a high fraction of carbon dioxide $\left(\mathrm{CO}_{2}\right)$ in the composition of pre-salt layer gas wells, whose molar fraction can reach up to $80 \% \mathrm{~mol} / \mathrm{mol}$ (ALMEIDA; VILELA, 2018; MELO; GRAVA, 2014), besides other impurities in lower percentages. Figure 1.1 shows a map with the distribution of $\mathrm{CO}_{2}$ percentage in the Brazilian Pre-Salt regions.

The main technologies currently available to perform natural gas separation, found in the literature (FORSYTH et al., 2017; MELO; GRAVA, 2014; IMAEV; BAGIROV, 2014; CARVALHO; NEVES, 2007; SUZUKI, 1990), are:

- Adsorption : In this process, an adsorbent is used to promote the separation at molecular level. The advantage lies in its high efficiency for small carbon dioxide concentrations ( 0.5 to $3 \%$ in mole fraction). However, the maintenance is expensive and the performance diminishes at higher concentrations. 


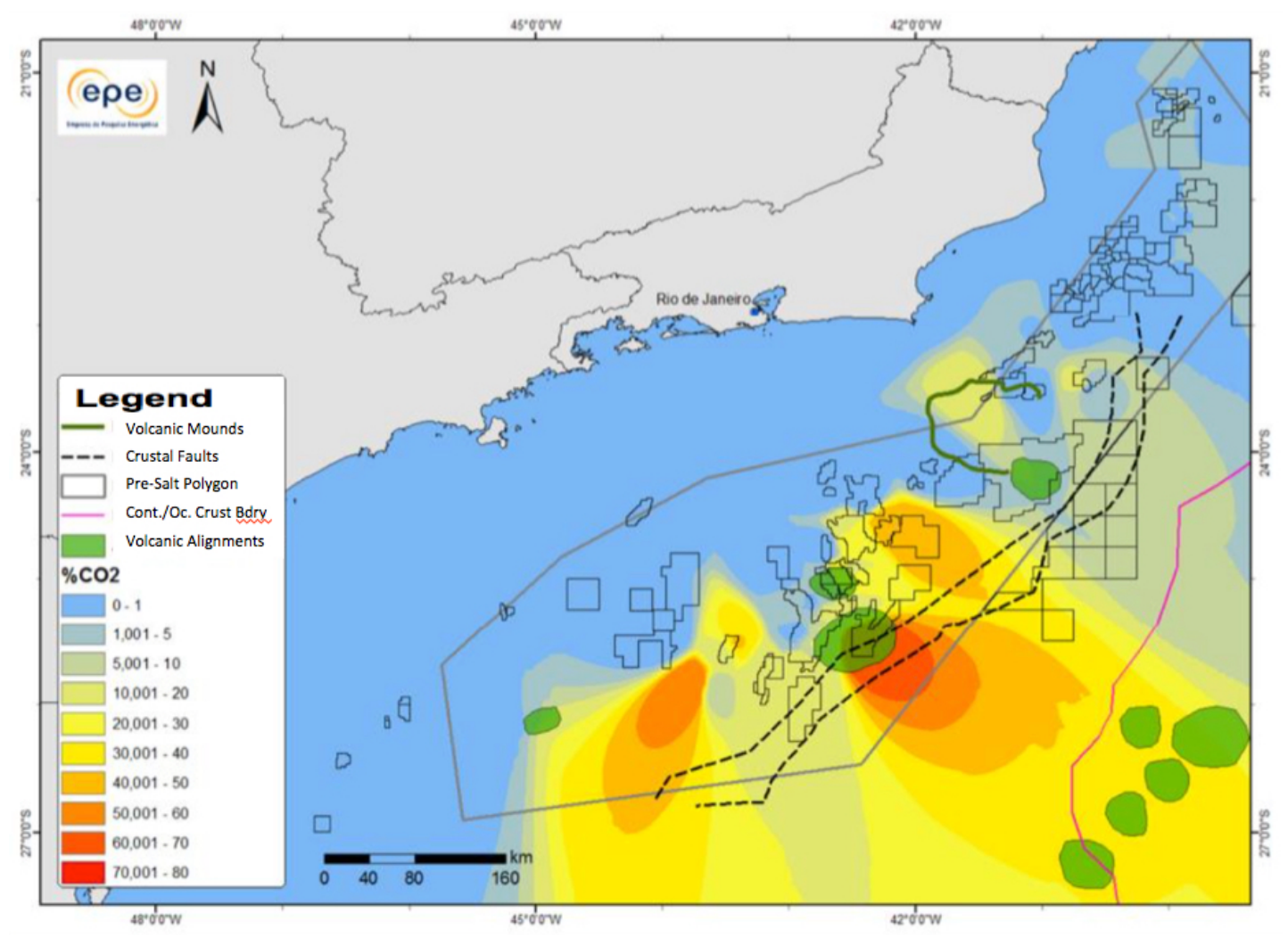

Figure 1.1: Brazilian Pre-Salt carbon dioxide percentage, according to (ALMEIDA; VILELA, 2018). Adapted from (ALMEIDA; VILELA, 2018).

- Membrane : This process is based on the selective permeability of a membrane. It is most often employed when there is a large variation in the molar fraction of $\mathrm{CO}_{2}$, although it becomes complex and expensive for multicomponent mixtures.

- Amine : Also known as Absorption process, it uses monoethanolamine (MEA), a solvent to $\mathrm{CO}_{2}$. This process requires solvent recirculation and its reheating for regeneration, thus the cost of this process is proportional to the volume of gas which is processed. It is currently applied to concentrations of carbon dioxide ranging from the 3 to $25 \%$ in molar fraction.

- LOW TEMPERATURE : This process is commonly used for removing acid components like $\mathrm{H}_{2} \mathrm{~S}$ and $\mathrm{CO}_{2}$. Among the available technique are the Ryan Holmes process (IMAEV; BAGIROV, 2014) and the supersonic separation. Those technologies consist in lowering the temperature of the gas flow, until a phase change of $\mathrm{CO}_{2}$ takes place. Supersonic separation is a compact novel technology (BETTING; EPSOM, 2007; TWISTERBV, 2016; HU, 2018; ENGO3S, 2016), efficient in the removal of large molar percentage of carbon dioxide from the natural gas. The principle behind the supersonic separator consists in a supersonic flow of the natural gas within a convergent-divergent nozzle. In the divergent portion of the nozzle, a supersonic expansion takes 
place, thus developing very low temperatures. Owing to the adiabatic expansion, and to the conversion of internal energy into kinetic energy; temperature and pressure decrease to the point where the $\mathrm{CO}_{2}$ condenses. The nozzle can be straight and the condensed component is forced to the walls by producing a swirl in the flow, or the nozzle can be curved ("elbow configuration"), and, in this case, there is no need of a swirling flow. The solid and/or liquid carbon dioxide is centrifuged to the walls of the separator thanks to the rotational flow (this part of the separation is denominated cyclonic separation), or the curved nozzle. $\mathrm{CO}_{2}$ is then captured and removed from the main natural gas flow in the divergent portion of the nozzle. In addition to the compact size, the supersonic separator presents other significant pros: Lower compression power required, lower re-injection power consumption (since liquid carbon dioxide is pumped into the well caves), no movable parts and lesser maintenance costs when compared with the other alternatives of separation.

Amongst the most relevant approaches to optimization of the convergentdivergent nozzle geometry, the adjoint method stands out as it allows an exceptional reduction in the computational costs of design sensitivity derivatives, thus allowing a more efficient analysis of design alternatives, without compromising the results accuracy. The method is also attractive for its high fidelity to the flow physics, and for the great diversity of its applications. The aim of this project is to use the adjoint method to optimize the supersonic separator. The study focuses on supersonic gas flow through a convergent-divergent nozzle that adequately represents those systems.

\subsection{Supersonic Separator}

The technology of the supersonic separation appeared about 50 years ago, and since then it is being progressively developed. In 1968, Garret (HAGHIGHI et al., 2015; GOOGLE-PATENTS, 2016) proposed a device for the separation of heavy gaseous components in a mixture through a convergent-divergent nozzle linked to a curved channel (which executes the same function as a swirling flow, by separating the condensed substances through inertial action). The device of Garret inspired other techniques, such as Linhardt and Beveridge, 1981 (HAGHIGHI et al., 2015), whose approach is very similar to the first one, and the Nasikas, 1994 (HAGHIGHI et al., 2015), which again uses a swirling flow for the multiphase separation of gases, but introduces normal shock waves to decelerate the central 
flow, and to end the separation of the components. Currently, the main suppliers of the technology that uses swirling flows are the companies Engo $3 \mathrm{~S}$ and Twister BV (ENGO3S, 2016; TWISTERBV, 2016). The former is a Russian group, and the second one has started as a joint venture between Shell and the Beacon Group (Dangote Industries (DIL), acquired TwisterBV in 2016). Both companies started around the year 2000 .

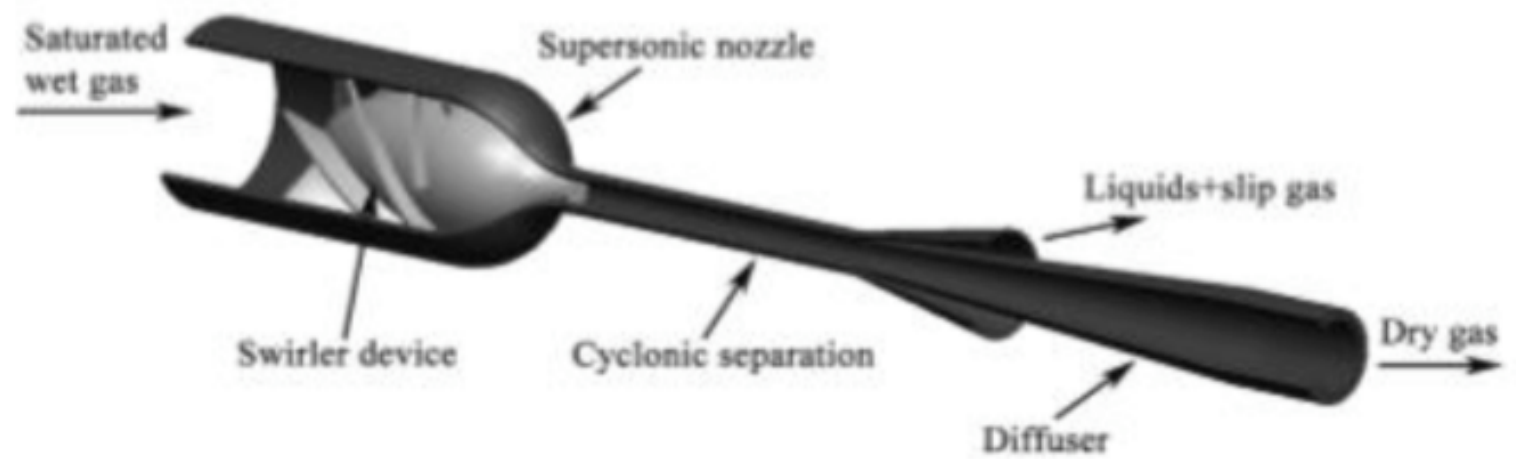

Figure 1.2: Schematic cut of a supersonic separator for gas, according to (YANG et al., 2014). Reproduced from (YANG et al., 2014).

Figure 1.2 shows a typical separator with an internal body with vanes to impose swirling to the flow. Figures 1.3, 1.4 and 1.5 show respectively the Engo 3S, the Twister BV and the Orbital ATK schemas.

\section{S-SEPARATOR DESIGN PRINCIPAL SCHEME}

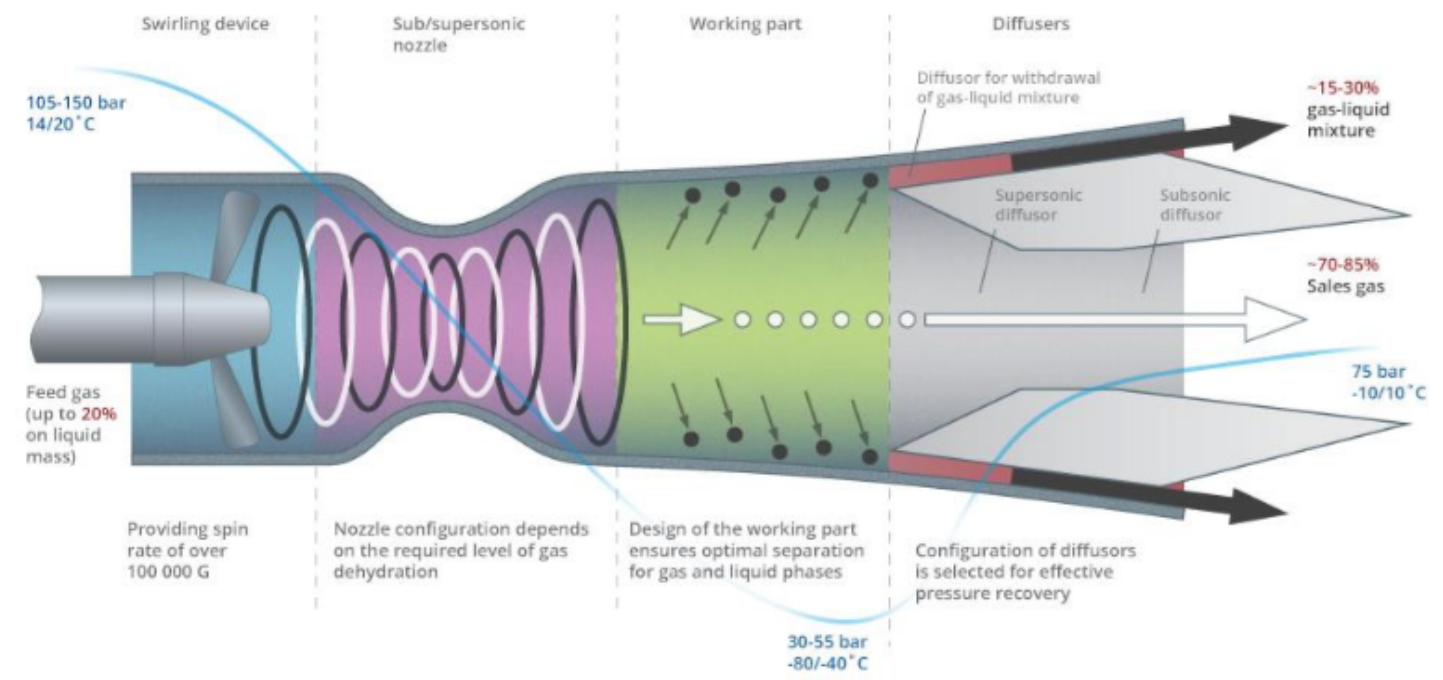

Figure 1.3: Schematic cut of the ENGO 3S supersonic separator, according to (ENGO3S, 2016). Reproduced from (ENGO3S, 2016).

The primordial difference between Engo 3S and TwisterBV approaches lies in the way to obtain the swirling: The Engo3S (2016) model employs fixed vanes connected to the inner walls of the separator, while the TwisterBV (2016) presents 


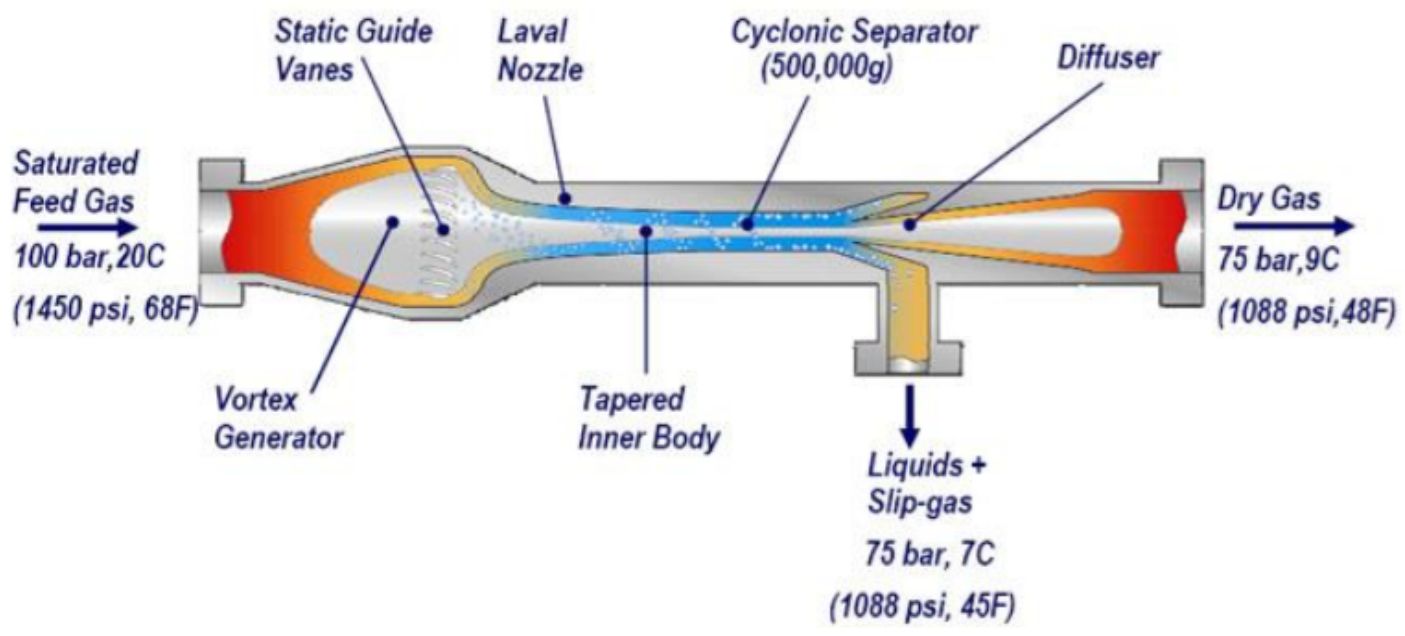

Figure 1.4: Schematic cut of the Twister Mark II supersonic separator, according to (TWISTERBV, 2016). Reproduced from (TWISTERBV, 2016).

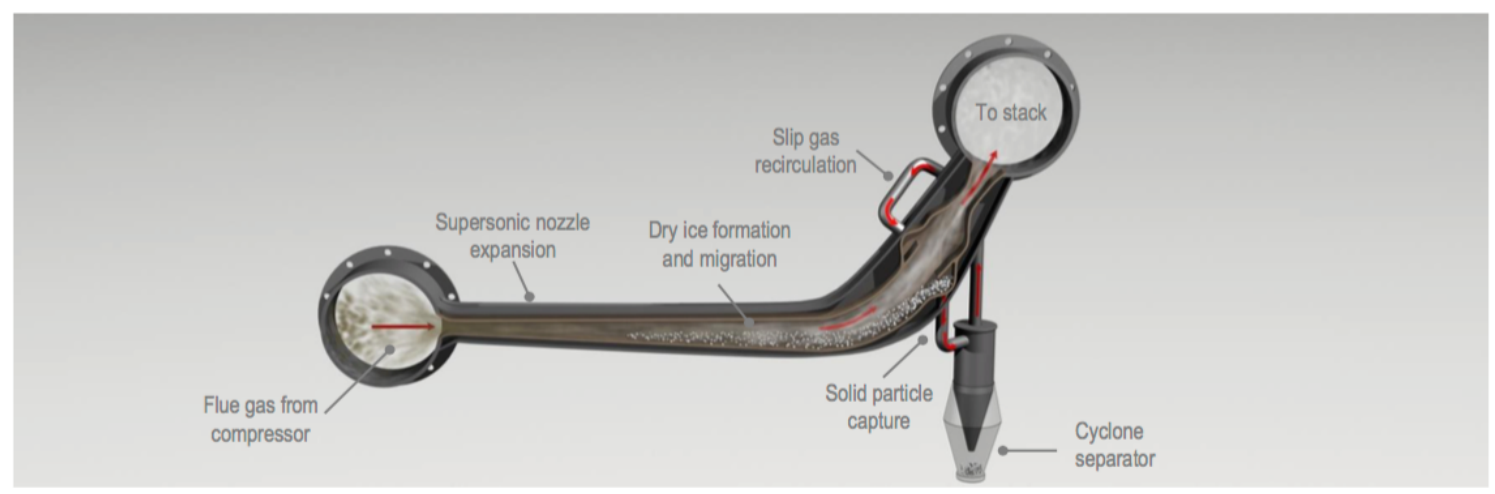

Figure 1.5: Schematic cut of the Orbital ATK ICES supersonic separator, according to (ORBITALATK, 2015). Reproduced from (ORBITALATK, 2015).

a central body with fixed vanes. The vanes are responsible for the swirling. The Engo 3S model uses a more conventional De Laval nozzle geometry. The main representative of the technology which uses a curved channel (similar to the one proposed by Garret) is Orbital Alliant TechSystems (OrbitalATK), whose first proof of concept design dates back to 2010. According to Orbital, the cost per ton of $\mathrm{CO}_{2}$ avoided is about half the one incurred by using amine based extraction (ORBITALATK, 2015). Figure 1.6 shows the nucleation of $\mathrm{CO}_{2}$ inside a supersonic separator.

\subsection{Scope and Objectives of the Project}

This project considers a supersonic separator as an assembly with two components: The first one is the convergent-divergent nozzle, where the phase change processes take place and the second one is a stationary swirl generator, located 


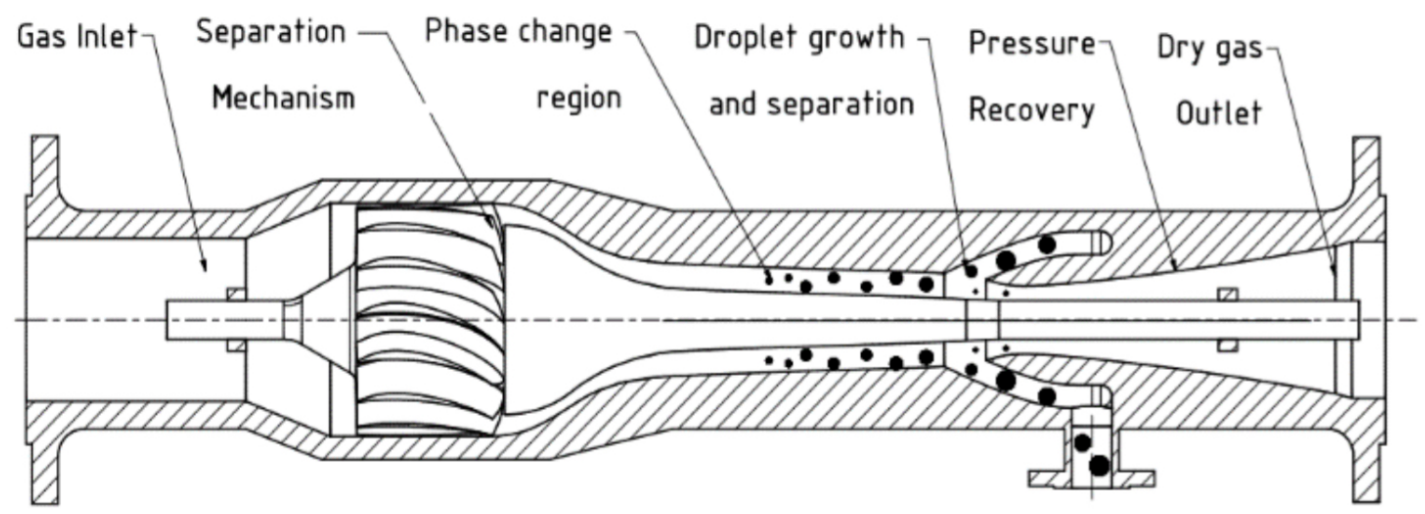

Figure 1.6: Schematic cut of a supersonic separator for gas, developed in the RCGI (University of São Paulo), showing the ocurrence of nucleation of $\mathrm{CO}_{2}$ according to (RESTREPO, 2019). Reproduced from (RESTREPO, 2019).

before the convergent nozzle portion, which is responsible for the introduction of a rotation in the flow, thus allowing the centrifugal force to bounce droplets of liquid carbon dioxide to the internal wall of the divergent nozzle region. The main goal is to delay the position of normal shock waves, which will allow more room to the phase change processes.

In this work, the swirler has been created with seven fixed vanes of complex shape, with expressive camber, not following any kind of known airfoil geometry. The nozzle has been defined using the geometry proposed by Renzo Arina (ARINA, 2004), usually known as the Arina profile, since it appears in a number of articles in the literature. In the original work, SI units are used, and the nozzle length $\left(x_{\max }\right)$ is 10 . The throat is located in $\left(x_{t h}=5\right)$ and the cross sectional area, $A(x)$, in the throat is 1 . The nozzle geometry is given by the expression:

$$
A(x)= \begin{cases}2.5+3\left(\frac{x}{x_{t h}}-1.5\right)\left(\frac{x}{x_{t h}}\right)^{2} ; & \forall x \leqslant x_{t h} \\ 3.5-\frac{x}{x_{t h}}\left[6-4.5 \frac{x}{x_{t h}}+\left(\frac{x}{x_{t h}}\right)^{2}\right] & \forall x \geqslant x_{t h}\end{cases}
$$

The expression (1.1) in the original article has a typo in the second half, where just a "4" appears, instead of "4.5": Figure 1.7 depicts an Arina profile whose maximum length $\left(x_{\max }\right)$ is 100 (WEN et al., 2012).

For this project, the dimensions are scaled to fit $x_{\max }=1 \mathrm{~m}$ in the $x$ direction (the $y$ direction was correspondingly scaled), to work properly with the parametrization with the Hicks-Henne bump functions (these functions are available in the standard SU2 package, and have been used in the preliminary nozzle optimizations). 


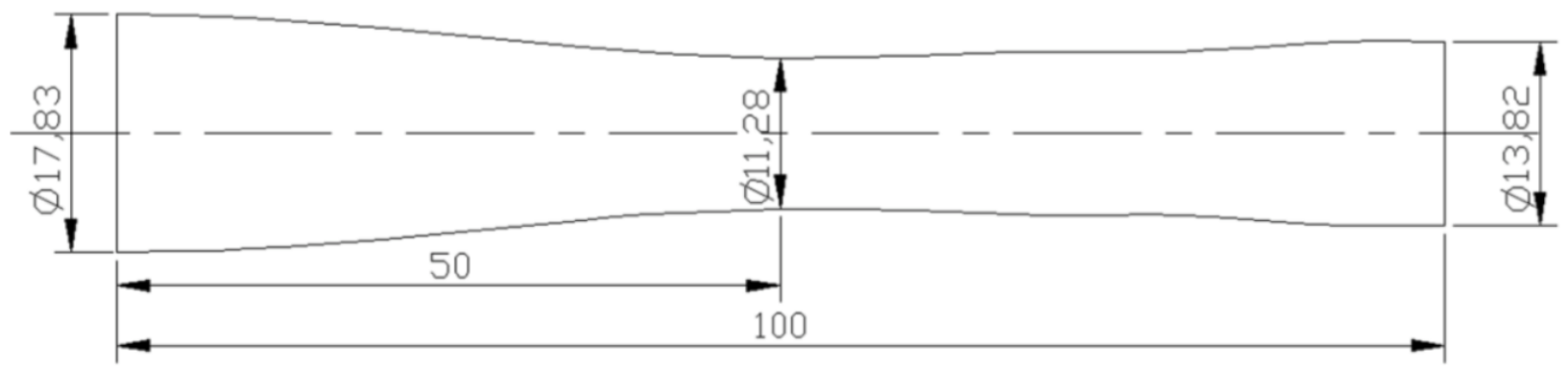

Figure 1.7: An Arina nozzle profile with $x_{\max }=100$, according to (WEN et al., 2012).

The initial configuration of the Supersonic Swirling Separator which is the object of this work is shown in the Figures 1.8 and 1.9, giving respectively, an external aspect of the Supersonic Swirling Separator, and a schematic view of it. The selected working fluid is methane $\left(\mathrm{CH}_{4}\right)$, since it represents the major molar fraction in most regions of the separator. Methane's behavior is defined by the ideal gas equation of state.

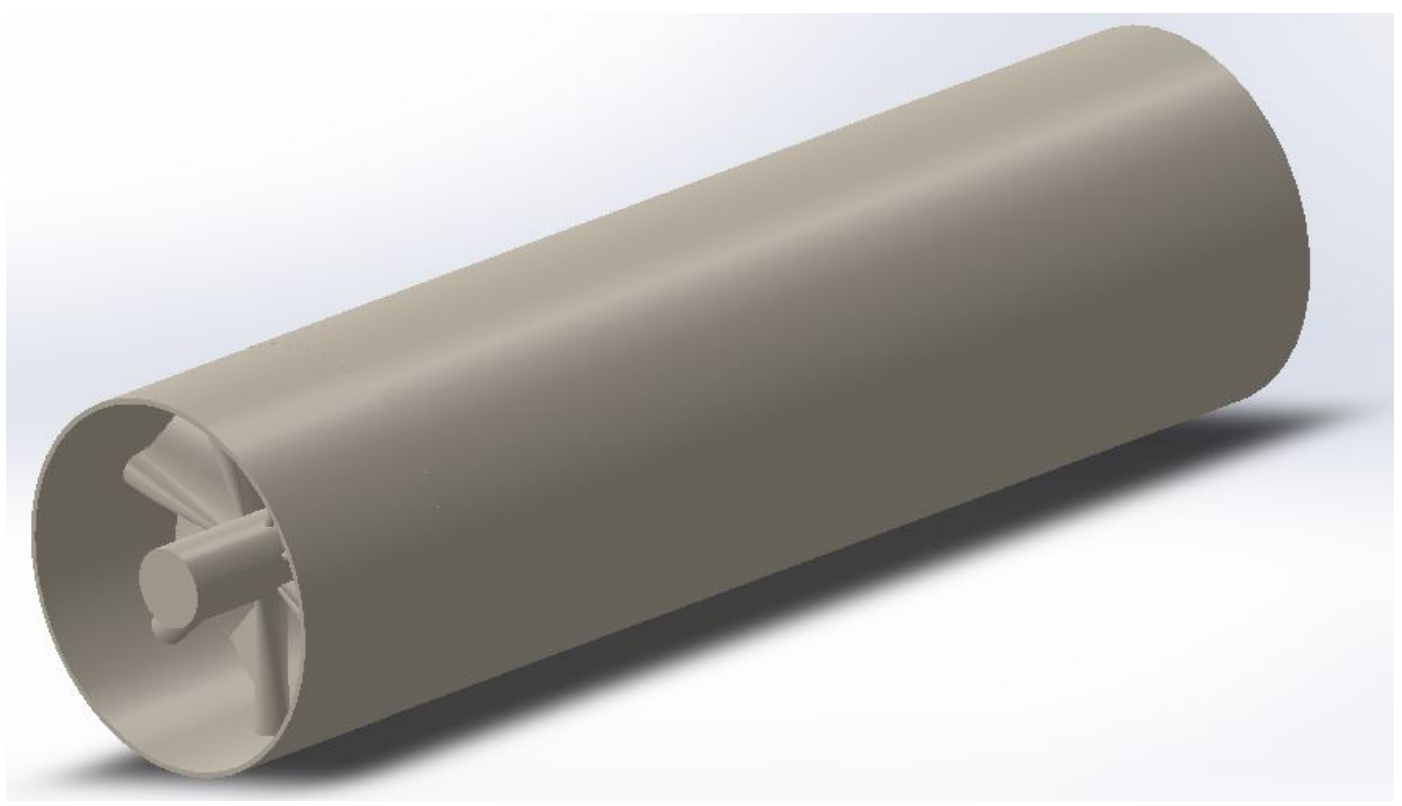

Figure 1.8: External aspect of the Supersonic Swirling Separator.

In the convergent-divergent nozzle, the simulation and optimization have been accomplished by using the 2-D Euler formulation; and here the aim is to investigate two very important aspects in a supersonic flow within a separator, which apparently have not received the due attention up to this moment in the literature:

- Prandt-Meyer expansion fan : The likely rise of Prandtl-Meyer expansion fan, which is a reversible isoentropic process, in the supersonic flow region. 


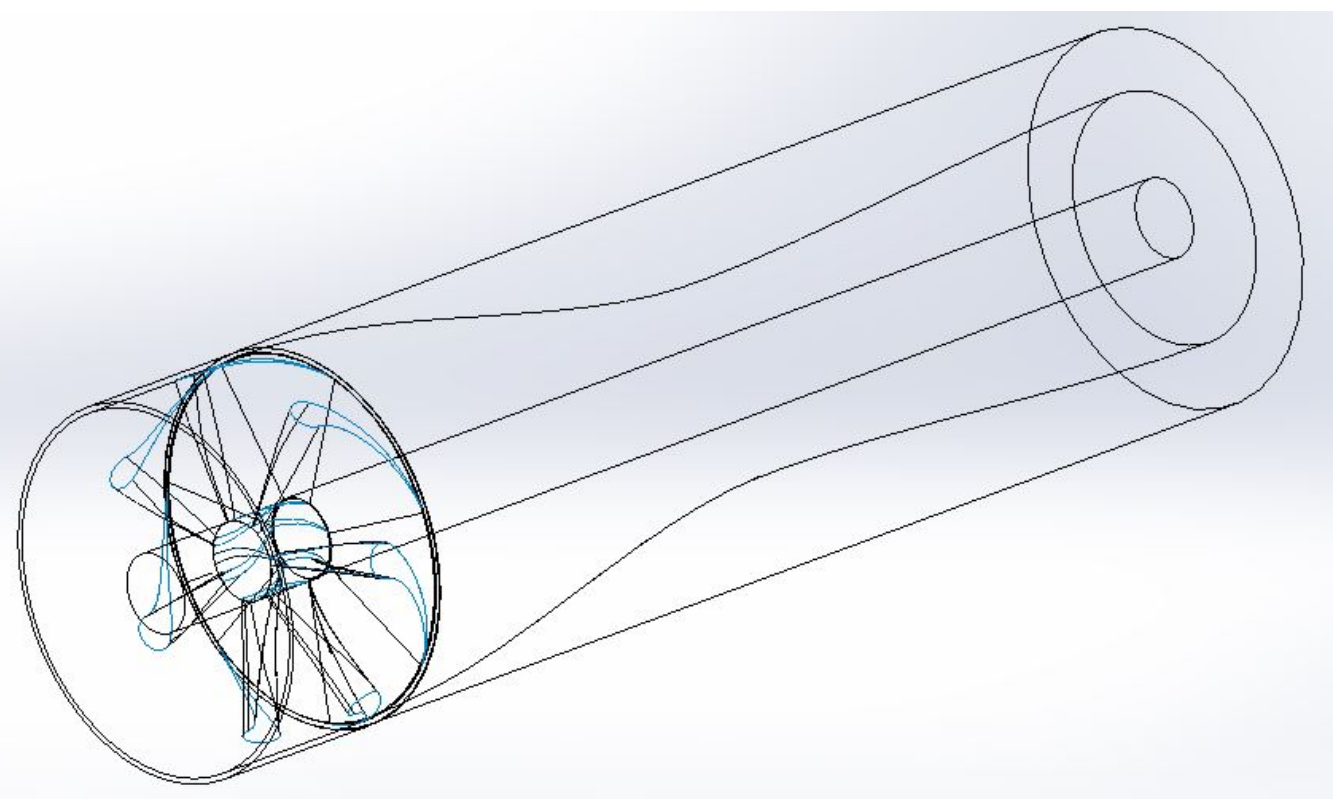

Figure 1.9: Schematic aspect of the Supersonic Swirling Separator.

- Static pressure And temperature Rise : The static pressure and temperature changes due to a shock wave in the supersonic flow region, which is an irreversible compression process that increases entropy.

The reason for depicting these two aspects above, lies in the well known fact that any obstacle which causes change in the directions of the supersonic flow, will induce either shock waves (whether normal or oblique shock waves) or other phenomena as well, due to the compressibility effects. Furthermore, shock waves cause an increase in temperature and static pressure, which can jeopardize the separation processes, owing to a re-evaporation of the carbon dioxide. In effect, devices for swirl generation have all the elements to foster the two aspects cited above, depending on their position within the device.

In this context, it seems substantially advantageous to investigate optimum solutions to those systems. In particular, on making use of a method that combines shape and parametric optimization capabilities, one could potentially tackle the full breadth of the problem. In that regard, it is instructive to note that temperature control is paramount to the efficiency of the separation process. The shock waves, in turn, ought to move nearer to the separator outlet thus allowing more room for the phase change to take place within the divergent portion of the separator. The geometry of the separator can be optimized to achieve this goal, under a given set of boundary conditions at inlet and outlet. This will contribute to enhance the amount of $\mathrm{CO}_{2}$ captured by the separator. In addition, the device is sensitive to the operational conditions, as abundantly reported in the literature (WEN; CAO, 2011; KARIMI; ABEDINZADEGAN, 2009; WEN; CAO, 2013). 
The software tool used in this work (SU2) has two standard options for parametrization of the shape: a set of Hicks-Henne bump functions (they have been already mentioned in the current section) (HICKS; HENNE, 1978), which is the usual choice for 2D geometry; and the free form deformation (FFD) functions (SEDERBERG; PARRY, 1986), which can be used for 2D or 3D geometries. A third 2D parametrization function, the Class function/Shape function Transformation (CST) parametrization, (KULFAN; BUSSOLETTI, 2006) is not standard in SU2 and has been implemented in this project into the code, to enhance the manipulation of complex 2D geometries, especially for the case of internal flows: The best results have been accomplished using this third parametrization technology.

During the first phase of this project, the nozzle portion has been treated as a 2D entity with symmetry, using Euler equations: the preliminary simulations have considered the Hicks-Henne bump functions and, after CST parametrization has been built into the code, it superseded the former one, due to better results, that is, it was possible to delay the shock waves somewhat nearer to the outlet than using Hicks-Henne functions. This finding has caused the use of CST for the rest of nozzle optimization tasks. The swirler device has been tackled in the second phase, firstly using 3D Euler equations and FFD (Bézier) parametrization. In the third and final phase, 3D Navier-Stokes with FFD parametrization has been employed. The turbulence model in all simulation during the last phase was the SST one (Menter's Shear Stress Transport, (MENTER, 1994, 2009; SMIRNOV; MENTER, 2009; ALAHMADI; NOWAKOWSKI, 2016)).

The adopted domain discretization is the non-structured one (MAVRIPLIS, 1997): it allows working with more complex geometries than the structured domain discretization. The initial mesh generation is done via Ansys Meshing: during the optimization process, SU2 is able to perform the mesh deformation, thus avoiding the re-meshing step, and decreasing the computational costs.

The stationary swirl generator produces the 3-D cyclonic effect, and then, the flow throughout the entire assembly (that is, swirler and nozzle) is simulated and optimized, using 3-D Euler and Navier-Stokes formulations

\subsection{Why Adjoint Method has been chosen}

As seen in the precedent paragraphs, the internal geometry in a supersonic separator is that of a convergent-divergent nozzle, and the goal is to minimally modify the internal geometry to give more space to the phase change process, 
and, at the same time, to preserve its original footprint. The way to preserve the footprint is to keep the same length of the original configuration. The nozzle diameter is allowed to freely change along axial direction, between the inlet and the outlet. When it is present a central shaft which fixes the swirler (to be described in Chapter 4), then its diameter also keeps the original dimension.

Essentially, the adjoint method is a powerful tool to compute the sensitivity (that is, the gradient) of a given measure of merit, with respect to parameters that control the boundary conditions of a physical system. That system is assumed to be governed by a set of Partial Differential Equations (PDEs), and the measure of merit is taken to be a functional (an objective functional, as it is also called). In this work, the flow represents the physical system and the objective functionals usually depend on flow variables and on the shape and location of the boundaries (JAMESON; PIERCE; MARTINELLI, 1998; JAMESON; SRIRAM; MARTINELLI, 2003). A few examples found in the literature are:

$$
I=\oint_{B} \frac{\left(C_{p}-C_{p t a r}\right)^{2}}{2} \mathrm{~d} S \quad ; \quad K=\int_{\mathcal{D}} \frac{\rho u^{2}}{2} \mathrm{~d} V \quad ; \quad \overline{C_{f}}=\frac{1}{T} \int_{0}^{T} \oint_{B} \frac{\mathbf{n} \cdot \boldsymbol{\sigma} \cdot \mathbf{e}}{q_{\infty}} \mathrm{d} S \mathrm{~d} t
$$

From left to right, the first integral is a measure of the mean square error of a pressure distribution, which is represented by $C_{p}$, with respect to a target distribution $\left(C_{p t a r}\right)$, on a body surface $(B)$ - it concerns inverse aerodynamic design applications. The second one represents the kinetic energy of the flow domain $(\mathcal{D})$. Whereas the third integral expresses a time average of the force the fluid exerts on the body surface $(\mathbf{n} \cdot \boldsymbol{\sigma})_{B}$, when it is projected onto a given direction $(\mathbf{e})$.

The adjoint method has proven to be a powerful tool for optimizing complex systems, where a high fidelity representation of the physics is essential (ZINGG; NEMEC; PULLIAM, 2008).

The adjoint method has shown to be particularly suitable to tackle problems with large number of control parameters and few measures of merit (that is, few objective functions), and several possibilities of optimum criteria. For it only requires two converged solutions to compute sensitivity gradients, regardless of their dimensionality and for any particular measure of merit. This translates in lower computational cost, when compared with other methods such as finite differences or genetic algorithms (CEZE, 2008). In the nozzle optimization work 
of this project, the definition of objective function for inverse design applications $(I)$ is given by the mean square error of the actual pressure distribution $p$ with respect to a target pressure distribution $p_{t a r}$, on the separator internal wall:

$$
I=\frac{1}{2} \int_{b_{w}}\left(p-p_{t a r}\right)^{2} \mathrm{~d} s
$$

The target pressure distribution $p_{t a r}$ is what one imposes to modify a surface $\left(b_{w}\right)$ where the pressures are evaluated, without knowing whether it will be possible or not. Owing to those characteristics, the adjoint method has been the subject of intense research activity. It has spawned a wide variety of applications, ranging from nuclear reactor thermo-hydraulics (CACUCI et al., 1980) to aerodynamics (JAMESON; PIERCE; MARTINELLI, 1997) and the design of ship hulls (JAMESON; MARTINELLI, 2007): It is the versatility and the high fidelity representation of the physics, the main motivation to employ the adjoint method in this work.

Since the pressure coefficient, $C_{p}$ is used as a dimensionless form of the forgoing objective functional (1.3), and the tool chosen for this project has built functions which directly deal with the pressure coefficient, it has been employed in the nozzle optimization in place of pressure. Then, the distributions used are the pressure coefficient, $C_{p}$ at the nozzle internal surface. Thus, the objective function then becomes:

$$
I=\frac{1}{2} \int_{b_{w}}\left(C_{p}-C_{p_{\text {tar }}}\right)^{2} \mathrm{~d} s
$$

With absolute pressures $p$ and $p_{\infty}$, the pressure coefficients are:

$$
C_{p}=\frac{p-p_{\infty}}{\frac{1}{2} \rho_{\infty} u_{\infty}^{2}}=\frac{2}{\gamma M^{2} \infty}\left(\frac{p}{p_{\infty}}-1\right)
$$

and

$$
C_{p_{t a r}}=\frac{p_{t a r}-p_{\infty}}{\frac{1}{2} \rho_{\infty} u_{\infty}^{2}}=\frac{2}{\gamma M_{\infty}^{2}}\left(\frac{p_{t a r}}{p_{\infty}}-1\right)
$$

Where the symbols $p_{\infty}, \rho_{\infty}, M_{\infty}$ and $u_{\infty}$ represent respectively the absolute pressure for internal flows, density, Mach number and velocity in the freestream: it is important to note here that for a nozzle (internal) flow, the infinity (farfield) references have no physical meaning. Instead, they should refer to a fixed (constant, but arbitrary) reference state. $p$ is the pressure on the internal surface of the nozzle; $p_{t a r}$ is the target pressure on the internal surface of the nozzle and $\gamma$ 
is the ratio of specific heats:

$$
\gamma \equiv \frac{C_{p}}{C_{v}}
$$

The identity (1.7) employs the usual symbols found in the literature, but one must keep in mind that here, $C_{p}$ represents the specific heat at constant pressure, and not the pressure coefficient. A diagram of the process of optimization using the adjoint method is shown in Figure 1.10.

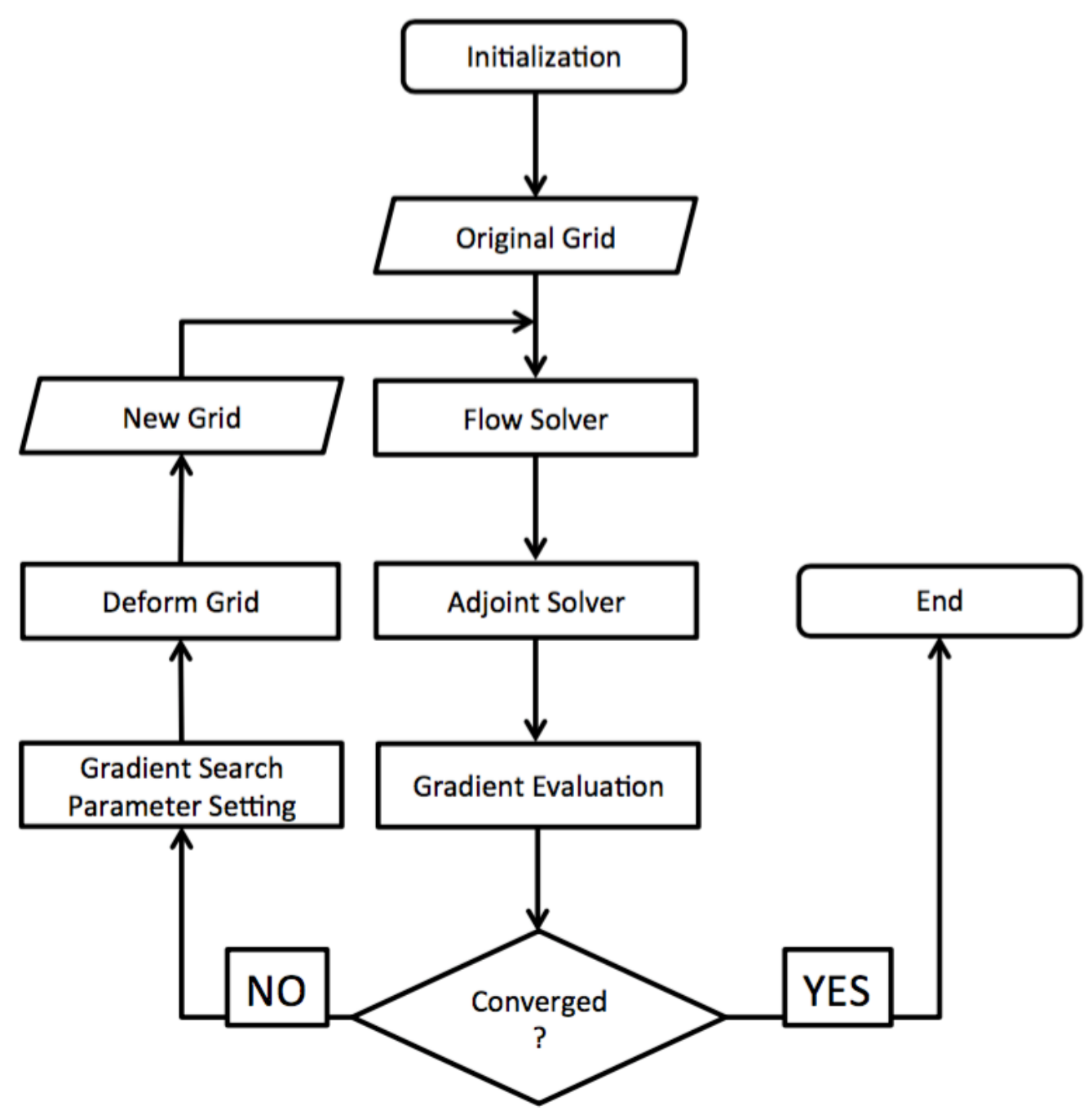

Figure 1.10: Diagram of optimization loop using the Adjoint Method. 


\section{AdJOINT METHOD}

\subsection{Adjoint Method Overview}

The material on this introduction regarding adjoint method expanded far beyond the common geometric sensitivities, follows very closely the work (HAYASHI; CEZE; VOLPE, 2017), which was a natural extension of (HAYASHI; CEZE; VOLPE, 2013). As was mentioned earlier, the optimization of the supersonic separator that is undertaken here is mostly a geometric optimization. However, there is a possibility of exploring inflow and outflow conditions, or at least, to point directions to explore them in subsequent projects.

The first attempt to treat the inverse aerodynamic design was pursued by M. J. Lighthill (1949), but then his general technique for rendering approximate solutions to physical problems uniformly valid was only applied to the simplest form of the problem of correcting the theory of thin wings near a rounded leading edge and the flow investigated was two-dimensional, irrotational and incompressible. Over the years, more comprehensive approaches have been proposed, and the Modified Garabedian-McFadden method has received much attention (VOLPE et al., 2007; VOLPE, 2004, 2005): it is based on the model of the linearized potential flow, and is efficient for transonic flows, but it cannot deal with discontinuities such as shock waves.

The adjoint method has been established as a major contribution in the aerodynamics field, thanks to the works of pioneers like Lions (1971), Pironneau (1973, 1974, 1983), Mohamadi e Pironneau (2000), Jameson (1988, 1995), Giles e Pierce (1998, 2000), Cacuci et al. (1980) and others.

Over the years since its extension to transonic flows by Jameson in a landmark work (JAMESON, 1988), the adjoint method has become a veritable field of research in the aerodynamics and CFD communities. It has been the subject of extensive investigation and spawned a large variety of applications, ranging from design optimization to flow stability analysis, error estimation and mesh adaptation, and uncertainty quantification. 
As a sensitivity analysis tool, the adjoint method allows for efficient computation of the sensitivity derivatives used in design optimization. In a discrete sense, adjoint solutions relate residual perturbations to output perturbations via the chain rule (MARTINS; HWANG, 2013). While in the continuous sense, adjoint variables correspond to a convolution of the linearized functional and the Green function (GILES; PIERCE, 2000, 1997). Within the sensitivity analyses space, applications of the method have been mostly focused on optimal geometric shape variations for design optimization and flow stability analyses. In the latter, adjoint solutions are used to calculate the rate of growth of eigenmodes in the flow field (HALL; CACUCI, 1983; LUCHINI; BOTTARO, 2014).

Another major application of the adjoint method is in estimation and control of discretization errors in outputs via the adjoint-weighted residual (AWR) method (FIDKOWSKI; DARMOFAL, 2011). In certain types of discretization, AWR yields consistent estimates of the output error and the elemental contribution to this error provides an adaptive indicator. With this information, degrees of freedom are added/removed by locally refining/coarsening ( $h$-adaptation) the mesh and/or by increasing/decreasing ( $p$-adaptation) the scheme's approximation order.

As a first reference (CACUCI et al., 1980), Cacuci et alii have formally established the theoretical basis behind the adjoint method of sensitivity analysis for nonlinear systems. Two equally relevant works by the same author followed soon after, with an in-depth analysis of the mathematical foundations underlying the method. The first one (CACUCI, 1981a) discusses the necessary and sufficient conditions for the existence and uniqueness of adjoint operators, whereas the second (CACUCI, 1981b) extends the scope of the adjoint formalism to a larger variety of responses, which includes general operators. It is worth adding that, along with his collaborators, that author went on to publish a number of relevant references on a wide range of applications of the method (CACUCI; WACHOLDER, 1982; CACUCI, 1990; CACUCI; IONESCU-BUJOR, 1990, 2005; IONESCU-BUJOR; JIN; CACUCI, 2005; CACUCI, 2003; CACUCI; IONESCU-BUJOR; NAVON, 2005; CACUCI, 2015, 2016).

Two of the above works by Cacuci are especially relevant. In (CACUCI et al., 1980), the author devises a sequence of formal steps to construct the adjoint problem. Whereas, in (CACUCI, 1981a), conditions for the existence and uniqueness of the adjoint operator require the underlying spaces to be complete and normed (Banach). They also demand that all operators that act upon the state vector admit densely defined partial Gâteaux derivatives with respect to all of their 
components (LUENBERGER, 1969; LUSTERNICK; SOBOLEV, 1961), and that the Gâteaux differentials be linear in the state vector variations. The need for an inner product is met by further setting the problem in Hilbert spaces (HAASER; SULLIVAN, 1991), which are self-dual and where Riesz representation theorem ensures the operators uniqueness (LUENBERGER, 1969; KREYSZIG, 1989; DACOROGNA, 2004; BREZIS, 2010). Next we present a brief account of those works, as they apply to the particular problem in hand. So as to put more emphasis on the formal, mathematical, aspects of proposed approach.

It starts by considering a measure of merit, an objective functional relative to Euler compressible flows. In generic form, it may be written as (CACUCI et al., 1980):

$$
I_{o}[\mathbf{Q}, \alpha]=\int_{\mathcal{D}} \mathcal{F}[\mathbf{Q}(\chi), \alpha(\chi), \chi] \mathrm{d} \chi
$$

where $\mathbf{Q}$ is the state vector, comprising density, linear momentum and total energy. While $\chi$ are coordinates of the domain $\mathcal{D}$ in physical space, $\mathcal{D} \subset \mathbb{R}^{J}$, and $\alpha$ represents the set of parameters that control the system, $\alpha \in \mathbb{R}^{N}$. In generic form, one has:

$\mathbf{Q}(\chi)=\left[Q_{1}(\chi), \ldots Q_{K}(\chi)\right] \quad ; \quad \chi=\left(\chi^{1}, \ldots, \chi^{J}\right) \quad ; \quad \alpha(\chi)=\left[\alpha_{1}(\chi), \ldots, \alpha_{N}(\chi)\right]$

The state space is taken to be a $K$-dimensional Hilbert space $\left(\mathbf{Q} \in H_{Q}\right)$ over the scalar field of real numbers $\mathbb{R}$. Inner products are defined on the basis of domain and surface integrals, respectively:

$$
\langle\mathbf{f}, \mathbf{g}\rangle \equiv \int_{\mathcal{D}} \mathbf{f}(\chi) \cdot \mathbf{g}(\chi) \mathrm{d} \mathcal{V}_{\chi} \quad ; \quad\langle\mathbf{f}, \mathbf{g}\rangle_{s} \equiv \int_{\partial \mathcal{D}} \mathbf{f}(\chi) \cdot \mathbf{g}(\chi) \mathrm{d} S_{\chi}
$$

and a $L^{2}$ norm is induced by that product: $\|\mathbf{f}\|^{2}=\langle\mathbf{f}, \mathbf{f}\rangle$.

Given the well-known properties of Hilbert spaces, and the fact that Gâteaux differentials of the Euler equations and boundary conditions are linear on $\delta \mathbf{Q}$ and $\delta \alpha$, a unique set of adjoint Euler equations can be promptly derived (VOLPE, 2016), which fully agrees with the literature on the method.

Under the above conditions, the objective functional $I_{o}$, eq. (2.1), is an application of type $H_{Q} \times \mathbb{R}^{N} \rightarrow \mathbb{R}$, which is defined in the flow domain $\mathcal{D} \subset \mathbb{R}^{J}$. A Vainberg theorem (number 3.2 in (VAINBERG, 1964)) gives the necessary and sufficient conditions for a generic functional to have Gâteaux differential that are linear on the variations (LUENBERGER, 1969; LUSTERNICK; SOBOLEV, 1961), what is used by Cacuci in establishing the theoretical foundation (CACUCI, 1981a, 
1981b). However, here we shall, a priori, confine the scope of the investigation to objective functionals that meet those conditions, that is, those with first variation of the form:

$$
\delta I_{o}=\underbrace{\left\langle\mathcal{F}_{Q}^{\prime}, \delta \mathbf{Q}\right\rangle}_{\delta I_{o_{Q}}}+\underbrace{\left\langle\mathcal{F}_{\alpha}^{\prime}, \delta \alpha\right\rangle}_{\delta I_{o_{\alpha}}}
$$

where $\delta I_{o_{Q}}$ is the physical part and $\delta I_{o_{\alpha}}$ is the parametric part of the total variation. Again, in generic form, the physical system is governed by a set $\mathbf{N}$ of $K$ nonlinear PDEs, which, in turn, are subject to a set $\mathbf{B}$ of boundary and initial conditions. In terms of operators, one can write (CACUCI et al., 1980),

$$
\begin{aligned}
\mathbf{N}[\mathbf{Q}(\chi), \alpha] & =\mathbf{R}(\chi, \alpha) \\
\mathbf{B}[\mathbf{Q}(\chi), \alpha]_{s} & =0
\end{aligned}
$$

where the subscript []$_{s}$ implies that the conditions are imposed on the appropriate domain boundaries $\partial \mathcal{D}$ and $\mathbf{R}(\chi, \alpha)$ is the source term of the equations which govern the flow. Then, in principle, one can define an augmented functional that represents the constrained variational problem,

$$
G(\mathbf{Q}, \alpha, \phi, \beta, \mathbf{a})=I_{o}[\mathbf{Q}, \alpha]-\langle\phi, \mathbf{N}-\mathbf{R}\rangle-\langle\beta, \mathbf{B}\rangle_{s}-\left\langle\mathbf{a}, \alpha-\alpha_{o}\right\rangle
$$

Usually non-holonomic (GELFAND; FOMIN, 1963; LIBERZON, 2012; GOLDSTEIN; POOLE; SAFKO, 2000; MONFORTE, 2002), the constraints are introduced by the Lagrange multipliers $\phi, \beta$ and $\mathbf{a}$, in the last three functionals. The first, $\phi$, imposes the governing equations and the second, $\beta$, enforces their boundary conditions. While the third, a, ensures that the control parameters take on a given set of prescribed values $\alpha=\alpha_{o}$, which corresponds to the baseline configuration.

Naturally, the variation of $\mathrm{G}$ in eq. (2.7) depends on that of the governing equations (2.5) and boundary conditions (2.6). These have Gâteaux differentials that are given by:

$$
\begin{aligned}
\mathbf{L} \delta \mathbf{Q} & =\mathbf{S} \delta \alpha \\
\mathbf{B}_{Q}^{\prime} \delta \mathbf{Q} & =-\mathbf{B}_{\alpha}^{\prime} \delta \alpha
\end{aligned}
$$

where the operators are defined as $\mathbf{L} \equiv \mathbf{N}_{Q}^{\prime}$ and $\mathbf{S} \equiv \mathbf{R}_{\alpha}^{\prime}-\mathbf{N}_{\alpha}^{\prime}$, respectively (CACUCI et al., 1980). The first, $\mathbf{L}$, is the linearized form of the governing equations, whereas the second, $\mathbf{S}$, gathers all parameter variations.

The first term on the right hand side of (2.7) is the measure of merit, for which the variation is given by (2.4). As for the second term, one must compute its Gâteaux derivative and substitute (2.8) for the corresponding terms. Then, 
on making use of Gauss' theorem, one can transfer the differential operators from the state vector $\mathbf{Q}$ to the Lagrange multiplier $\phi$. That leads to:

$$
-\langle\phi, \mathbf{L} \delta \mathbf{Q}\rangle=\left\langle\mathbf{L}^{*} \phi, \delta \mathbf{Q}\right\rangle-P[\phi, \delta \mathbf{Q}]_{s}
$$

where the term $P[\phi, \delta \mathbf{Q}]_{s}$ is the bilinear concomitant the operation ensues (CACUCI et al., 1980; MORSE; FESHBACH, 1953; INCE, 1956) and, again, the symbol []$_{s}$ refers to the domain boundaries $\partial \mathcal{D}$. Furthermore, the first term on the right hand side of (2.10) contains $\mathbf{L}^{*}$, which is the adjoint operator to $\mathbf{L}$.

Finally, by computing the Gâteaux diferentials of the remaining functionals and on combining them with the above results, one obtains the first variation of the augmented functional, $\delta G$. It reads,

$$
\begin{aligned}
\delta G= & -\langle\delta \phi, \mathbf{N}-\mathbf{R}\rangle-\langle\delta \beta, \mathbf{B}\rangle_{s}-\left\langle\delta \mathbf{a}, \alpha-\alpha_{o}\right\rangle+\left\langle\mathbf{L}^{*} \phi+\mathcal{F}_{Q}^{\prime}, \delta \mathbf{Q}\right\rangle+ \\
& -\left\langle\beta, \mathbf{B}_{Q}^{\prime} \delta \mathbf{Q}\right\rangle_{s}-\left[\left\langle P_{1}(\phi), \mathbf{B}_{Q}^{\prime} \delta \mathbf{Q}\right\rangle_{s}+\left\langle\mathbf{B}^{*}(\phi), \mathbf{M} \delta \mathbf{Q}\right\rangle_{s}\right]+\left\langle\mathcal{F}_{\alpha}^{\prime}, \delta \alpha\right\rangle+ \\
& +\langle\phi, \mathbf{S} \delta \alpha\rangle-\langle\mathbf{a}, \delta \alpha\rangle-\left\langle\beta, \mathbf{B}_{\alpha}^{\prime} \delta \alpha\right\rangle_{s}
\end{aligned}
$$

where $\delta I_{o}$ has already been replaced by eq. (2.4). In addition to that, the bilinear concomitant $P[\phi, \delta \mathbf{Q}]_{s}$ from (2.10) has been decomposed into the two terms within square brackets. Both of them are inner products, only they must be computed over the appropriate boundaries. The first one involves a $P_{1}(\phi)$ and the linearized boundary operator $\mathbf{B}_{Q}^{\prime} \delta \mathbf{Q}$. While the second involves a $\mathbf{B}^{*}(\phi)$, which represents the adjoint boundary operator, and a term $\mathbf{M} \delta \mathbf{Q}$.

The decomposition of $P$ is not unique, and neither are the definitions of $P_{1}$ and $\mathbf{M}$ (CACUCI et al., 1980). On the contrary, the only restriction that is actually imposed on the procedure is that the operator $\mathbf{M}$ be linearly independent of $\mathbf{B}_{Q}^{\prime}$. As a result of this, the very determination of the adjoint boundary problem hinges upon a non-unique decomposition, and it only makes sense that it should be this way. After all, there must be some leeway left to ensure the problem is well-posed.

The augmented functional $G$ realizes extrema upon the condition that (2.11) vanishes for arbitrary, albeit realizable, variations of its parameters:

$$
\delta G=0 \forall\{\delta \mathbf{Q}, \delta \alpha, \delta \phi, \delta \beta, \delta \mathbf{a}\} \in\{\text { locus of realizability }\}
$$

That, in turn, requires that the following conditions be met:

1. The equations that govern the physics (2.5) and their boundary conditions (2.6) are satisfied. In addition, the control parameters take on the prescribed baseline values, $\alpha=\alpha_{o}$. These requirements imply that the first 
three terms of (2.11) are identically zero.

2. On imposing the condition,

$$
\beta=-P_{1}(\phi)
$$

one drives to zero the sum of the fifth and sixth terms of (2.11). This particular equation also solves the $\beta$ in terms of the $\phi$.

3. The vector $\phi$ must satisfy the adjoint equation, which is given by:

$$
\mathbf{L}^{*} \phi+\mathcal{F}_{Q}^{\prime}=0
$$

as it appears in the fourth term of (2.11). The corresponding boundary conditions are given by the operator

$$
\mathbf{B}^{*}(\phi)=0
$$

which comes from the seventh term in that equation. Equation (2.15) determines $\phi$ at the boundaries, along with the $\beta$ thereof.

4. The vector $\mathbf{a}$ is specified by the following condition:

$$
\langle\mathbf{a}, \delta \alpha\rangle=\left\langle\mathcal{F}_{\alpha}^{\prime}, \delta \alpha\right\rangle+\langle\phi, \mathbf{S} \delta \alpha\rangle-\left\langle\beta, \mathbf{B}_{\alpha}^{\prime} \delta \alpha\right\rangle_{s}
$$

which collects all the remaining terms when $\delta G=0$. In fact, this is the realizable part of the sensitivity gradient, $\delta I_{o}$, as will be shown next.

To prove the above statement regarding the sensitivity gradient (CACUCI et al., 1980), suffices it to recognize that: If the governing equations, (2.5) and (2.6) are identically satisfied for a given variation $\Delta G$, of any size. Then, from the very definition of $G$ in (2.7), it comes that

$$
\begin{aligned}
& \Delta G=\Delta I_{o}-\langle\mathbf{a}, \Delta \alpha\rangle \\
& \text { for }\left\{\begin{array}{l}
\Delta G=G\left(\mathbf{Q}_{2}, \alpha_{2} ; \phi_{2}, \beta_{2}, \mathbf{a}_{2}\right)-G\left(\mathbf{Q}_{1}, \alpha_{1} ; \phi_{1}, \beta_{1}, \mathbf{a}_{1}\right) \\
\Delta I_{o}=I_{o}\left(\mathbf{Q}_{2}, \alpha_{2}\right)-I_{o}\left(\mathbf{Q}_{1}, \alpha_{1}\right) \\
\Delta \alpha=\alpha_{2}-\alpha_{1}
\end{array}\right.
\end{aligned}
$$

In particular for an infinitesimal variation $\Delta G \rightarrow \delta G$, under the above conditions and where $\phi, \alpha$ and $\beta$ fulfill the above four requirements, there must correspond 
a stationary value of $G$. Therefore, one can write

$$
\begin{aligned}
\delta G & =\delta I_{o}-\langle\mathbf{a}, \delta \alpha\rangle=0 \\
\delta I_{o} & =\langle\mathbf{a}, \delta \alpha\rangle \\
\delta I_{o} & =\left\langle\mathcal{F}_{\alpha}^{\prime}, \delta \alpha\right\rangle+\left\langle\phi,\left(\mathbf{R}_{\alpha}^{\prime}-\mathbf{N}_{\alpha}^{\prime}\right) \delta \alpha\right\rangle+\left\langle P_{1}(\phi), \mathbf{B}_{\alpha}^{\prime} \delta \alpha\right\rangle_{s}
\end{aligned}
$$

where the eqs. (2.13), (2.16) and the definition of $\mathbf{S}$ have been used. With the above expression (2.18), one can estimate the sensitivity gradient on the basis of the adjoint solution $\phi$ and parameter variations $\delta \alpha$, alone.

It is worth noting here that all physical variations $\delta \mathbf{Q}$ have been successfully removed from the gradient expression. Moreover, the first term on the right hand side of (2.18) is precisely $\delta I_{o_{\alpha}}$, whereas the second measures the direct effects of $\delta \alpha$ on the governing equations, and the third does so with respect to their boundary conditions. 


\section{Arina Nozzle Optimization}

For convenience, the Arina nozzle profile expression is repeated here:

$$
A(x)= \begin{cases}2.5+3\left(\frac{x}{x_{t h}}-1.5\right)\left(\frac{x}{x_{t h}}\right)^{2} ; & \forall x \leqslant x_{t h} \\ 3.5-\frac{x}{x_{t h}}\left[6-4.5 \frac{x}{x_{t h}}+\left(\frac{x}{x_{t h}}\right)^{2}\right] & \forall x \geqslant x_{t h}\end{cases}
$$

The flow simulation was solved with Euler 2D formulation, using methane as an ideal gas (this way, the stagnation pressure, the stagnation temperature, the stagnation enthalpy and the entropy are easily obtained). The optimization via inverse design simulation used $C_{p}$ (pressure coefficient on the wall) directive, (3.2). The three parameters defined for the inlet were: Inflow temperature, 288.0 $\mathrm{K}$, inflow static pressure, $100000 \mathrm{~Pa}$ and flow direction according to the $x$ cartesian direction. In the outlet, the only parameter set up was the static back pressure, 83049.0 Pa. These parameters are the ones used in the article of Renzo Arina (ARINA, 2004). The flow solver calculates the boundary conditions based on the parameters informed (temperature, static pressures, flow direction): in the inlet section, the boundary conditions are stagnation pressure and stagnation temperature; and in the outlet section, the boundary condition being the static back pressure itself. In all figures in this chapter, where the nozzle profile is shown, the botton straight line represents its center line, and the top curve is the nozzle wall (either the original Arina profile, described in equation (3.1); or the optimized profile, obtained through the inverse design). Figures (3.1) and (3.2) show, respectively, the non-dimensional distribution of stagnation temperature and stagnation pressure.

The numerical method selected for the spatial gradients of the flow variables is the WEIGHTED-LEAST-SQUARE one, (SHIMA; KITAMURA; HAGA, 2013; SHIMA; KEIICHI; KEIICHIRO, 2010), due to the smoother profile that an Arina nozzle presents and to the absence of finer mesh at boundaries; the Linear solver for implicit formulations was FGMRES (Flexible Generalized Minimal Residual method, an iterative solver for non-symmetric systems of linear equations) using a Krylov precontitioner (LU-SGS, Lower-Upper Symmetric Gauss-Seidel 


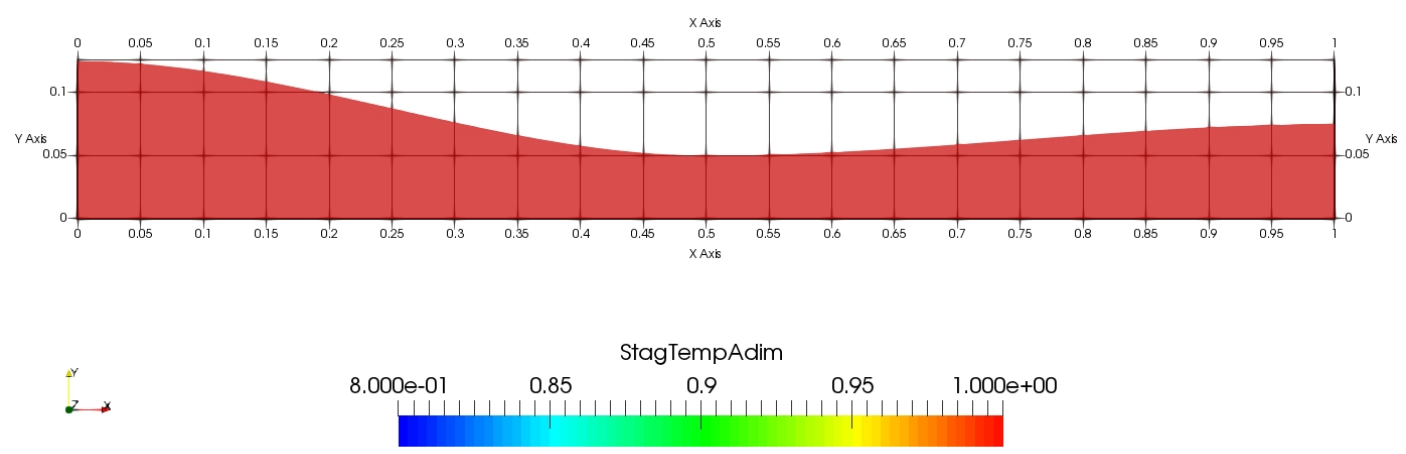

Figure 3.1: Stagnation temperature (non dimensional) in an Arina nozzle with methane as a perfect gas and using 2D Euler equations.
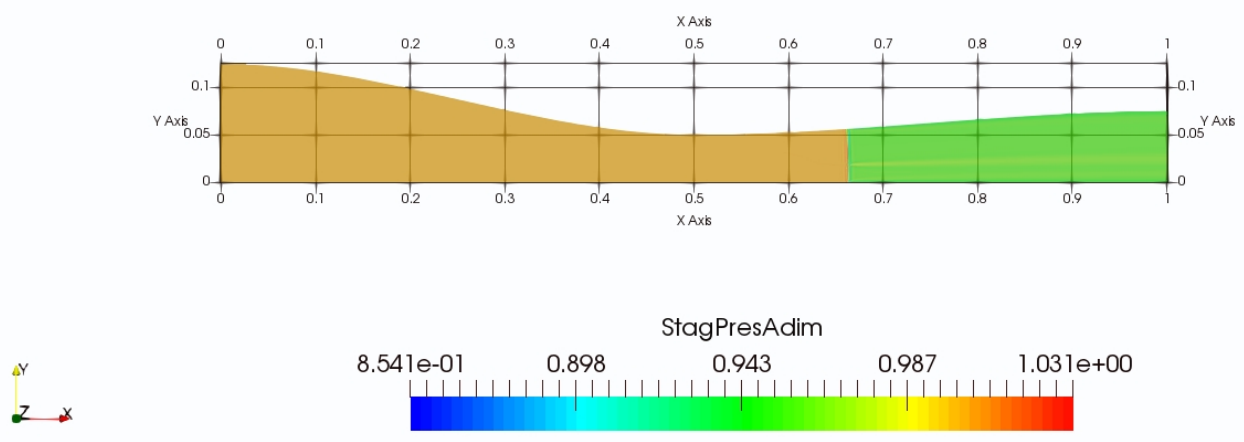

Figure 3.2: Stagnation pressure (non dimensional) for an Arina nozzle with methane as a perfect gas and using 2D Euler equations.

method). The convective numerical method built upon the finite volume method is the Jameson-Schmidt-Turkel (JST: (JAMESON; SCHIMIDT; TURKEL, 1981)) one. Time discretization is Euler implicit (Euler explicit and Runge-Kutta explicit methods are also availble in SU2, but have not been used).

The Arina meshes have been adjusted to allow good computational performance while keeping the desired accuracy: thus the "optimum" mesh which has been largely employed in most of the simulatios is a grid with 85504 triangles and 43485 vertices, obtained via Ansys Meshing: With this mesh, the definition of the shock is still sharp. Two levels of Multi-grid cycle scheme have been used, via a V-CYCLE approach. Geometry deformation based on CST (KULFAN; BUSSOLETTI, 2006) parametrization is used in the majority of simulations, and 

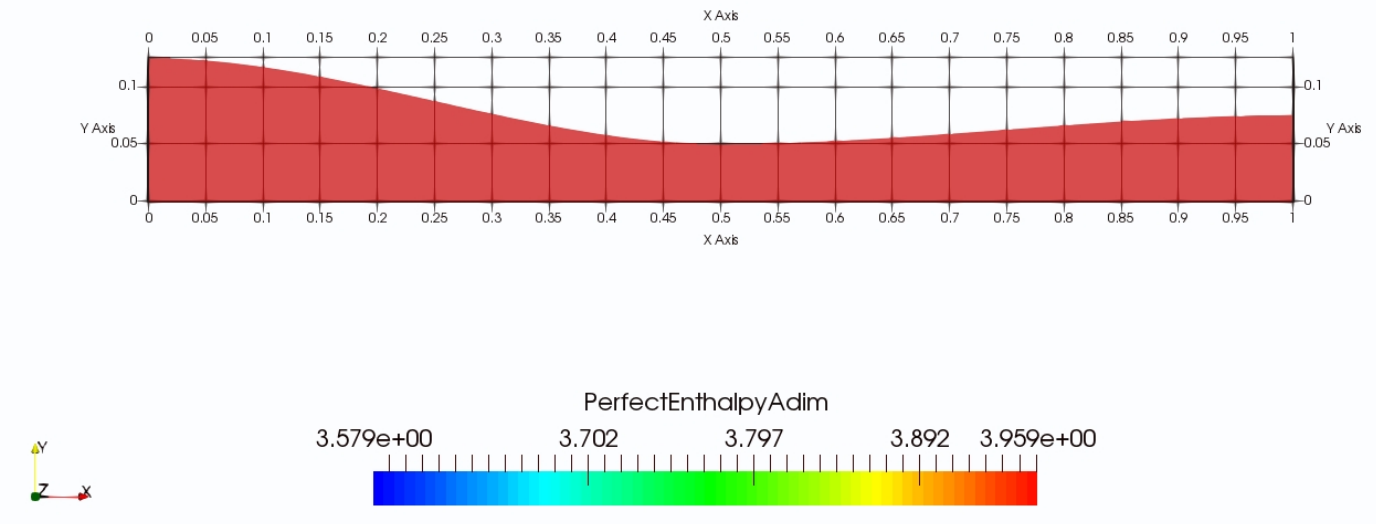

Figure 3.3: Stagnation enthalpy (non dimensional) for an Arina nozzle with methane as a perfect gas and using 2D Euler equations.

the corresponding number of design variables is 15 . The convergence criterion is based on residual and the maximum residual is set up to $10^{-8}$. Optimization was set up without any kind of geometry constraints but the length of the separator and the nozzle sections of inlet and outlet.

The fluid used in the Arina nozzle optimization is methane $\left(\mathrm{CH}_{4}\right)$, considered as an ideal gas, where the state of stagnation is reached through a reversible and adiabatic process (HODGE; KOENIG, 2016) which allows one to check the sanity of solution by easily calculating the stagnation properties. The flow solution using SU2 with the same fluid and parameters as reported by Arina (ARINA, 2004) has presented good agreement with the experimental and numerical results in his article, thus validating the SU2 solution for this particular test. The stagnation enthalpy value holds even if the fluid is not a perfect gas, and the entropy does not require the stagnation qualifying adjective, since the stagnation state is reached by an isoentropic process. Thus, the entropy in the state of stagnation is the very same one as in the original state, by definition. For an ideal gas, it is suffices to know the stagnation pressure and temperature.

Figures 3.3 and 3.4 represent respectively, the stagnation enthalpy and the entropy for the original Arina profile together with coordinate axis and grid, to ease the location of the normal shock wave in the geometry. The working fluid is methane. These graphs show that the solution satisfies both the first and second Laws of Thermodynamics and also, that the solution passes the sanity check.

As seen in chapter 1, of this plan, the distributions used to work in the 

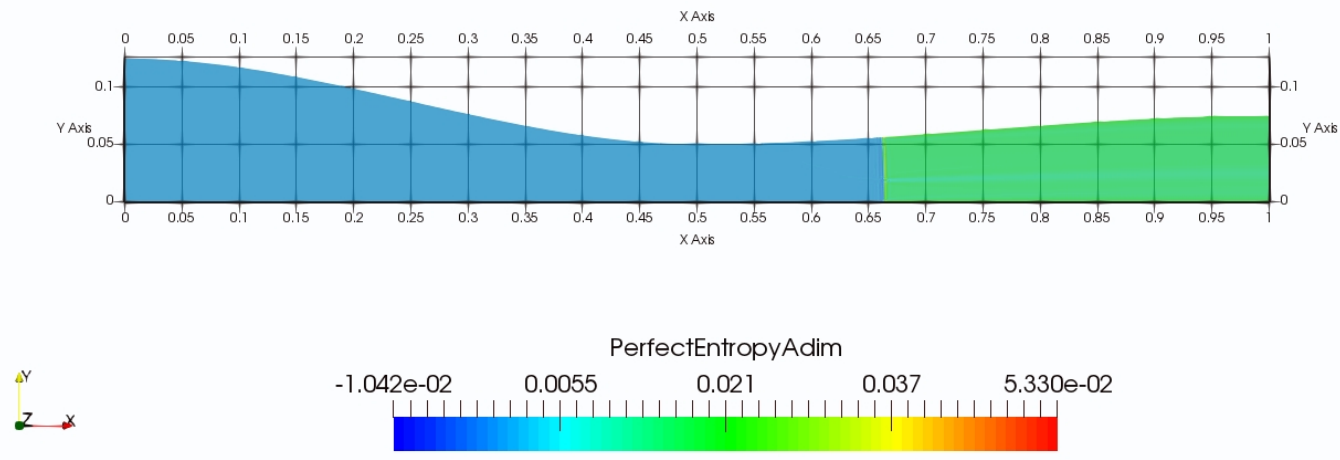

Figure 3.4: Entropy (non dimensional) for an Arina nozzle with methane as a perfect gas and using 2D Euler equations: The amount of entropy is greater after the normal shock wave, thus satisfying the second law of Thermodynamics.

inverse design are the pressure coefficient, $C_{p}$ at nozzle internal surface. Thus, the objective function becomes:

$$
I=\frac{1}{2} \int_{b_{w}}\left(C_{p}-C_{p_{\text {tar }}}\right)^{2} \mathrm{~d} s
$$

The target $C_{p_{t a r}}$ distribution is proposed on the basis of the designer knowledge and it is not necessarily realizable (CEZE, 2008). For this project, it has been estimated based on the original $C_{p}$ curve, aiming to delay the normal shock wave position to the new desired shock wave location, by extrapolating the $C_{p}$ curve from the former shock wave position up to the new location, via the piecewise cubic Hermite interpolating polynomial method (KAHANER; MOLER; NASH, 1989), thus preserving most of the original distribution: From this new position, the remaining original $C_{p}$ curve is resumed. Although there is no guaranty, in this case, that the new geometry will be entirely realizable. However, after a number of cycles, the process delivers a modified geometry that best approximates the target $C_{p}$ within the space of realizable flows. Naturally, for some problems, the process can diverge. Although numerical divergence cannot be completely ruled out, in and of itself, it does not necessarily mean that the target $C_{p_{t a r}}$ is unreachable. The method used in most of the optimizations to drive the cost function to its minimum is the steepest descent. Beyond the use of the steepest descent method, the biconjugate gradient method has also been used in a few instances (FITZGIBBON et al., 2014; KORNHUBER et al., 2005; AXELSSON; KOLOTILINA, 1989), to 
accelerate processing.

During optimization cycles, the system tries to match the target values and sometimes the output of a given cycle, say N, yields values which are better than cycle $\mathrm{N}+1$ in some sense, but are still farther from the target values. One such occurrence has been found in the 17th optimization cycle in a simulation with CST parametrization: the delayed normal shock wave happens to be located nearer the nozzle outlet than the target shock wave location: this result is 'better', in the sense that it allows more room, within the separator, to the phase change to occur despite a small reduction in the mass flow rate (throat area is slightly smaller than the original one), then one could "capture", the $C_{p}$ distribution of that particular cycle and make it a target. The next four figures will focus on this final (17th) cycle. One should recall that, in a chocked flow, the Mach number

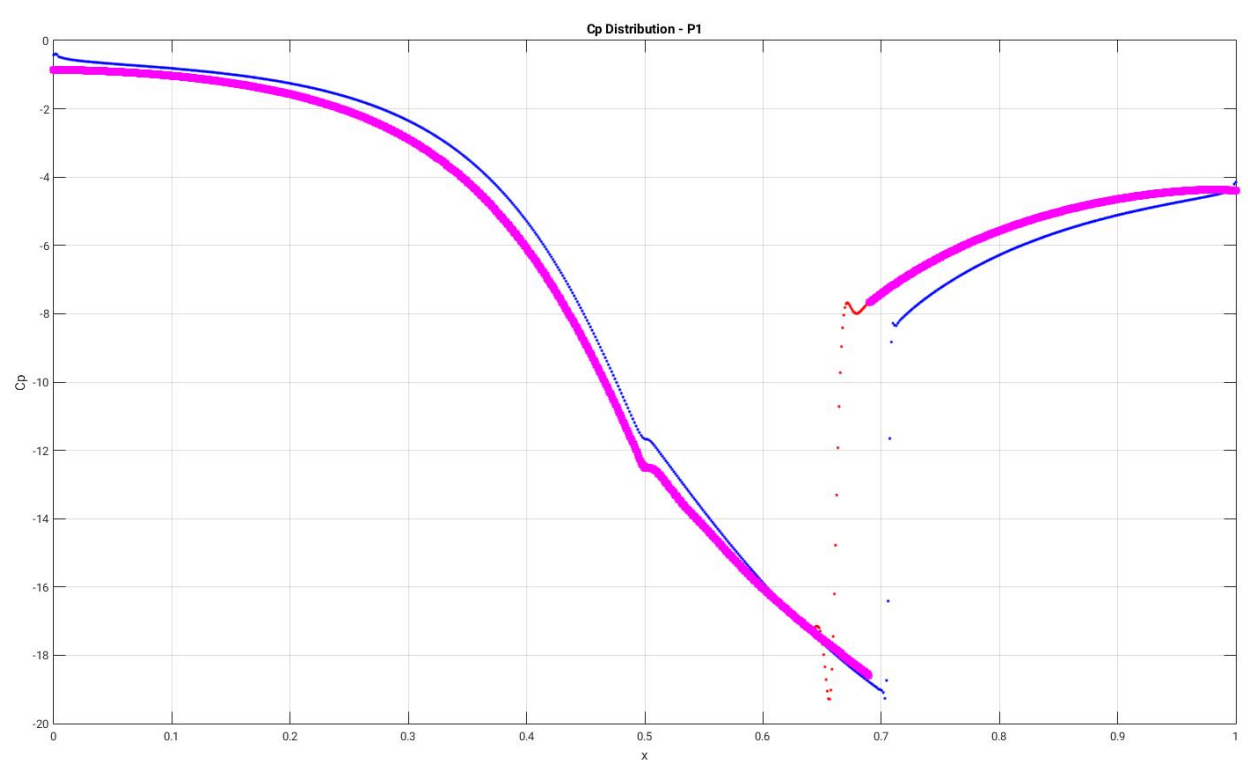

Figure 3.5: Pressure coefficient values: red corresponds to the original Arina profile values; magenta corresponds to the target values and blue corresponds to the 17th optimization cycle values for methane as a perfect gas.

is 1 at the throat in an isentropic flow, and the mass flow rate $\left(\dot{m}_{t h}\right)$ is given by equation (3.3):

$$
\dot{m}_{t h}=\left(\frac{2}{\gamma+1}\right)^{(\gamma+1) /[2(\gamma-1)]} \sqrt{\gamma / R} \frac{A_{t h} P_{o}}{\sqrt{T_{o}}}
$$

where

$\gamma$ is the ratio of specific heats,

$R$ is the gas constant,

$A_{t h}$ is the cross section area of the nozzle at the throat, 
$P_{o}$ is the stagnation pressure, and

$T_{o}$ is the stagnation temperature.

Figures 3.5, 3.6 and 3.7 compare respectively, the pressure coefficient $(C p)$, the mach number and the geometry with the target values. The values shown, are those obtained in the 17th optimization cycle with the same conditions of inlet and outlet as in the original Arina profile. In each graph, red curves or points represent the original flow solver outputs for the original Arina profile, blue curves or points represent the values resulting in the 17 th optimization cycle and magenta curves or points represent the target values. It can be observed that the shock wave in the optimized profile tends to be stronger than the one in the original profile: This makes sense, for it has a lower upstream pressure, since it has been delayed and yet it must recover the same back pressure

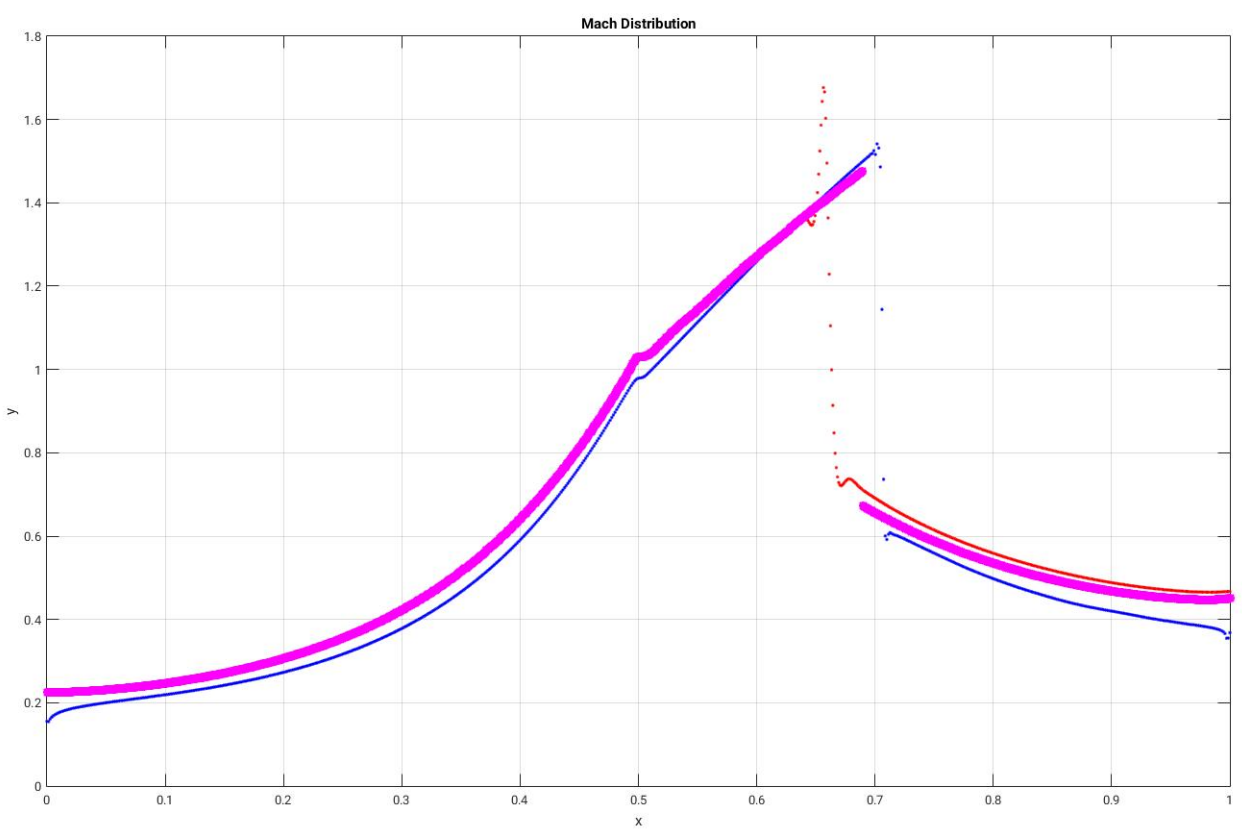

Figure 3.6: Mach values: red corresponds to the original Arina profile values; magenta corresponds to the target values and blue corresponds to the 17th optimization cycle values for methane as a perfect gas.

The residual history for the last optimization cycle in the flow solution is shown in Figure 3.8.

Figures $3.9,3.10,3.11$ and 3.12 , all of them show a typical sort of triangle wave which are consistently longer for delayed shock waves.

Figures 3.13, 3.14, 3.15 and 3.16 show the residual distribution, which from around the throat, are close to the machine precision.

Figure 3.17 gives a sample of the original grid for the inlet portion and Figure 

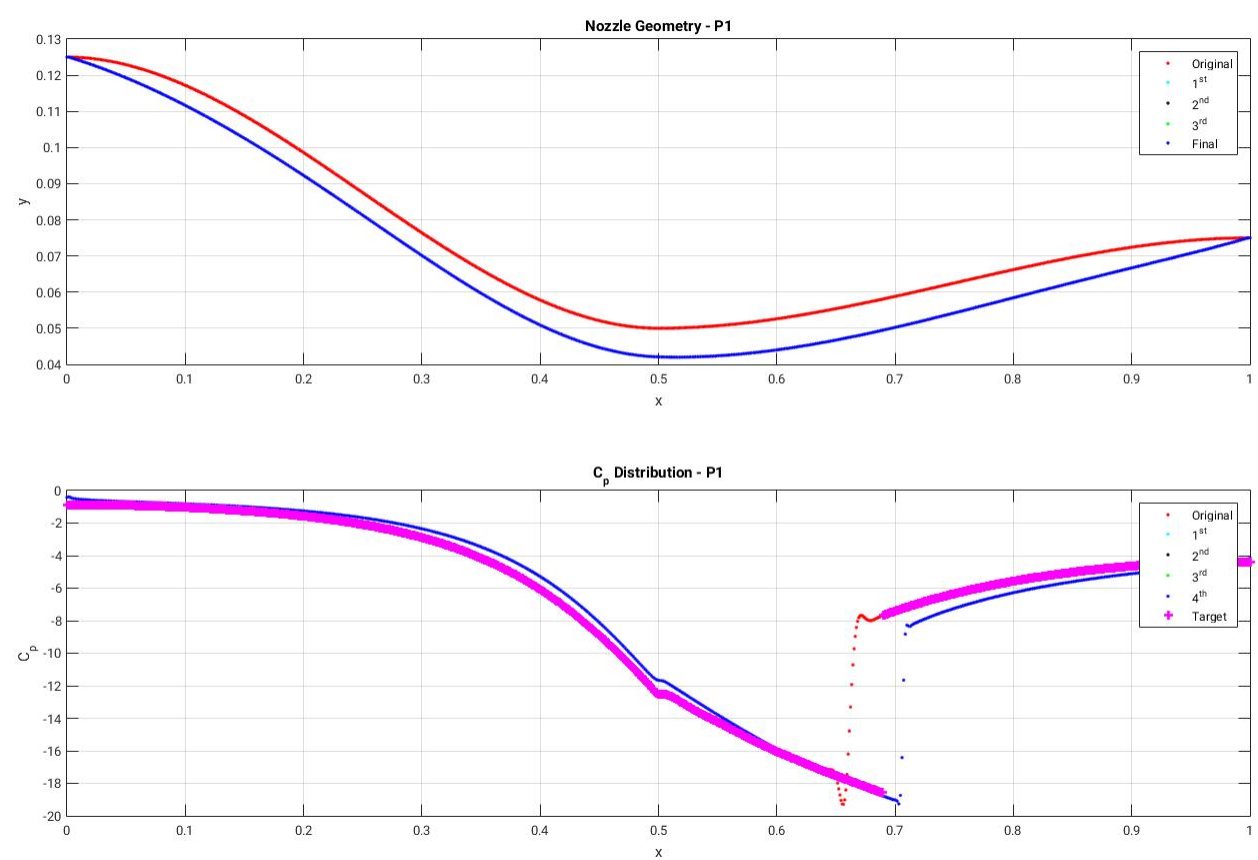

Figure 3.7: Original Geometry versus Optimized Geometry: red corresponds to the original Arina profile values and blue corresponds to the 17th optimization cycle values in conjunction with the corresponding data regarding the Pressure Coefficient for methane as a perfect gas. Intermediate initial cycles $\left(1^{s t} \ldots 4^{t h}\right)$ have been removed to better reading.

3.18 shows the optimization work: The original Arina profile (in red) and the optimized profile (in blue) in the 17th cycle combined.

\subsection{Closing Remarks on Nozzle Optimization}

In this phase of the project, that is, the nozzle optimization, the formation of a shock wave has been successfully delayed. Also, as a consequence of such delay, the temperature just upstream from the shock has gotten even lower. The shock in the optimized geometry became also stronger. The footprint of the nozzle has been kept, with a smaller throat diameter.

The objective to change slightly the geometry has been reached in a realizable flow solution: This validated the choice of the adjoint method, and paved the way to the more complex planned tasks, such as the inclusion of a swirler, with the use of both, Navier-Stokes and Euler equations. 


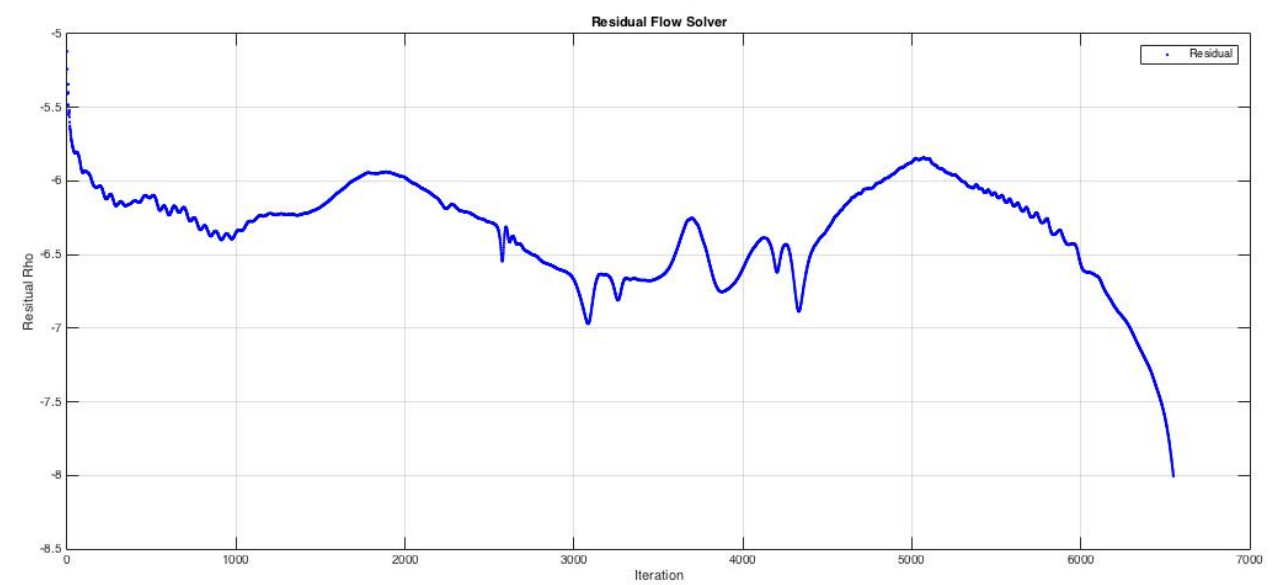

Figure 3.8: Residual history for the flow solution in the 17th cycle using 2D Euler equations. Abscissa axis is the number of iterations and ordinate axis is $\log _{10}$ of residuals

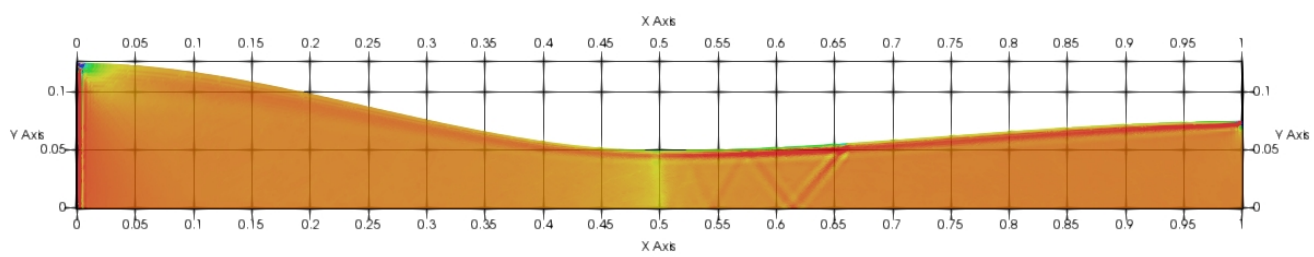

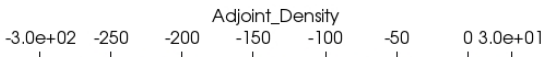

Figure 3.9: Adjoint density distribution in the Arina nozzle after the first optimization cycle using 2D Euler equations and considering methane as a perfect gas (original nozzle geometry). 

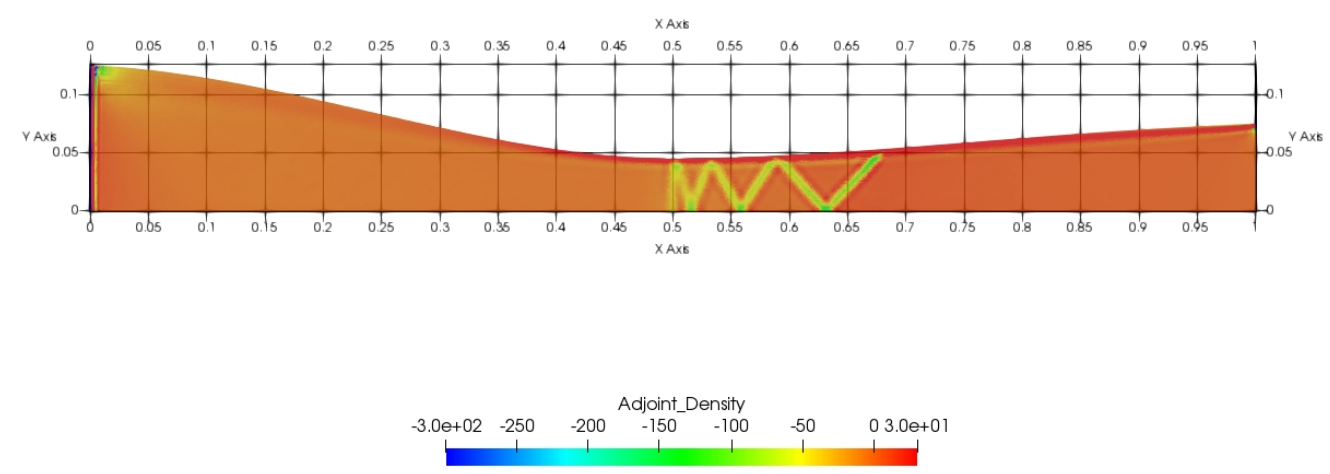

Figure 3.10: Adjoint density in the optimization cycle which has defined the nozzle profile obtained in the 17 th cycle, using methane as a perfect gas.
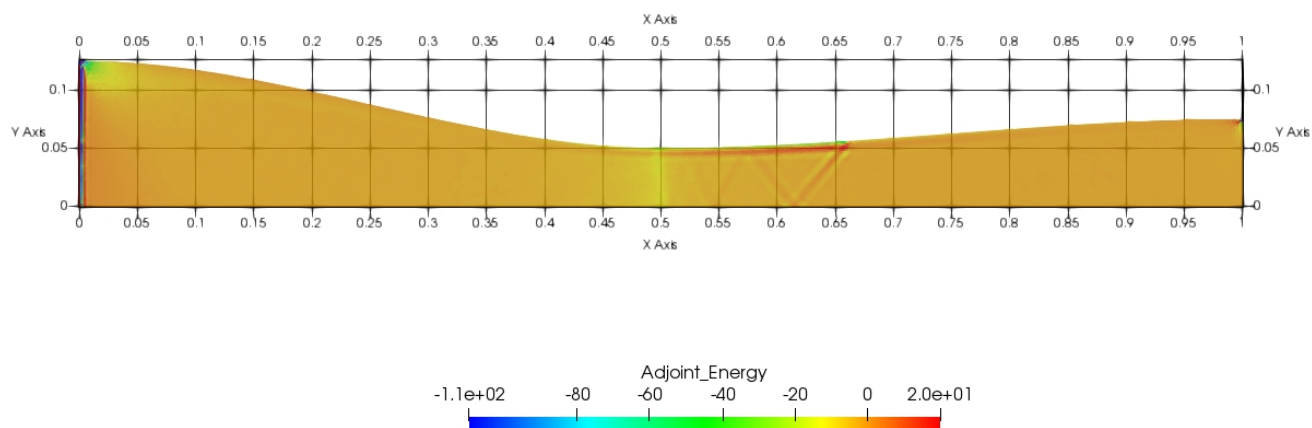

Figure 3.11: Adjoint Energy in the first optimization cycle, using methane as a perfect gas. 

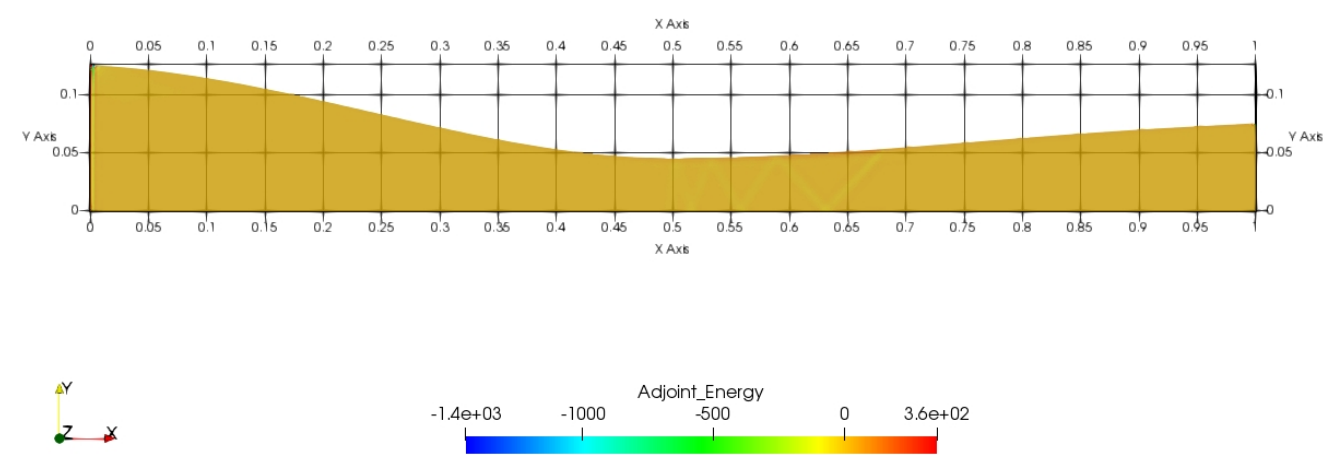

Figure 3.12: Adjoint Energy in the optimization cycle which has defined the nozzle profile obtained in the 17 th cycle, using methane as a perfect gas.
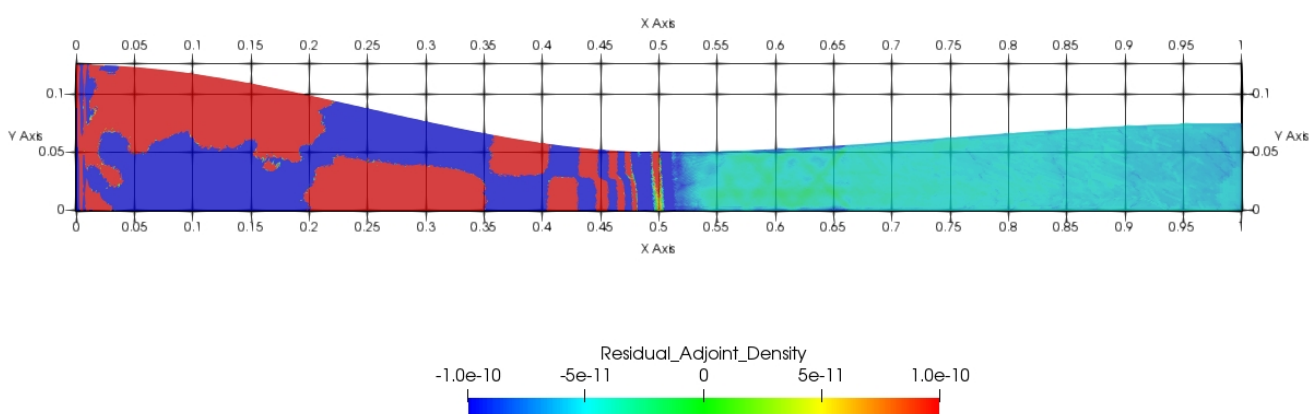

Figure 3.13: Adjoint Density Residual in the first optimization cycle, using methane as a perfect gas. 

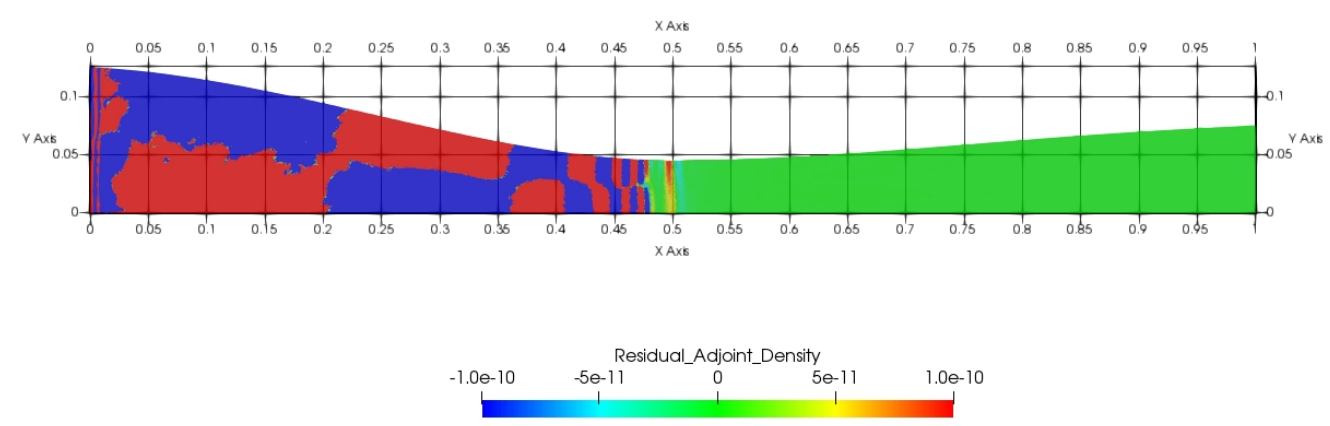

Figure 3.14: Adjoint Density Residual in the optimization cycle which has defined the nozzle profile obtained in the 17th cycle, using methane as a perfect gas.
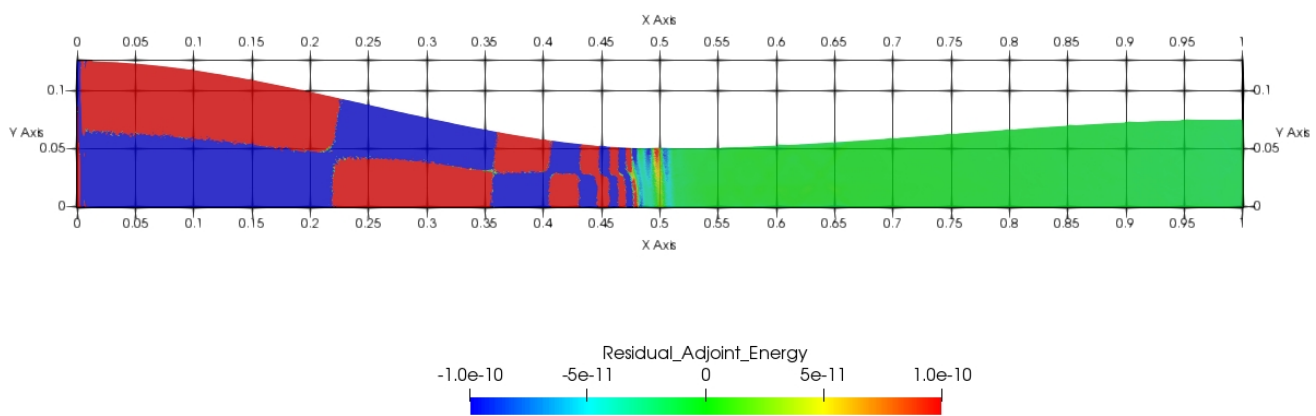

Figure 3.15: Adjoint Energy Residual in the first optimization cycle, using Euler equations and considering methane as a perfect gas. 

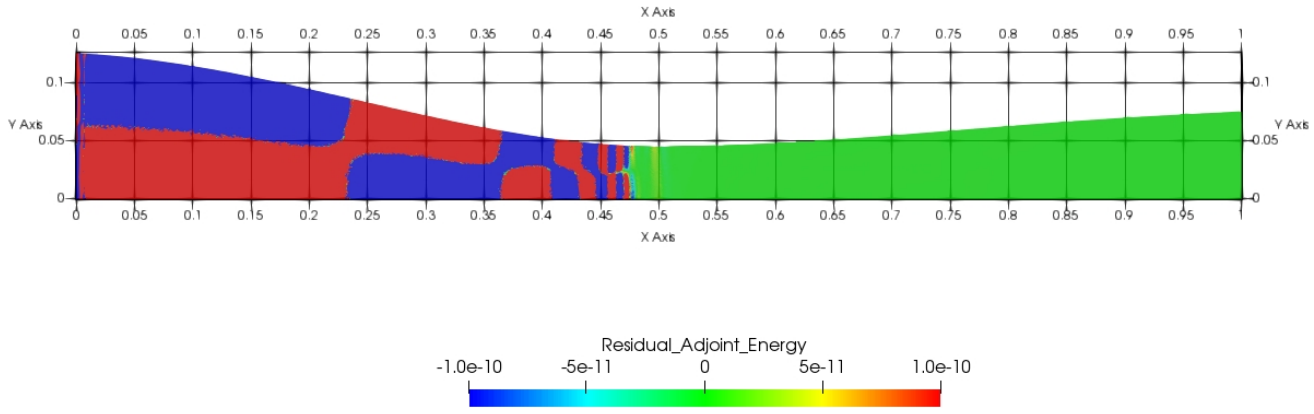

Figure 3.16: Adjoint Energy Residual in the optimization cycle which has defined the nozzle profile obtained in the 17th cycle, using Euler equations and considering methane as a perfect gas.

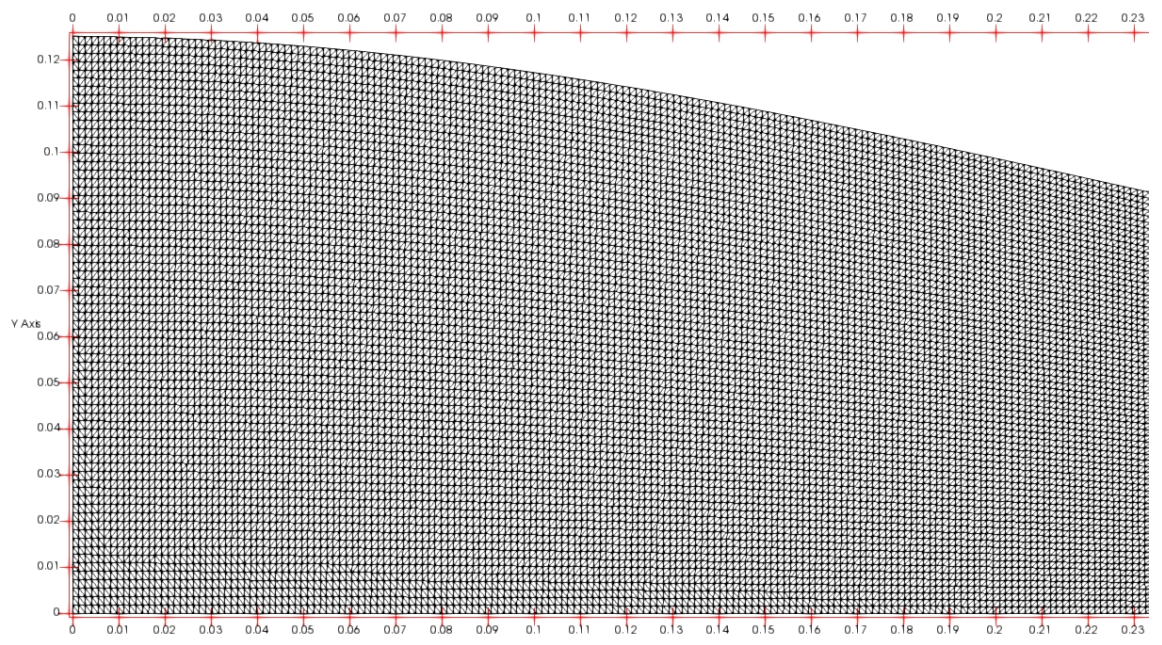

Figure 3.17: Original 2D grid for the Arina Nozzle at the inlet portion. 

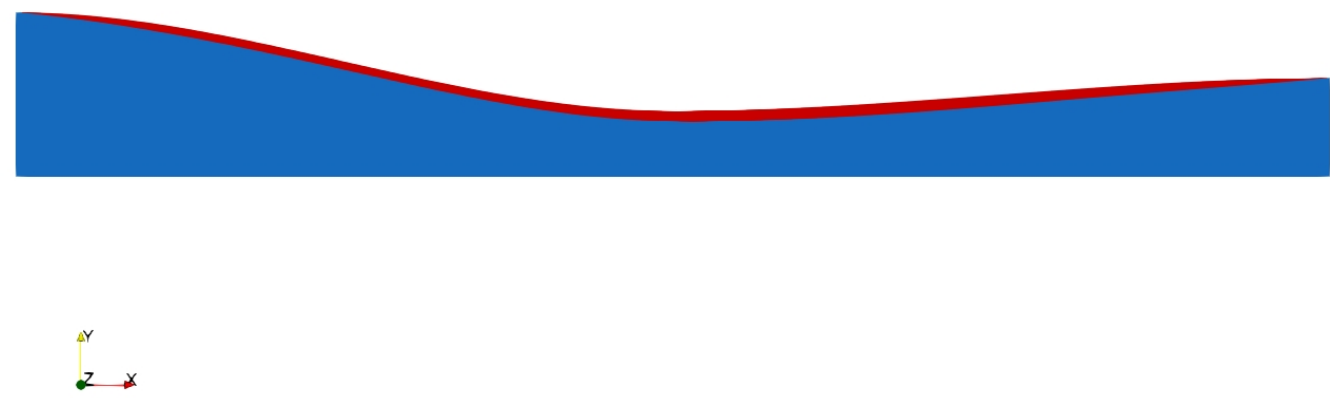

Figure 3.18: Comparison of the original Arina profile (in red) with the optimized profile (in blue), obtained using the inverse design pressure with 2D Euler equations. 


\section{INTEGRATED SEPARATOR OPTIMIZATION}

\subsection{The Static Swirl Generator}

The swirler is the part of the separator which precedes the nozzle. Its mission is to generate the cyclonic flow, which produces a high radial acceleration, thus bouncing the denser (liquid) particles to the separator internal walls, allowing the capture of the liquid carbon dioxide. It is formed by seven twisted vanes equally spaced: even thought this number could have been determined by using genetic optimization, in this case, its has been simply chosen as a mean to get expressive camber in the vanes profile. The vane angle of attack is zero and its profile does not follow any cataloged geometry: it has been created by the author. Figure 4.1 shows the two main regions of the fluid domain in the separator: the Swirler region and following it, the Nozzle region.

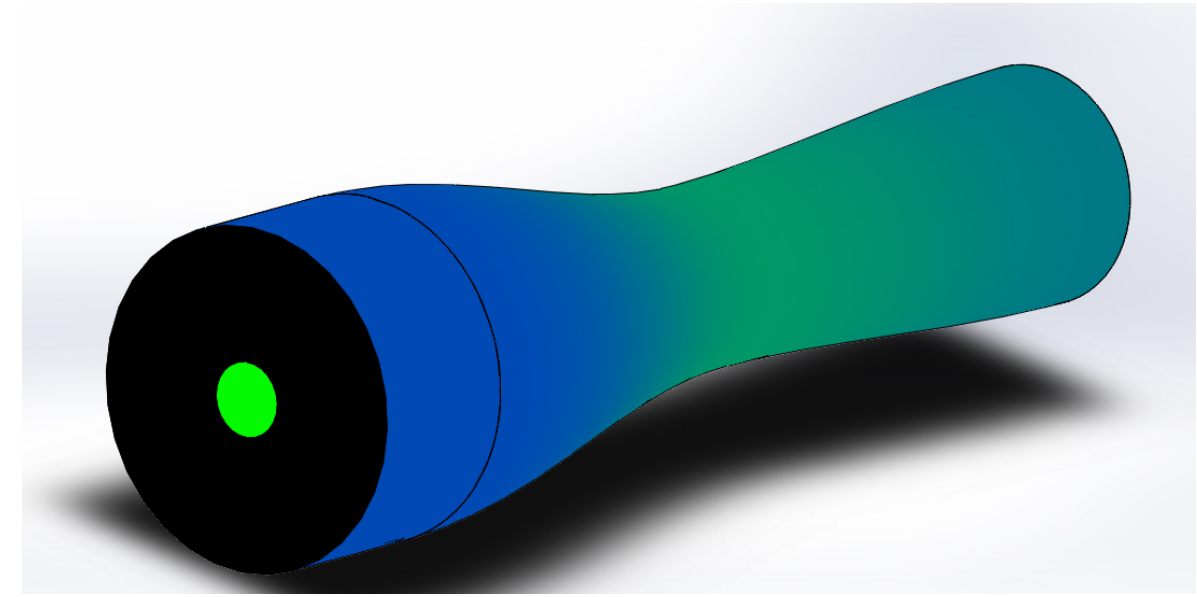

Figure 4.1: The fluid domain is shown divided in two portions: the first one, at the left side, is the portion which envelops the Swirler and the second part corresponds to the proper Nozzle of the Supersonic Swirling Separator.

Figure 4.2 shows the fluid domain inside of a FFD box. FFD is the instrument to produce the 3D deformation needed in the optimization steps and is used with both, Euler formulation and Navier - Stokes formulation. 


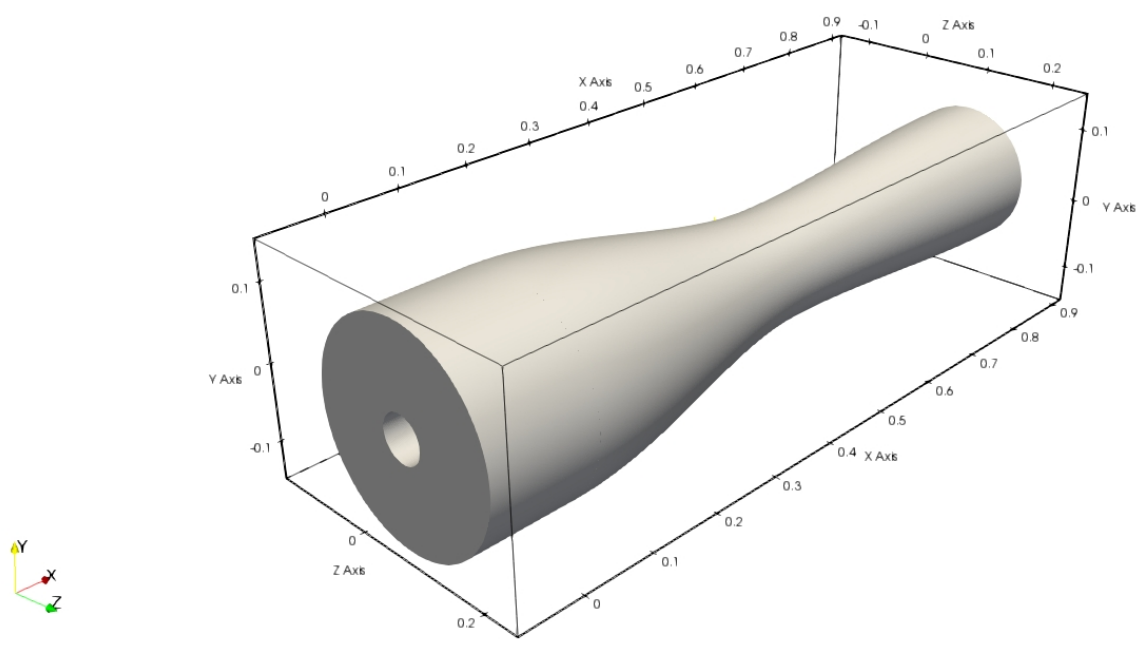

Figure 4.2: The fluid domain immersed in a FFD box. The FFD box is used with both, Euler formulation and Navier - Stokes formulation.

As earlier said in Chapter 1, the Supersonic Swirling Separator optimization has been developed in three fundamental phases: The first phase is the nozzle optimization, using $2 D$ Euler equations: The objective of this phase is to delay the shock wave by using inverse design pressure, thus providing more room to the phase change processes. The second phase introduces the swirling flow, it has dealt with $3 D$ flow using Euler equations, and the third and final phase has taken into account 3D swirling flow under Navier-Stokes equations. In the two last phases, inverse design has been used and a new objective function has been imposed, whose purpose is to increase the moment in the $x$ direction (which coincides with the hub center). This new function is denominated in this text "MOMENT-X". It is part of the standard library of objective functions available in de SU2 code.

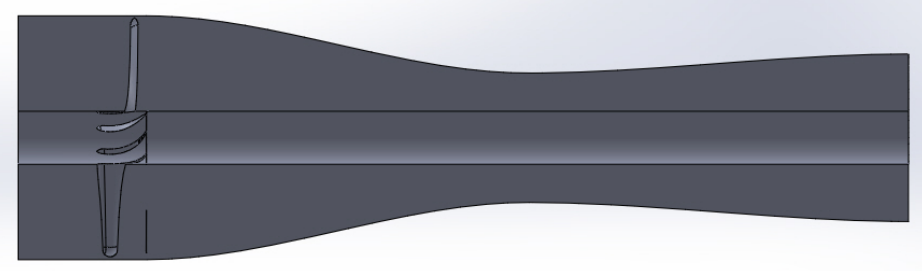

Figure 4.3: Longitudinal section of the fluid domain in the Supersonic Swirling Separator. 
Figure 4.3 shows a longitudinal section of the fluid space in the separator. The hollow regions in the fluid domain (that is, those regions without fluid) represent the solid vanes and the separator central shaft (hub).

The swirler causes the flow to be fully 3D, which requires a corresponding $3 \mathrm{D}$ simulation. If, on the one hand, the preliminary $2 \mathrm{D}$ simulations has given us a basic understanding of the shock wave influence on the flow field; it is only a $3 \mathrm{D}$ simulation the one that can capture the physics of the swirling mechanism. Initially the 3D case will be presented using the Euler formulation, and afterwards, the Navier-Stokes formulation will be used.

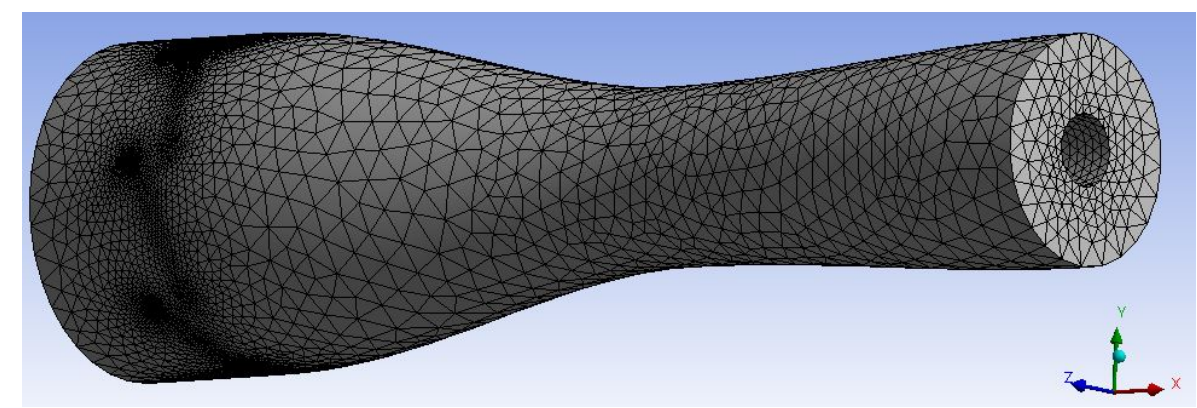

Figure 4.4: A coarse mesh for the fluid domain in the Supersonic Swirling Separator which as been employed with Euler formulation.

\subsection{The 3D Euler approach}

The governing equations for the compressible Euler formulation are given in the Appendix. The software setup and flow parameters are basically the same used in the nozzle simulation. The items which are different from the values used during the nozzle optimization phase, are noted below:

- Formulation : 3D Euler.

- GRID : 3D Tetrahedral unstructured mesh. Figure 4.4 shows a coarse mesh for the fluid domain.

- Parametrization : 3D Free Form Deformation (FFD).

- Inflow PARAmeters : Pressure $=120000 \mathrm{~Pa}$ and MachNumber $=0.3395$. The former values have not produced a shock wave.

Those parameters have been modified, since the original conditions used in the nozzle simulation and established in the work of Renzo Arina (ARINA, 2004), were insufficient to form a well defined shock wave when the swirler is in place. 
Minor changes in the general simulation parameters are noted wherever they are introduced.

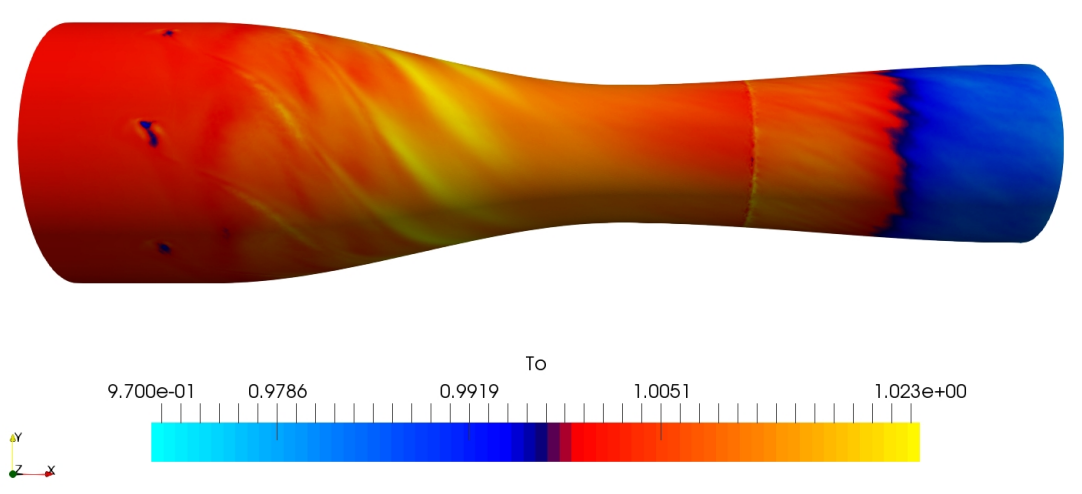

Figure 4.5: The stagnation temperature distribution in the Supersonic Swirling Separator, using 3D Euler equations. The flow direction follows according to the $x$ axis direction.

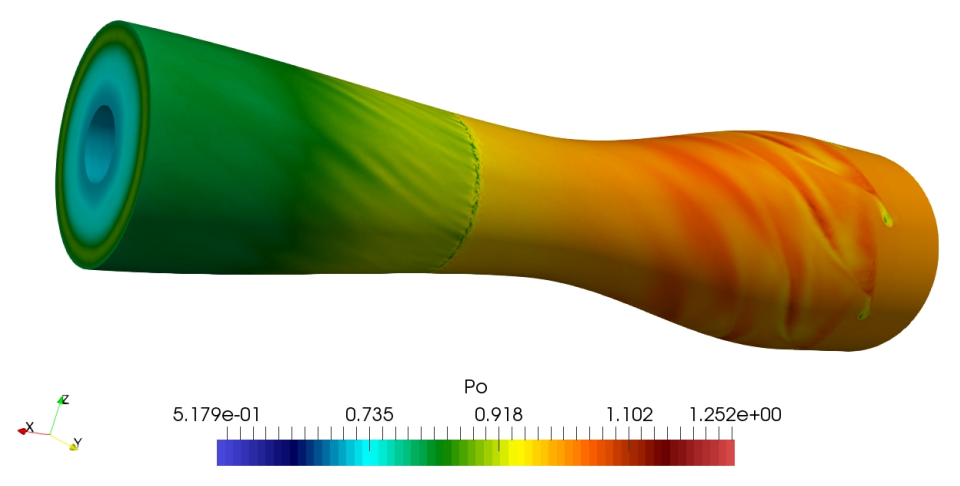

Figure 4.6: The stagnation pressure distribution in the Supersonic Swirling Separator, using 3D Euler equations. The flow direction follows according to the $x$ axis direction: the change in the figure orientation intends to show pressure nuances at the nozzle outlet.

As in the first phase, methane is the working fluid and its behavior is considered the one of an ideal gas; and, for purposes of optimization, the stagnation properties of temperature and pressure are used as a sanity check of the solution. The Figures 4.5 and 4.6 respectively, show the non-dimensional temperature and the stagnation pressure distribution (just as a remark, in the Section 4.4, Figures 4.17 and 4.18 represent the equivalent stagnation values for Navier-Stokes equations). One must bear in mind that, for Euler equations, the stagnation temperature should remain constant, and the stagnation pressure changes only through a shock wave. A color pallet highly saturated has been employed in Figures 4.5 and 4.6, to capture the faintest nuances, which evidentiate the swirler influence: 


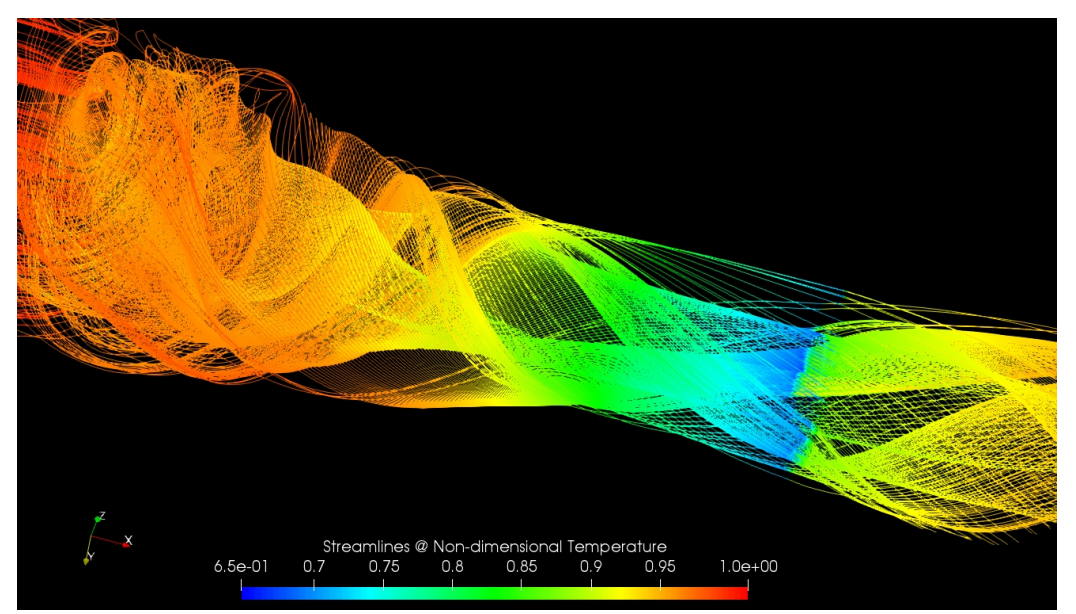

Figure 4.7: The non-dimensional temperatures shown in streamlines. Output according to the 3D Euler equations.

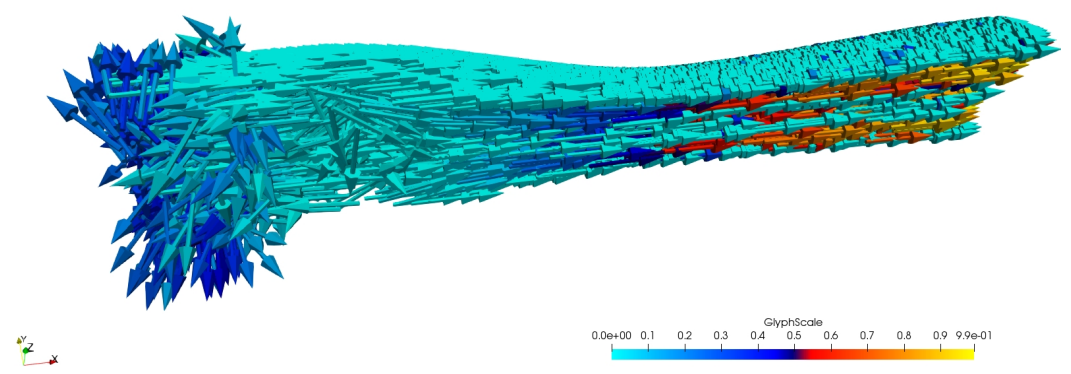

Figure 4.8: Vector representation in a longitudinal cut of the fluid domain showing magnitudes and directions in the Mach number within the Supersonic Swirling Separator, using 3D Navier-Stokes equations.

When the standard pallets are used, they make inconspicuous the differences of nuances.

The non-dimensional temperature is exposed as streamlines in the Figure 4.7, clearly showing the nature of the swirling flow.

The flow solution highlights the complex effects when the swirler is present: the complexity in this region of the flow is shown in the longitudinal cut of the fluid domain where a vector representation (sometimes called glyph) highlights the magnitudes and directions in the flow in Figure 4.8. This figure has been obained using Navier-Stokes equations.

The Mach number distribution is shown in Figure 4.9; and Figure 4.10 presents a longitudinal section of it. An important information the figure points out is that now, the shock wave is no longer flat, as it was in the case with Euler simulation without the swirling effects.

Figure 4.11 shows a circular section near the separator shaft with details in 


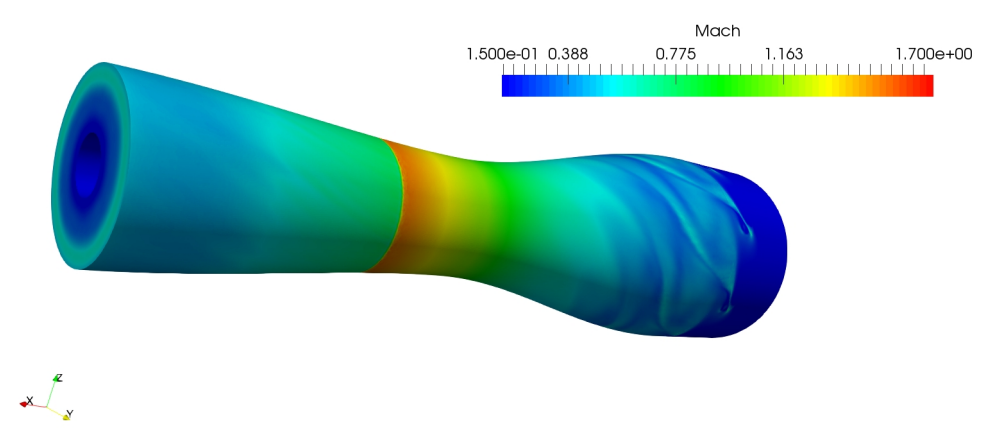

Figure 4.9: The Mach distribution according to the 3D Euler equations in the Supersonic Swirling Separator, showing the well defined shock wave region.

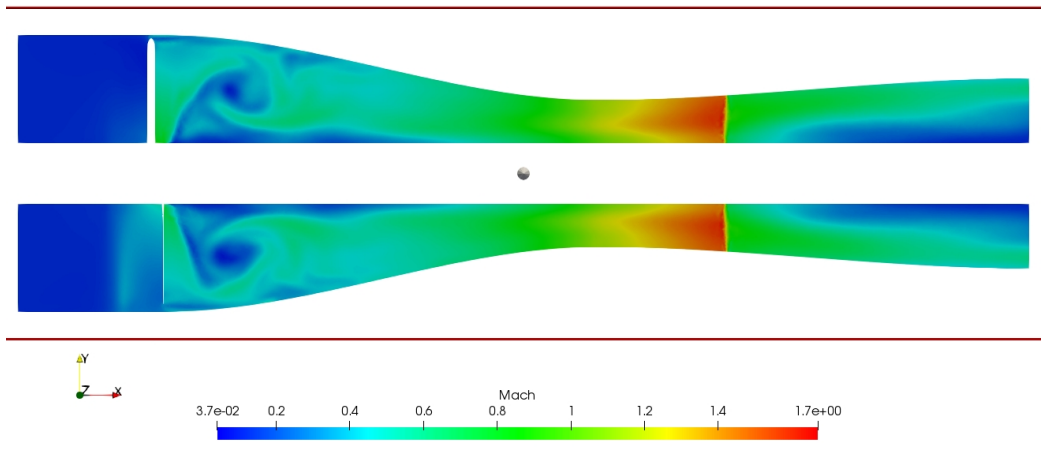

Figure 4.10: A longitudinal section in the Mach distribution in the Supersonic Swirling Separator, using 3D Euler equations. It is important to note that under the swirling mechanism, the shock wave is no longer flat.

the Mach number variation of the flow passing through the vanes and Figure 4.12 allows one to see the vane profile midway to the swirler casing, with a modified Mach scale in the opposite orientation than the one in Figure 4.11, to show more clearly the higher velocities on the vanes upper surfaces (cambers).

The software tool used in this work (SU2) has two standard options for parametrization of the shape: a set of Hicks-Henne bump functions (HICKS; HENNE, 1978), which is the usual choice for 2D geometry or the Free Form Deformation (FFD) functions (SEDERBERG; PARRY, 1986), which can be used for $2 \mathrm{D}$ or $3 \mathrm{D}$ geometries. During the 2D nozzle optimization, the The 2D Class function/Shape function Transformation (CST) parametrization, (KULFAN; BUSSOLETTI, 2006) has been implemented into the SU2 code, to enhance the manipulation of complex geometry, especially for the case of internal flows in the nozzle: The best results have been accomplished using this parametrization technology when compared to the Hicks-Henne one, that is, better accuracy and less compute cycles in some simulations. It was also observed that CST have been 


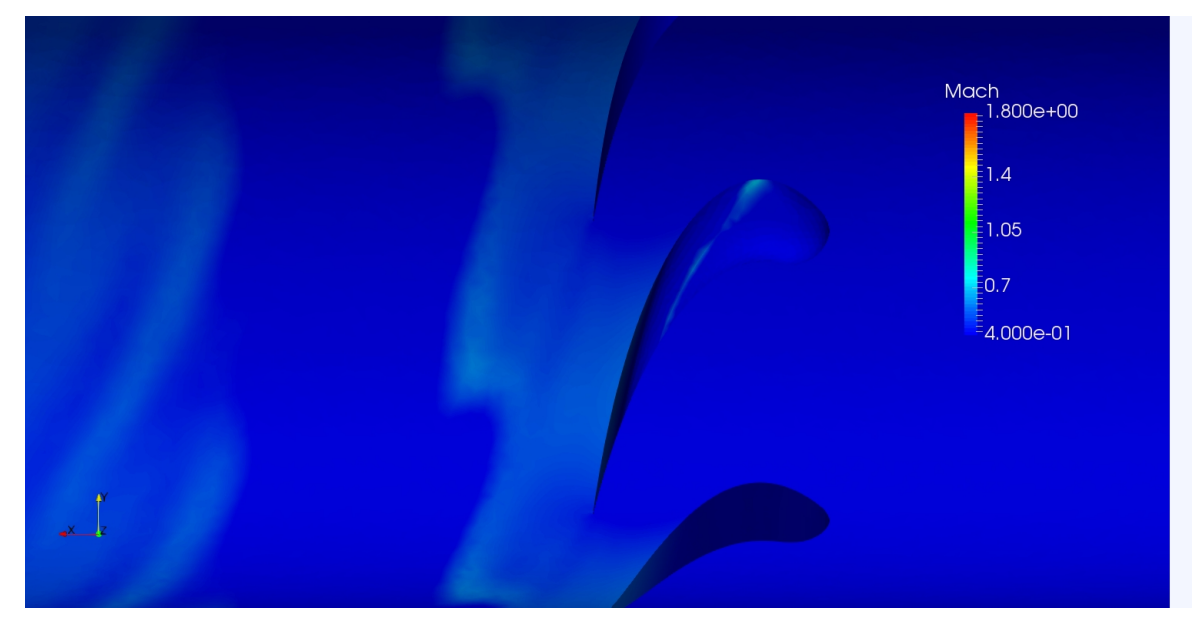

Figure 4.11: A circular section showing the variation in the Mach number passing through the vanes near the separator shaft using 3D Euler equations.

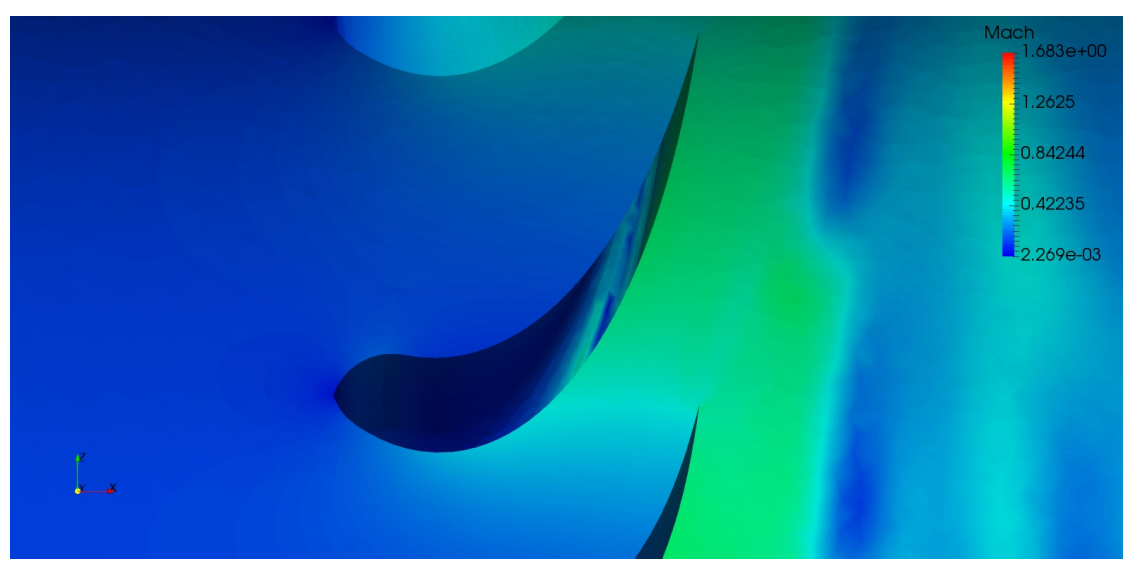

Figure 4.12: Detail of the vane profile at the midway to the swirler casing, showing the Mach number distribution with a modified Mach scale and inverse orientation, to make clearer the higher velocities on the vane upper surface (camber), using 3D Euler equations.

able to produce even somewhat greater delays in the position of shock waves than the delays reached via Hicks-Henne. Owing to tight time schedule, the 3D CST parametrization has not been implemented into the code in this project: instead, for the 3D work in the swirl region or in the full domain coupling swirler and nozzle effects though, the Free Form Deformation (FFD) has been employed. In this method, the supersonic separator fluid domain is immersed in a parallelepiped, which is elastically deformed as a response to the optimization tasks, then also deforming the selected surfaces of the separator.

\subsection{The Swirling Flow}

When the swirler is not present, only the axial and radial components of velocity are encountered in the flow. If one imparts rotation motion to the nonswirling flow, then it will have another velocity component, the tangential (also 


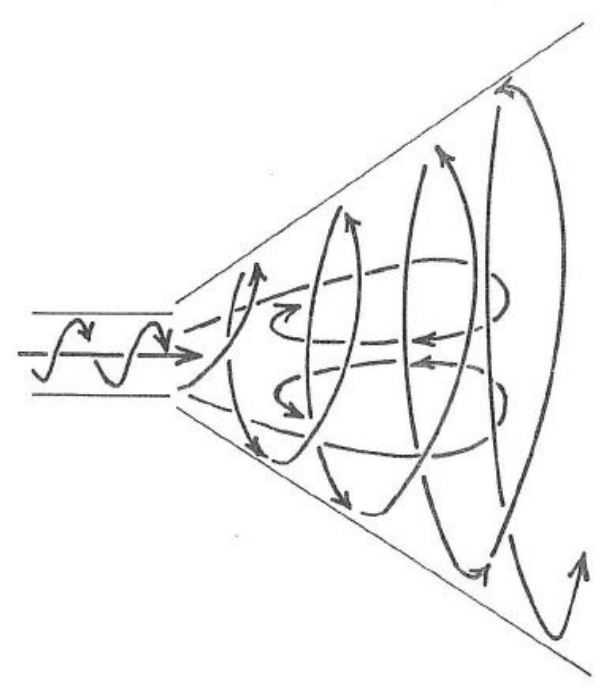

Figure 4.13: Typical jet flow with high degree of swirl (strong swirl $S>0.6$ ) resulting in significant lateral and longitudinal pressure gradients, a much wider, slower jet than its nonswirling countpart and a central toroidal recirculation zone. Figure extracted from (GUPTA; LILLEY; SYRED, 1984).

known as azimuthal or lateral) component (BEÉR; CHIGIER, 1972; GUPTA et al., 1982; GUPTA; LILLEY; SYRED, 1984; WIDMANN; CHARAGUNDLA; PRESSER, 2000). As the result of the new tangential velocity component, the swirling flow will appear, and it will cause axial and radial pressure gradients which, in sequence, will affect the flow field. The swirling flow has been characterized in the literature by the non-dimensional Swirl number, defined in Equation (4.1) (BEÉR; CHIGIER, 1972, 1964a; SYRED; BEÉR, 1974; GUPTA; LILLEY; SYRED, 1984; MADDAHIAN et al., 2011; ZHOU et al., 2013), although it is not the unique criterion (ALEKSEENKO et al., 1999). When the swirl is strong enough, the contrary axial pressure gradient is sufficiently powerful to cause a reverse flow along that axis, and then establishing an internal recirculation zone. Figure 4.13 shows a schematic representation of the recirculation which takes place when the Swirl number $S>0.6$ and Figure 4.10 shows this recirculation zone as it appears in a 3D output. The complexity in this region of the flow is shown in the longitudinal cut of the fluid domain where a vector representation (sometimes called glyph) highlights the magnitudes and directions in the flow of Figure 4.8. The Swirl number $S=0.6$ is so typical, that this value is sometimes said 'critical swirl number' (SYRED; BEÉR, 1974), the margin from which a swirling flow is considered strong: in fact, this value refers to a hubless swirl generator and the 'critical swirl number' is higher for a swirler with a central shaft, as seen in (ZHOU, 2012). In the swirling flow, both axial flux of the tangential (or angular) momentum, $G_{\varphi}$, and the axial flux of the axial momentum (or thrust), $G_{x}$, are conserved: The moment fluxes are balanced out by the forces that act upon the control volume; that is, the axial torque on the 
swirler, as a whole, corresponds to the flux $G_{\varphi}$, since there was no tangential flow upstream of the swirler, and there is, definitely, tangential flow downstream from it. Using the notation of János Beér (BEÉR; CHIGIER, 1972), the non-dimensional number which defines the swirl intensity, the swirl number, $S$, is defined as:

$$
S=\frac{G_{\varphi}}{R_{s o} G_{x}}
$$

where

$$
G_{\varphi}=\int_{0}^{R_{s o}}(W r) \rho U 2 \pi r \mathrm{~d} r
$$

and

$$
G_{x}=\int_{0}^{R_{s o}}(U) \rho U 2 \pi r \mathrm{~d} r
$$

Where

$R_{s o}$ in (4.1) is the Radius of the Swirler Outer wall (annulus), and the variables in the integrands of (4.2) and (4.3), are:

$$
\begin{aligned}
& W=\text { Tangential velocity component } \\
& U=\text { Axial velocity component } \\
& r=\text { Radius } \\
& \rho=\text { Fluid density }
\end{aligned}
$$

In the definition of the Swirl number, the premise is that viscous forces can be neglected. The effect of compressibility is preserved by keeping the density in the integrands, which means that the Swirl number is more compatible with Euler formulation than Navier-Stokes formulation.

In the original work (BEÉR; CHIGIER, 1964b), Chigier and Beér evaluated their experimental findings against incompressible flows: However, an important remark they describe is, according to their own words:

"As the degree of swirl is increased the values of the tangential and radial 

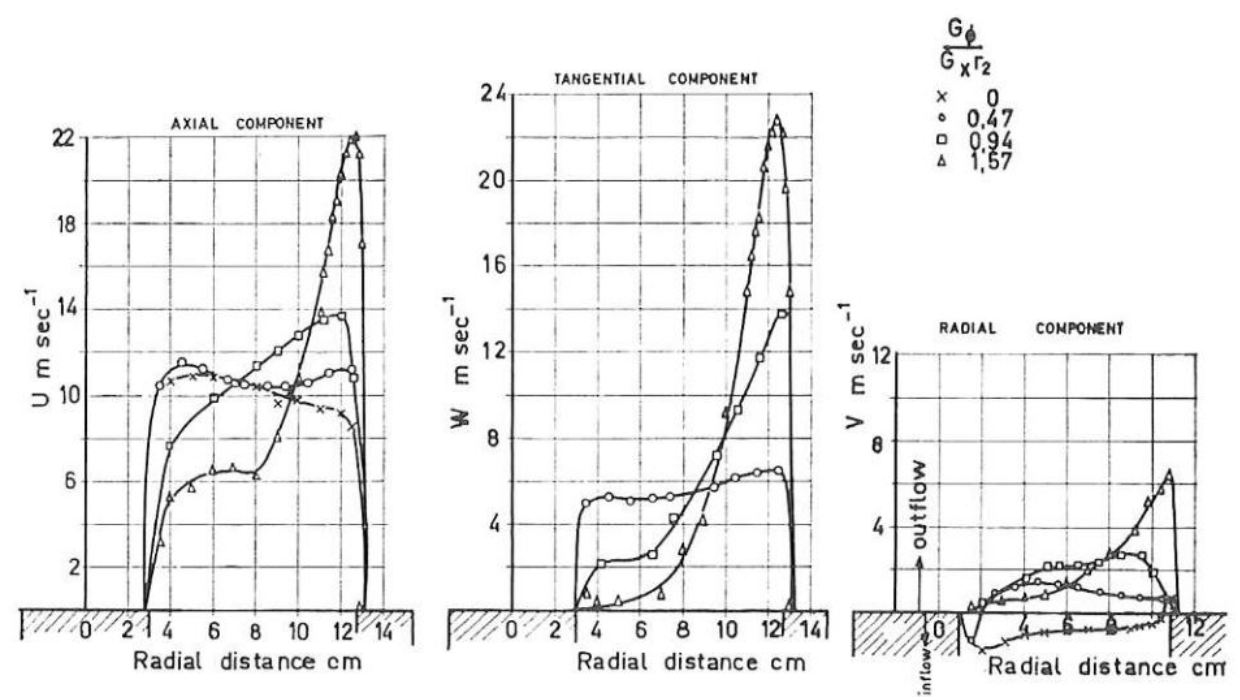

Figure 4.14: Radial distributions of axial, tangential, and radial-velocity components at exit from swirl generator for varying degrees of swirl. Figure extracted from Chigier and Beér (BEÉR; CHIGIER, 1964b)

velocities increase and the flow is forced into an increasingly narrow boundary layer along the outer wall. The progressive distortion of the axial velocity profile from that of a nearly uniform distribution for the case without swirl to that of a highly peaked form with the maximum at the outer wall is shown in..."

... the Figure 4.14 .

Although the article (BEÉR; CHIGIER, 1964b), based on empirical data, refers to an increasingly narrow boundary layer, it is virtually inconspicuous in the Figure 4.14. Also, in the simulations, it is not visually perceptible.

Equations (4.2) and (4.3), are valid for a swirl generator which does not have an central shaft (a hub). When the swirler has a hub, as in the case of the axial one considered here (Figure 1.9), then those equations become:

$$
G_{\varphi}^{a}=\int_{R_{s i}}^{R_{s o}}(W r) \rho U 2 \pi r \mathrm{~d} r
$$

and

$$
G_{x}^{a}=\int_{R_{s i}}^{R_{s o}}(U) \rho U 2 \pi r \mathrm{~d} r
$$


Where $R_{s o}$ and $R_{s i}$ are, respectively, the outer and the inner radii of the swirler annulus.

Another similar definition for the Swirl number is the one proposed in (SHEEN et al., 1996). They claim that their expression has better physical meaning, because $S$ is linearly proportional to the ratio of volumetric mean tangential to axial velocity for various Reynolds numbers tested. They have found that the Swirl number is also dependent on the Reynolds number for radial swirlers with vanes. Their proposed expressions for a swirl generator without a central shaft, are:

$$
G_{\varphi}=\int_{0}^{R_{s o}} U W r^{2} \mathrm{~d} r
$$

and

$$
G_{x}=\int_{0}^{R_{s o}} U^{2} r \mathrm{~d} r
$$

These new values are to be used in the expression (4.1). On doing so, Sheen et alii, keep the old simplification already present in (BEÉR; CHIGIER, 1964b), when the density is constant in some instances. The expressions for a swirler with a central shaft just require a change in the inferior limit of integration : Instead of being 0 , it ought to be changed to $R_{s i}$.

Another Swirl number definition which is simpler than that proposed by Sheen and alii for a hubless swirler, appears in (ZHOU, 2012; ZHOU et al., 2013):

$$
\begin{gathered}
S=\frac{G_{v \varphi}}{G_{v x}} \\
G_{v \varphi}=\int_{0}^{R_{s o}} U W r \mathrm{~d} r
\end{gathered}
$$

and

$$
G_{v x}=\int_{0}^{R_{s o}} U^{2} r \mathrm{~d} r
$$


where

$W=$ Tangential velocity component

$U=$ Axial velocity component

$r=$ Radius

$G_{v \varphi}=$ Momentum of tangential velocity component

$G_{v x}=$ Momentum of axial velocity component

Since it is difficult to measure with much certainty the characterization of the momenta, a number of simplifications has been proposed to estimate the Swirl number: sometimes turbulent stress terms or pressure terms are neglected. Sometimes solid body rotation plug flow is assumed (GUPTA; LILLEY; SYRED, 1984). Besides of these simplifications, it is possible to find lean expressions to the Swirl number which agree very well with empirical data, when certain limits are kept. For example, one such expression is:

$$
S=\frac{G / 2}{1-(G / 2)}
$$

Where

$$
G=\frac{w_{m o}}{u_{m o}}
$$

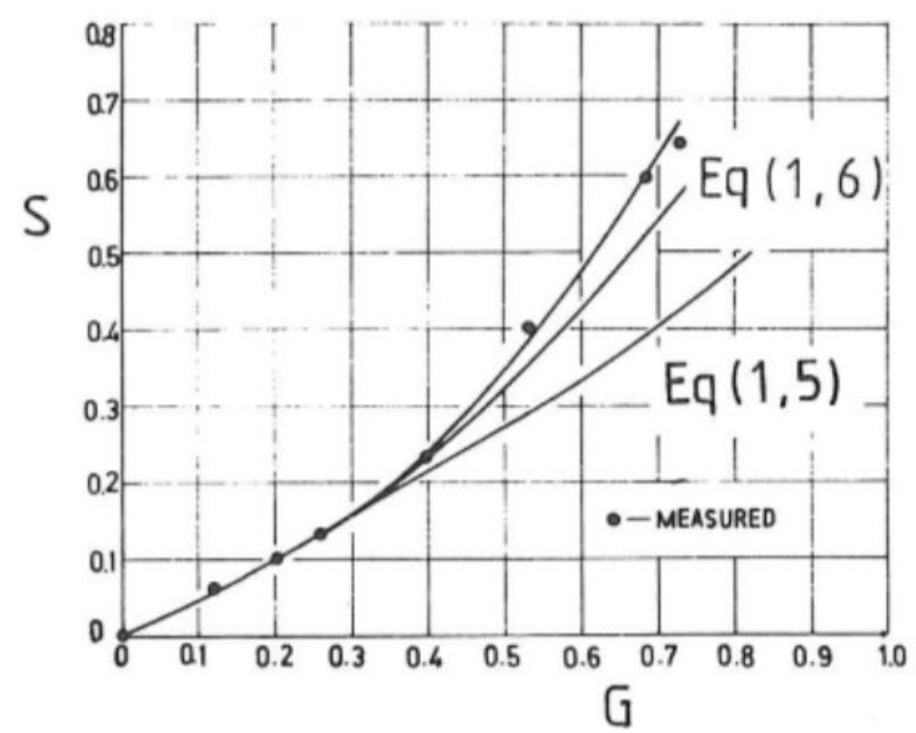

Figure 4.15: The relationship between the Swirl number $S$

and $G=w_{m o} / u_{m o}$, where $w_{m o}$ is the maximum tangential velocity and $u_{m o}$ is the maximum axial velocity measured in the outlet plane. |Figure extracted from (GUPTA; LILLEY; SYRED, 1984). 
With $w_{m o}$ being the maximum tangential velocity measured at the exit plane, and similarly, $u_{m o}$ being the maximum axial velocity measured on the same plane. Expression (4.11) is virtually exact for values of $G$ less than 0.4 . Figure 4.15 shows the relationship between $S$ and $G$ with experimental data. Expression (4.11) is found in (GUPTA; LILLEY; SYRED, 1984) and is very good when the Swirl number is around 0.2 , but for the optimization cases in this project, it can be neglected, since the Swirl numbers can exceed it in one magnitude order.

The pressure gradient owing to the swirling effects, when neglecting the viscous forces, is: (BEÉR; CHIGIER, 1972; GUPTA; LILLEY; SYRED, 1984; SHEEN et al., 1996; ALEKSEENKO et al., 1999):

$$
\frac{\partial p}{\partial r}=\rho \frac{W^{2}}{r}
$$

Where

$$
\begin{aligned}
& W=\text { Tangential velocity component } \\
& p=\text { Pressure } \\
& r=\text { Radius } \\
& \rho=\text { Fluid density }
\end{aligned}
$$

In this work, the Swirl number has been calculated using the definition proposed in (BEÉR; CHIGIER, 1972), because it takes into account the compressibility effects.

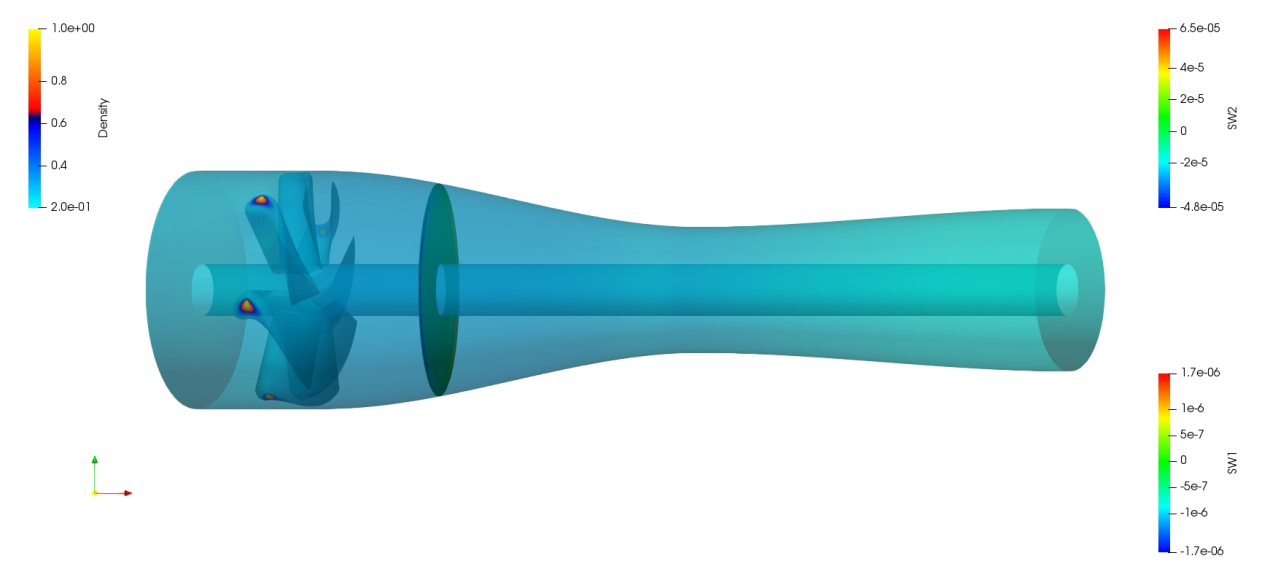

Figure 4.16: Transparent view of the Supersonic Swirling Separator, which scales for density, axial flux of the tangential momentum ( $S W 1)$ and axial flux of the axial momentum $(S W 2)$. The momenta are integrated on the disc region

to allow the calculation of the Swirl number. Output according to the 3D Navier-Stokes. Although three scales are shown (one for density, other for $S W 1$ and another for $S W 2$, only the density scale is active). 
culated when using an optimized geometry for the abscissa $x=0.155$ : According to (ZHOU, 2012), this value represents a typical case of a strong swirl for swirlers with hub $(S>1.67)$. It is well accepted in the literature ((BEÉR; CHIGIER, 1972, 1964b; GUPTA; LILLEY; SYRED, 1984), that for a hubless swirler, it can be considerd that a value $S>0.6$ characterizes a strong swirl. Figure 4.16 shows the interior of the separator and the position where the strong Swirl number is found: The Swirl number is computaded for the disc region, with $R_{s o}=0.0685$.

The swirl intensity can be considered weak $(S<0.2$ (ZHOU, 2012)) in the nozzle throat, what is in visual accordance with Figures 4.3, 4.5, 4.6 and 4.7.

\subsection{The Navier-Stokes approach}

The governing equations for the compressible Navier-Stokes formulation and for the Menter's SST modeling, are given in the Appendix. The software setup is basically the same used for the 3D Euler simulation, with the following differences:

- Formulation : 3D Navier-Stokes.

- GRID : 3D Tetrahedral, pyramid and prism elements in an unstructured mesh. Grids are finer than those employed in the Euler simulations. The input grid has 12465980 elements: that input mesh has produced faster convergence in an HPC environment. When running in parallel (which is true for this project phase), SU2 can use ParMETIS (PARMETIS, 2020) to redefine elements internally, so the actual mesh in general is larger than the input grid and the geometry of the elements can vary.

- Turbulence model : two-equations Menter's Shear Stress Transport (SST), which is described in (MENTER, 1994). In the literature, some authors advise against the use of this model in swirling flows (MADDAHIAN et al., 2011) suggesting alternative models, such as the Large Eddy Simulation (LES). Other authors propose some modifications (ALAHMADI; NOWAKOWSKI, 2016) on it, in order to use it with swirling flows.

- Specific Menter SST Boundary COnditions : $\kappa$ at inflow is $0.05 ; \kappa$ at wall is zero; $\omega$ at inflow is 10 ; $\omega$ at wall is calculated according to the expression (4.14), below, which is the recommendation in (MENTER, 1994). The equation seeks to simulate the wall boundary condition of a perfectly smooth surface, without mass injection, as given in (WILCOX, 1988) : 


$$
\omega_{\text {wall }}=10 \frac{6 \nu}{\beta_{1}\left(\Delta d_{1}\right)^{2}}
$$

where,

$\nu$ is the kinematic viscosity,

$\beta_{1}$ is one of the closure coefficients, $\beta_{1}=3 / 40$ : Wilcox (2006) revised this number to 0.0708 for compressible flows

and

$\Delta d_{1}$ is the distance to the next point from the wall.

- Additional Boundary COnditions : Adiabatic walls; no slip; impenetrability.

- Viscosity model : The viscosity model is the Sutherland one with three coefficients, as shown in (4.15):

$$
\mu_{\text {Sutherland }}=\mu_{0} \frac{T_{0}+S}{T+S}\left(\frac{T}{T_{0}}\right)^{3 / 2}
$$

where

$\mu_{0}=1.036 E-5$ is the reference Sutherland viscosity,

$T_{0}=273.15$ is the reference temperature,

$T$ is the static temperature

and

$S=215.0$ is the Sutherland constant.

- Thermal Conductivity model : The thermal conductivity model is based on constant Pradtl number, and is expressed by (4.16):

$$
k=\mu \frac{C_{p}}{\operatorname{Pr}}
$$

with laminar Prandtl number $\operatorname{Pr}=0.731$ and turbulent Prandtl number $P r_{t}=0.914$; and $C_{p}$ is the specific heat at constant pressure.

To work with this finer mesh and Navier-Stokes with parametric optimization, considering more than one measure of merit (typically using inverse design pressure and moment-x, in the SU2 non-combined mode), the use of HPC facilities has been instrumental. 


\subsection{The Supersonic Swirling Separator Optimiza- tion}

The first optimization phase has been the subject of the chapter 3 . In the second phase, owing to the complexity imposed to the flow by the swirler, it required a 3D treatment, but still using Euler equations. Although inviscid, the flow simulation with Euler equations sometimes presented convergence difficulties, which has been solved with refined grids, and fine tuning of numerical parameters. In the third phase, viscous flow has been simulated with Navier-Stokes: very few problems with convergence showed up, which meant that it required less fine tuning of parameters. However, Navier-Stokes equations present additional time complexity, and then poweful cores, interconnection and parallelism are yet more important for this sort of solvers.

The approach used in the parametric optimization has been the combination of the Adjoint method in the evaluation of gradients, with the steepest descent method for optimization. During this phase, although the code SU2 offers two Adjoint formulations: the Continuous one and the Discrete one; almost exclusively the continuous formulation has been employed, since it uses less memory, and this fact has helped to workaround some constraints with the available hardware, especially when working in $3 \mathrm{D}$ problems.

The optimization libraries are the open Python ones, provided in SciPy and NumPy packages, which are coupled to the SU2 software. The optimization process is the same used in the $2 \mathrm{D}$ problems and which is shown in the Figure 1.10 .

Figures 4.17 and 4.18 represent the equivalent stagnation values using NavierStokes equations, and comprehend a sanity check of the solution, in the exact way those values have been used in the two first phases of this project. Figure 4.19 shows the stagnation pressure expected gradual drop in the boundary layer, at the nozzle outlet.

SU2 provides a variety of measures of merit within its standard libraries, which can be used during the optimization process, among them:

- DRAG : Drag force.

- LIFT : Lift force.

- MOMEnT-X, MOMEnT-Y, MOMEnT-Z : Cartesian Moment components. 


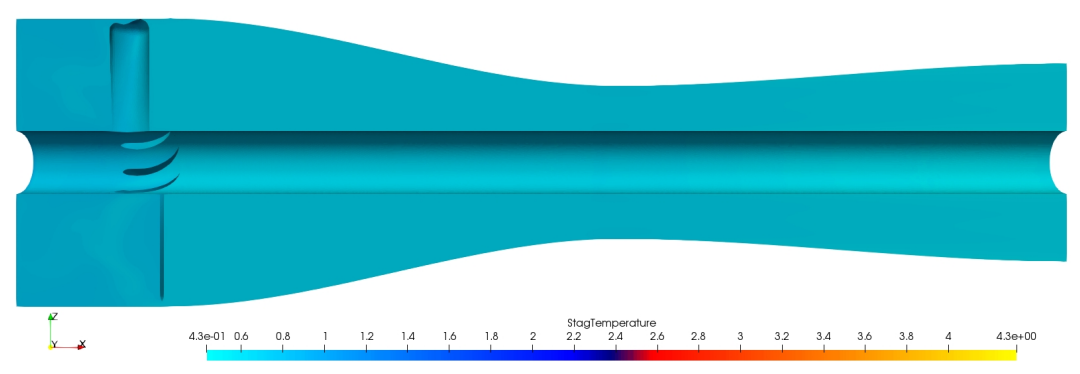

Figure 4.17: The stagnation temperature distribution in the Supersonic Swirling Separator, using 3D Navier-Stokes equations. It can be noticed that nuance is virtually uniform.

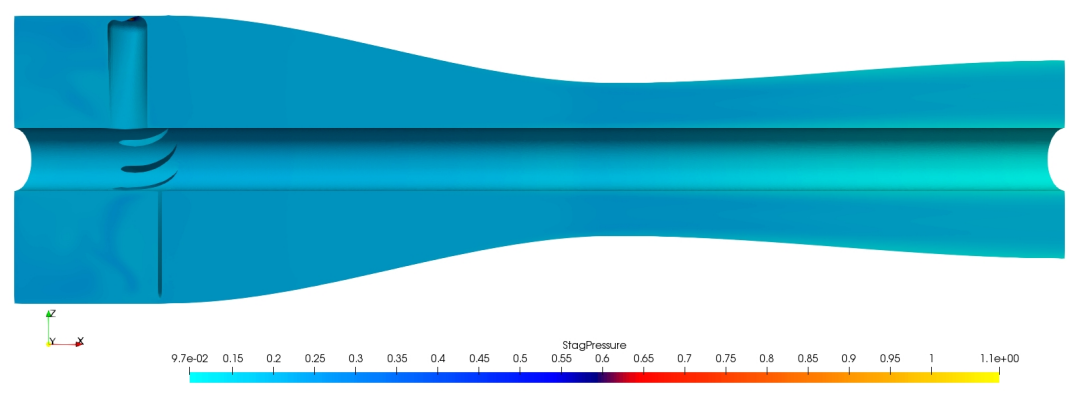

Figure 4.18: Longitudinal cut showing the stagnation pressure distribution in the Supersonic Swirling Separator, using 3D Navier-Stokes equations. In this simulation a shock wave form beyond the nozzle outlet, whence the hue change is relatively small.

- INVERSE-DESIGN-PRESSURE, INVERSE-DESIGN-HEATFLUX : Inverse design respectively based on Pressure or Heat flux.

- FORCE-X, FORCE-Y, FORCE-Z : Cartesian Force components.

In this work, Drag force, Lift force (only meaninful for one vane), Moments and Inverse design based on pressure have been used both individually or combined at least once.

The MOMENT-X, that is the moment along the nozzle axis, the torque that acts upon the swirler is very important, since it corresponds to the amount of swirl that the device imparts to the flow is profoundly tied to the swirling flow, since the larger the swirl intensity, the larger the moment in the axial (Cartesian $\mathrm{x}$ axis) direction is: Therefore, the focus has been kept on MOMENT-X, althought optimization based on INVERSE-DESIGN-PRESSURE or with combination of these two measures of merit, using 3D Navier-Stokes equations have been also studied. The goal has been to improve the vanes geometry in order to enhance 


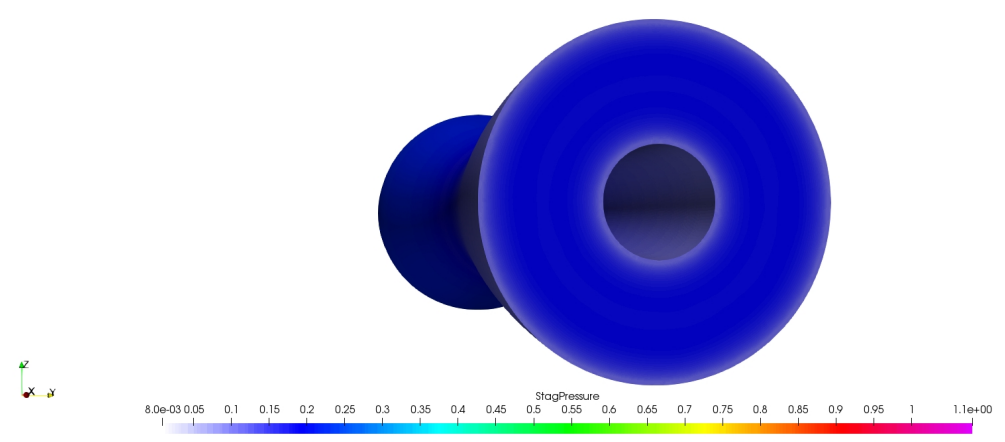

Figure 4.19: The stagnation pressure distribution in the nozzle outlet of the

Supersonic Swirling Separator, using 3D Navier-Stokes equations, shows a gradual drop in the boundary layer, which corresponds to an increasing entropy, as expected.

the MOMENT-X as a whole (that is, including the effect of all of the seven vanes). As expected, the influense of both MOMENT-Y and MOMENT-Z is small and can be neglected when compared to MOMENT-X: In fact, owing to axial symmetry, the resulting moment should be aligned with the device axis, thus lacking components along the $\mathrm{y}$ and $\mathrm{z}$ directions. Naturally, a quite different a scenario would emerge on considering a single vane, but this is not the focus of our analysis.

The sole use of the INVERSE-DESIGN-PRESSURE function with 3D Euler equations, has produced similar results to those obtained in the 2D Euler case, described in chapter 3 and are shown in Figures 4.20 and 4.21, using the coarse mesh of Figure 4.4 .

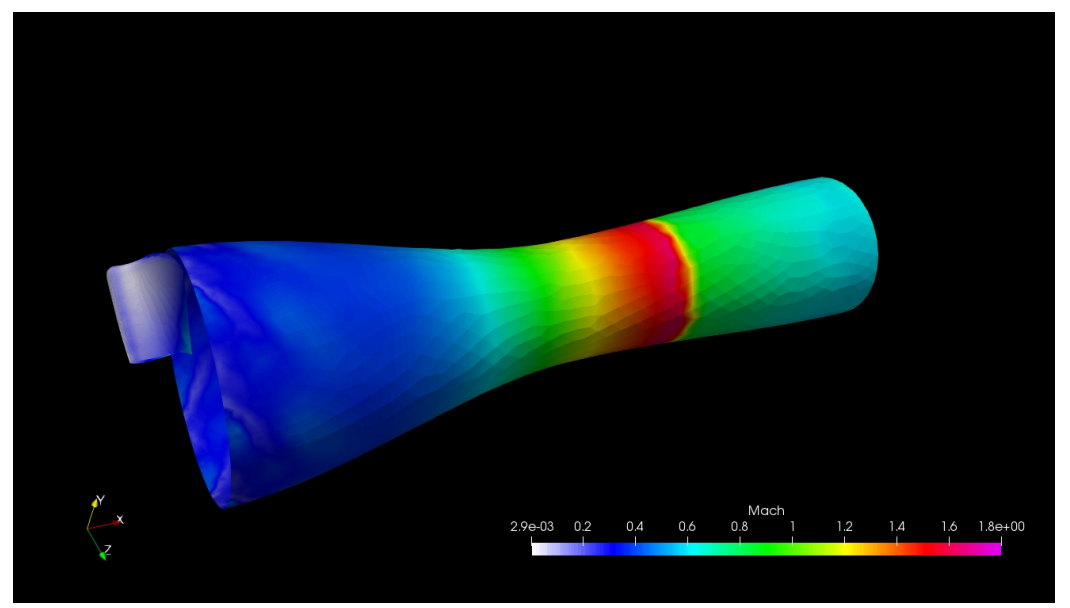

Figure 4.20: Original surface with Mach distribution on the fluid domain, showing one vane and nozzle on a coarse mesh. Output according to the 3D Euler equations.

The effect of the optimization on the swirler vanes, considering the inverse design pressure, are shown in the details presented in Figures 4.22, 4.23 and 4.24, 


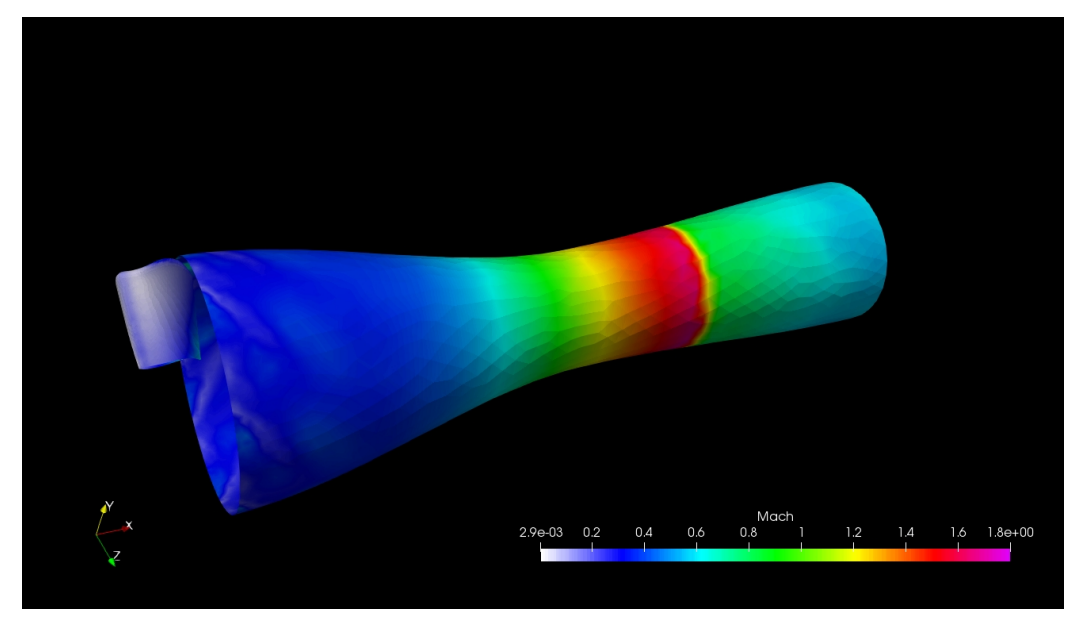

Figure 4.21: Optimized surface with Mach distribution on the fluid domain on a coarse mesh, using the inverse design pressure, showing one vane and nozzle.

Output according to the 3D Euler equations.

with increasing magnification, where the original geometry is represented in solid green color and the optimized geometry is represented with points. It is possible to notice the nearly stretched dimension in the Cartesian directions Y and Z. The constraint is to keep the original axial $(\mathrm{X})$ direction, thus preserving the same footprint of the separator, but, at the same time, increasing the space and time for the change phase processes at lower temperatures than the original ones, take place.

The pressure distribution according to the Navier-Stokes solution on a vane can be observed on Figure 4.25, and the corresponding non-dimensional temperature profile can be seen on Figure 4.26. The respective same parameters output after the optimization whose measure of merit is the MOMENT-X, are shown in Figures 4.27 and 4.28. It can be noticed that the static pressure on the vane lower surface after the optimization process is higher than that of the original geometry and the non-dimensional temperature is lower on the upper vane surface: Even before entering the nozzle inlet, the optimized geometry causes a slight drop in temperature.

The Swirl number $S$, has been calculated at the same axial position $\left(x_{s o}=\right.$ 0.155), since the imposed constraint has been that one of no deformation along the axial direction, as shown in Figure 4.16, using the same definition as given by Equations (4.1), (4.2) and (4.3). It has been obtained for several samples of optimization cycles. Although it is difficult to see the deformations which take place in the optimization cycles, one can realize that a small variation on the vanes geometry produces significant variations on the swirl number. It also confirms the efficacy of choosing MOMENT-X as the measure of merit: the results present 
higher Swirl numbers, higher momentum in the axial direction (Figures 4.29 and 4.30) and larger areas on the lower surface of the vanes loaded with high pressures (Figures 4.25 and 4.27), and the corresponding lower non-dimensional temperatures (Figures 4.26 and 4.28).

Table 4.1 shows the Swirl number per cycle $\left(S=G_{\varphi} /\left(R_{s o} G_{x}\right)\right)$, of selected samples of a typical optimization job, using MOMENT-X as the measure of merit: Cycle 1 represents the original geometry. The table also shows the current values of the outer annulus radius, $R_{\text {so }}$; the axial flux of the tangential (or angular) momentum, $G_{\varphi}$; and the axial flux of the axial momentum (or thrust), $G_{x}$.

Table 4.1: Swirl numbers per optimization cycle, calculated for abscissa $x=0.155$. Cycle 1 represents the original geometry. Cycle 32 is the last realizable cycle.

\begin{tabular}{|l|l|l|l|l|}
\hline \multicolumn{5}{|c|}{ Swirl number per cycle } \\
\hline Cycle & Swirl number $(S)$ & $R_{\text {so }}$ & $G_{\varphi}$ & $G_{x}$ \\
\hline 1 & 0.397694 & 0.129157 & $2.743998 \mathrm{E}-11$ & $5.342155 \mathrm{E}-10$ \\
31 & 1.080520 & 0.129157 & $1.338033 \mathrm{E}-10$ & $9.587732 \mathrm{E}-10$ \\
32 & 2.998887 & 0.129158 & $1.575179 \mathrm{E}-10$ & $4.066760 \mathrm{E}-10$ \\
\hline
\end{tabular}

While it is true that the optimization using MOMENT-X as a measure of merit obtains significant better Swirl numbers, its influence in delaying the shock wave is small and only perceived numerically under Euler equations. The simulation using Navier-Stokes equations has not formed a shock wave, but showed lower temperatures after the nozzle throat: while before the shock wave, the temperature reaches -68 Celsius degrees, with Euler equations; by using Navier-Stokes formulation, the temperature drops to -97 Celsius degrees (Figure 4.31) at about the middle of the nozzle divergent portion. However, simulations using the inverse design pressure, combined or not, with the MOMENT-X measure of merit, have been effective in delaying the oblique shock wave with Euler equations. 


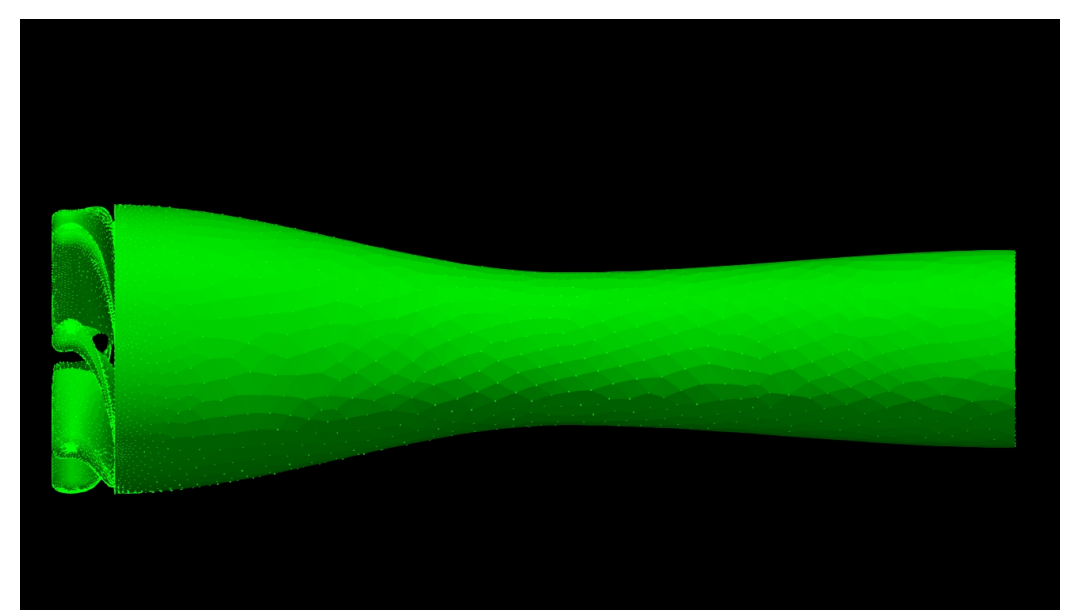

Figure 4.22: Original geometry (solid green color) and optimized geometry (points) on the fluid domain, showing the vanes and nozzle on a coarse mesh, using the inverse design pressure as a measure of merit. Output according to the 3D Euler equations.

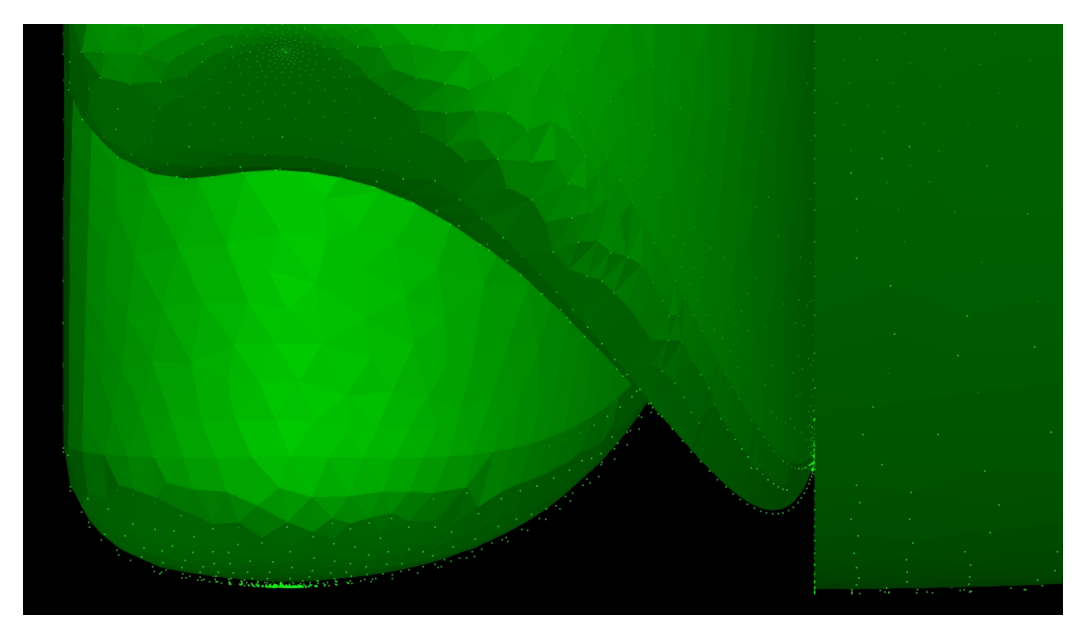

Figure 4.23: Detail of the vanes portion and the nozzle inlet extremity: One can realize that the optimized vanes are slightly radially outstretched. Output according to the 3D Euler equations.

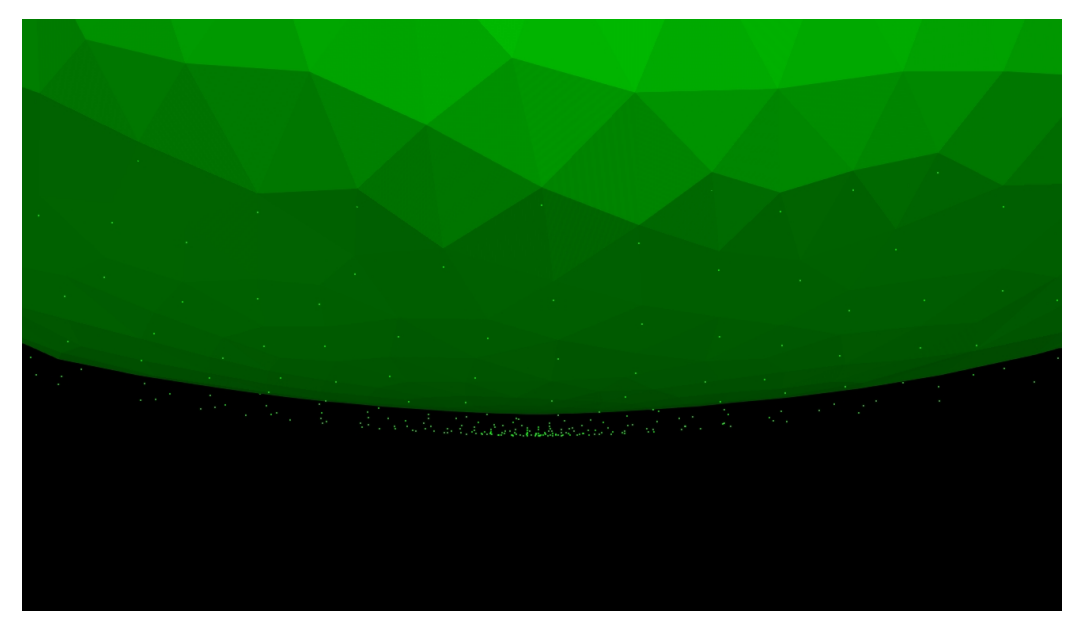

Figure 4.24: Original geometry (solid green color) and optimized geometry (points) on the fluid domain, showing the magnified portion of a vane, using the inverse design pressure as a measure of merit. Output according to the 3D Euler equations. 


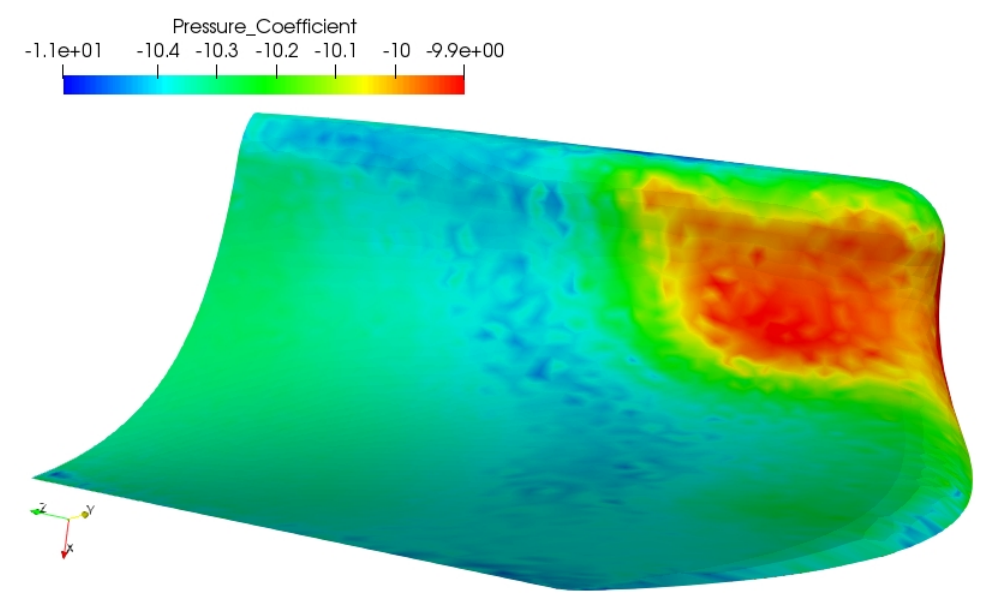

Figure 4.25: Original pressure coefficient distribution on a vane using a fine mesh. Output according to the 3D Navier-Stokes equations.

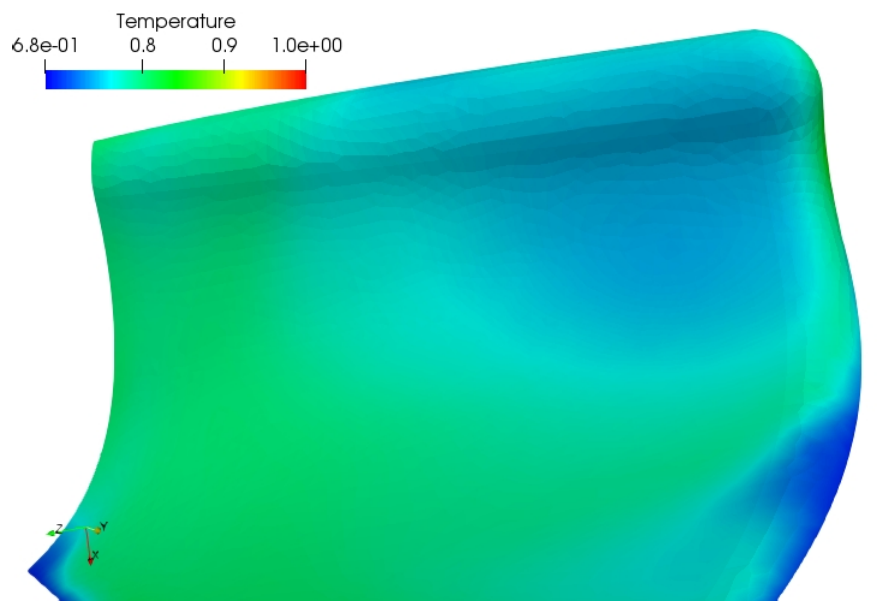

Figure 4.26: Original non-dimensional temperature distribution on a vane using a fine mesh. Output according to the 3D Navier-Stokes equations.

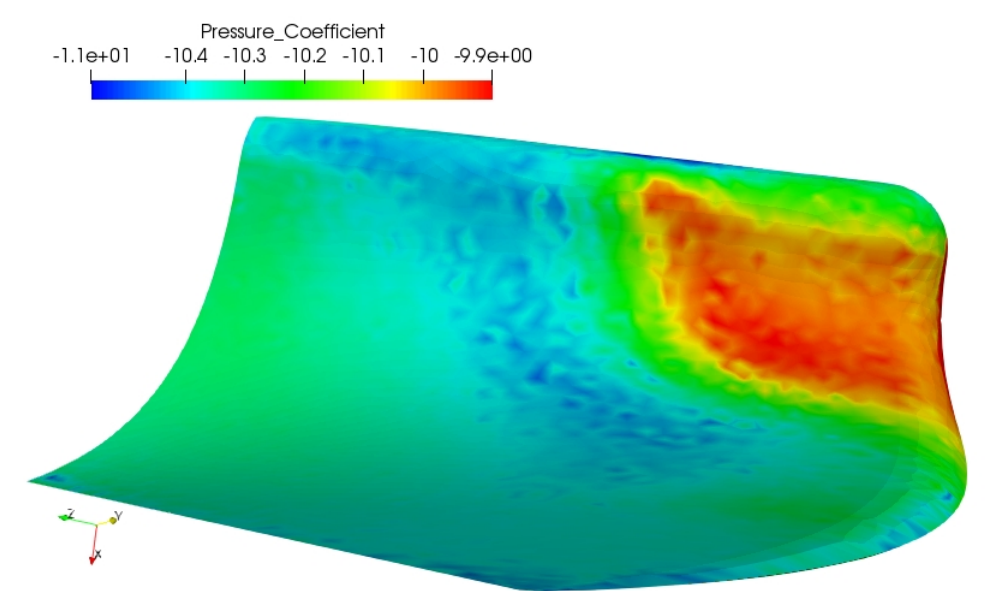

Figure 4.27: Optimized pressure coefficient distribution on a vane using a fine mesh, with MOMENT-X as a measure of merit. Output according to the 3D Navier-Stokes equations. 


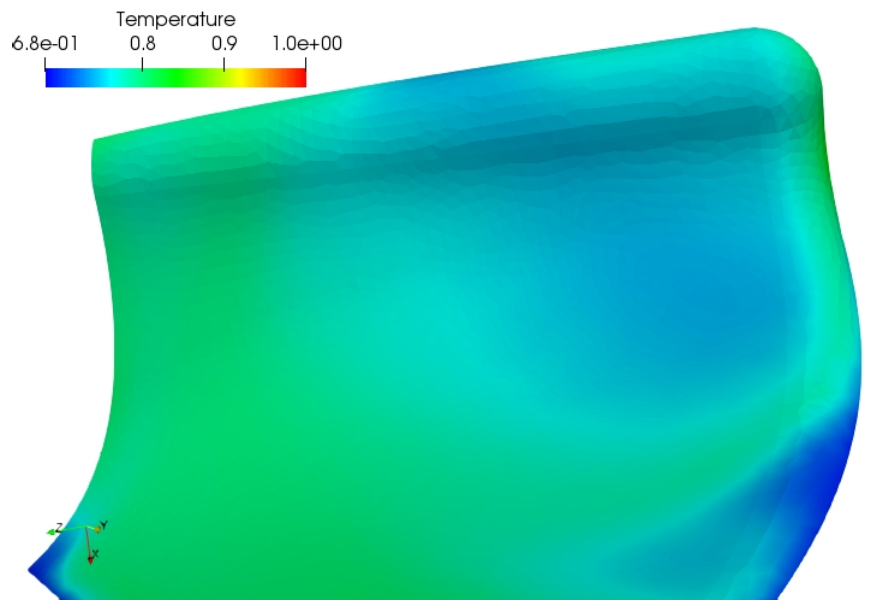

Figure 4.28: Optimized non-dimensional temperature distribution on a vane using a fine mesh, with MOMENT-X as a measure of merit. Output according to the 3D Navier-Stokes equations.

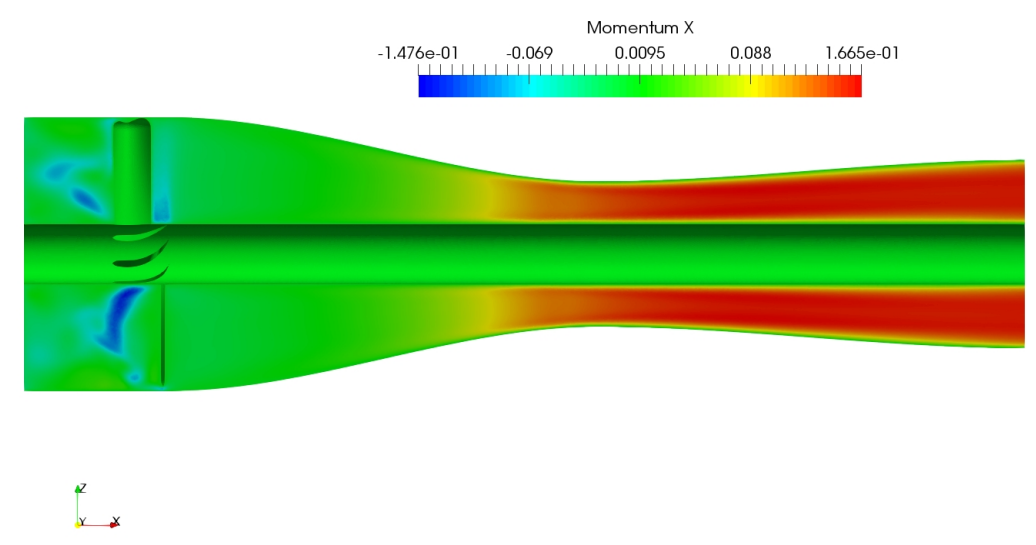

Figure 4.29: Cut showing the Momentum in the axial direction obtained in the Cycle 31 with a fine mesh, using MOMENT-X as a measure of merit. Output according to the 3D Navier-Stokes equations.

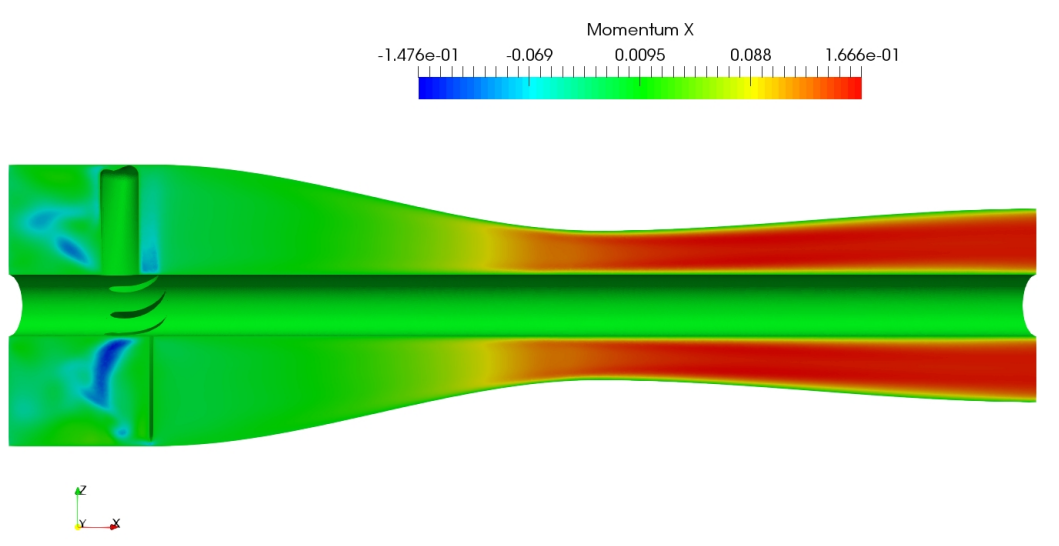

Figure 4.30: Cut showing the Momentum in the axial direction obtained in the Cycle 32 with a fine mesh, using MOMENT-X as a measure of merit. Output according to the 3D Navier-Stokes equations. 


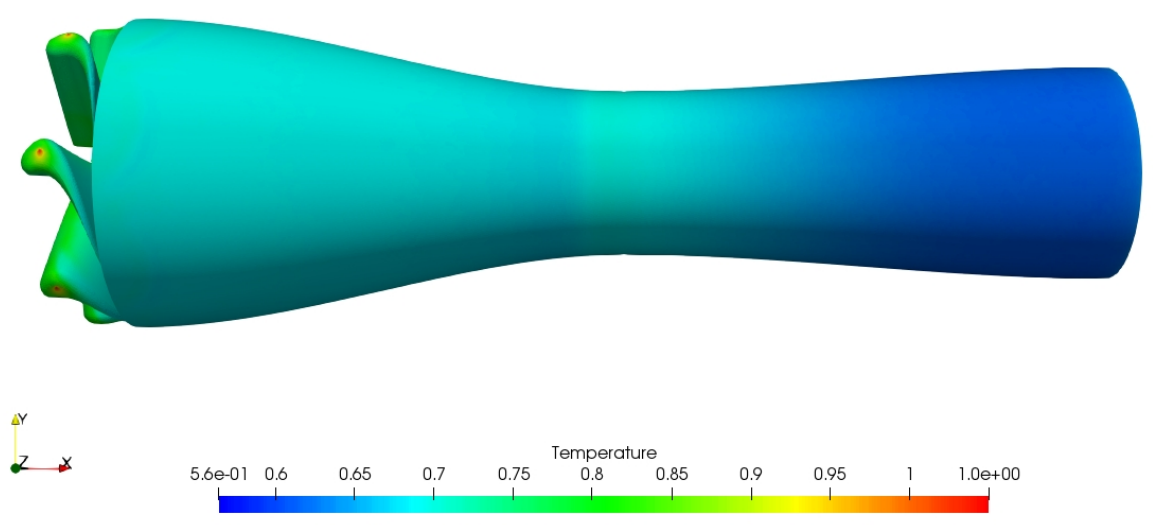

Figure 4.31: Non-dimensional temperature distribution on nozzle and vanes surfaces with a fine mesh, using MOMENT-X as a measure of merit. Output according to the 3D Navier-Stokes equations. 


\section{FINAL CONSIDERATIONS}

In this work, a Supersonic Swirling Separator has been analyzed and optimized using the open source code SU2. The activities have included 2D and 3D simulations using both, Euler and Navier-Stokes equations. The two main components of the separator have been entirely considered in all of the simulations, that is, the swirler and the nozzle. The initial nozzle profile has been based on the Arina's nozzle and the swirler vanes have been created in this project with no constraints in complexity, thus favouring the solution in the real world.

Two of the measures of merit available in the SU2 standard libraries, have been evaluated, the Inverse Design Pressure (INVERSE-DESIGN-PRESSURE) and the Moment in the axial direction (MOMENT-X). Inverse design pressure has been successfully employed during the $2 \mathrm{D}$ nozzle optimization to delay the shock wave (together CST parametrization), and MOMENT-X has been confirmed as a good choice to increase the Swirl number (during the 3D simulations with both Euler and Navier-Stokes equations): in increasing that moment, a corresponding increased boost in the swirl intensity is obtained. This matches two purposes: Firstly, it provides more room and lower temperatures to the change phase processes, thus enhancing the separator performance and keeping the shape deformation to a minimum, which brings as a bonus, that the separator's footprint is also conserved at the same time. Secondly, the increase in the swirl intensity, also implies in a increased amount of droplets of condensed material which are radially bounced to the separator walls, facilitating their collection. The results have met the expectations based on theoretical grounds.

Several interisting findings have come up: While it is true that the optimization using MOMENT-X as a measure of merit obtains significant better Swirl numbers, its influence in delaying the shock wave is small and only perceived numerically under Euler equations, but higher Swirl numbers also showed lower temperatures after the swirl generator, so, with a swirler, the fluid goes into the convergent portion of the nozzle, with a lower temperature, if compared with a separator without it. The simulation using Navier-Stokes equations has not 
formed a shock wave within the divergent part of the nozzle, but showed the lower temperatures after the throat. However, simulations using the inverse design pressure, combined or not with the MOMENT-X measure of merit, have been effective in delaying the shock wave with Euler equations. When a static swirl generator is not present, the simulation with Euler equations show a flat shock wave, but when the swirler is included, it is possible to observe that the shock wave profile becomes somewhat oblique. Also, it has been noticed that slight geometric modifications in the vane profiles, produce significant variation in the swirl intensity.

One of the ways to measure the performance of the optimized separator can be by looking at the lower temperatures in the nozzle divergent portion, Another approach could be running the flow solver equipped with a condensation library, to estimate the fraction of $\mathrm{CO}_{2}$ which can be subtracted from the mixture mass flow rate in the optimized separator versus the original separator.

The SU2 code has kept up with the load and complexity of the problem, and being an open source software, it has allowed the implementation, in this project of the 2D CST parametrization, which produced better results than those using Hicks-Henne parametrization, during the optimization of the nozzle. Another advantage of being open source, consists in the possibility of implementation of other (more) powerful turbulence models, in the code. The software has scaled well, from small computers to the high performance computation (HPC): in the flow simulations with the complete separator (nozzle and swirler), grids with more than twelve million elements have been successfully employed.

CST parametrization has been implemented in this project for 2D geometries, with good results: A further extension of it could include the 3D CST variant (KULFAN, 2007) into the SU2 code.

In this project, the fluid behavior has been treated as an ideal gas. For future developments, one can consider the use of other equations of state (some of them are available in SU2). The turbulence model used in this work has been the two-equations Menter's Shear Stress Transport (SST), also available in the SU2 standard libraries. In the literature, some authors advise against the use of twoequations SST in swirling flows (MADDAHIAN et al., 2011), and others propose some modifications (ALAHMADI; NOWAKOWSKI, 2016) on the SST model, to use it in this class of flow. The inclusion of similar (or others, such as LES) capabilities in the software would improve the results found in this work, and it is another interesting future challenge. 
The optimization of the supersonic separator that has been undertaken in this project is the geometric optimization. However, in the NDF2 laboratory, several works (VOLPE; SANTOS, 2009; HAYASHI; CEZE; VOLPE, 2013; HAYASHI et al., 2016; HAYASHI, 2016; HAYASHI; CEZE; VOLPE, 2017) have been produced in the aim of exploring non-geometric optimization, such as aerodynamic operating conditions, which can be further incorporated into the SU2 code libraries, thus allowing the possibility of exploring inflow and outflow boundary conditions, or at least, to point directions to explore them in the realm of supersonic swirling separators or in subsequent projects. 


\section{REFERENCES}

ALAHMADI, Y. H.; NOWAKOWSKI, A. F. Modified shear stress transport model with curvature correction for the prediction of swirling flow in a cyclone separator. Chemical Engineering Science, v. 147, p. 150-165, 2016.

ALEKSEENKO, S. V.; KUIBIN, P. A.; OKULOV, V. L.; SHTORK, S. I. Helical vortices in swirl flow. Journal of Fluid Mechanics, v. 382, p. 195-243, 1999.

ALMEIDA, K.; VILELA, P. e. a. Ocorrência de $\mathrm{CO}_{2}$ em campos petrolíferos na margem leste brasileira. 2018. Empresa de Pesquisa Energética - report.

ARINA, R. Numerical simulation of near critical fluids. Applied Numerical Mathematics, v. 51, p. 409-426, 2004.

AXELSSON, O.; KOLOTILINA, L. Preconditionated Conjugate Gradient Methods. In: Proceedings of a Conference held at Nijmegen, June 19-21. Berlin: Springer-Verlag, 1989.

BEÉR, J. M.; CHIGIER, N. A. The Flow Region Near the Nozzle in Double Concentric Jets. Journal of Basic Engineering, p. 797-804, 1964.

BEÉR, J. M.; CHIGIER, N. A. Velocity and Static-Pressure Distributions in Swirling Air Jets Issuing From Annular and Divergent Nozzles. Journal of Basic Engineering, p. 788-796, 1964.

BEÉR, J. M.; CHIGIER, N. A. Combustion Aerodynamics. New York: Halsted - John Wiley and Sons, INC, 1972.

BETTING, M.; EPSOM, H. Supersonic separator gains market acceptance. World Oil, p. 197 to 200, 42007.

BREZIS, H. Functional Analysis, Sobolev Spaces and Partial Differencial Equations. New York: Springer, 2010.

CACUCI, D. G. Sensitivity theory for nonlinear systems: I. nonlinear functional analysis approach. J. Math. Phys., Vol. 22 p. 2794 to 2802, 1981.

CACUCI, D. G. Sensitivity theory for nonlinear systems: Ii. extensions to additional classes of responses. J. Math. Phys., Vol. 22 p. 2803 to 2812, 1981.

CACUCI, D. G. Global optimization and sensitivity analysis. Nuclear Science and Engineering V. 104 p. 78 to 88, 1990.

CACUCI, D. G. Sensistivity and Uncertainty Analysis: Theory, Vol. 1. Boca Raton: Chapman \& Hall/CRC, 2003.

CACUCI, D. G. Second-order adjoint sensitivity analysis methodology (2nd-asam) for computing exactly and efficiently first and second-order sensitivities in large-scale linear systems: I. computational methodology. Journal of Computational Physics, Vol. 284 p. 687 to 699, 2015. 
CACUCI, D. G. Second-order adjoint sensitivity analysis methodology (2nd-asam) for large-scale nonlinear systems: I. theory. Nuclear Science and Engineering, Vol. 184 p. 16 to 30, 2016.

CACUCI, D. G.; IONESCU-BUJOR, M. Global optimization and sensitivity analysis. Nuclear Science and Engineering V. 136 p. 59 to 84, 1990.

CACUCI, D. G.; IONESCU-BUJOR, M. Deterministic local sensitivity analysis of augmented systems: I. theory. Nuclear Science and Engineering V. 151 p. 55 to $66,2005$.

CACUCI, D. G.; IONESCU-BUJOR, M.; NAVON, M. I. Sensistivity and Uncertainty Analysis: Sensitivity and Uncertainty Analysis: Applications to Large Scale Systems Theory, Vol. 2. Boca Raton: Chapman \& Hall/CRC, 2005.

CACUCI, D. G.; WACHOLDER, E. Adjoint sensitivity analysis for transient two-phase flow. Nuclear Science and Engineering V. 104 p. 461 to 468, 1982.

CACUCI, D. G.; WEBER; F., C.; M., O. E.; MARABLE, J. H. Sensitivity theory for general systems of non-linear equations. Nuclear Science and Engineering, v. 75, p. 88-110, 1980.

CARVALHO, L. S.; NEVES, S. e. a. Estudo da tecnologia de separação de $\mathrm{CO}_{2}$ de gases industriais por absorção com monoetanolamina-MEA. In: 4PDPETRO_6_3_0417-1. [S.1.]: 4 PDPETRO, Campinas, SP, 2007.

CEZE, M. A. B. Projeto Inverso Aerodinâmico Utilizando o Método Adjunto Aplicado às Equações de Euler. Thesis (Master) — University of São Paulo, 2008.

DACOROGNA, B. Introduction to the Calculus of Variations. London: Imperial College Press, 2004.

ENGO3S. 2016. http://www.engo3s.com/3s-technology. Accessed: $05 / 07 / 2017$.

EPAREPORT. 2017. www . epa.gov/globalwarming/publications/emissions. Accessed: 18/05/2018.

FIDKOWSKI, K. J.; DARMOFAL, D. L. Review of output based error estimation and mesh adaptation in computational fluid dynamics. AIAA Journal, Vol. 49, No. 4 p. 673 to 694, 2011.

FITZGIBBON, W.; KUZNETSOV, Y.; PEKKA, N.; PIRONNEAU, O. Modeling, Simulation, and Optimization for Science and Technology Computational Methods in Applied Sciences, Vol. 34. [S.l.]: Springer, 2014.

FORSYTH, J.; LODGE, S.; CONSONNI, S.; BONA, D.; GATTI, M.; MARTELLI, E.; SCACCABAROZZI, R.; VIGANO, F. Evaluation of five alternative $\mathrm{CO}_{2}$ capture technologies with insights to inform further development. Energy Procedia, Elsevier, v. 114, p. 2599-2610, 2017.

GELFAND, I.; FOMIN, S. Calculus of Variations. Englewood Cliffs: Prentice-Hall, 1963. Translated and Edited by R. A. Silverman. 
GILES, M.; PIERCE, N. On the properties of solutions of the adjoint Euler equations. In: Numerical Methods for Fluid Dynamics VI. ICFD. [S.l.: s.n.], 1998.

GILES, M.; PIERCE, N. An introduction to the adjoint approach to design. Flow, Turbulence and Control, v. 65, p. 393-415, 2000.

GILES, M. B.; PIERCE, N. A. Adjoint equations in cfd: duality, boundary conditions and solution behaviour. In: AIAA Paper 97-1850. [S.l.: s.n.], 1997.

GOLDSTEIN, B.; POOLE, C.; SAFKO, J. Classical Mechanics. Boston: Addison Wesley, 2000.

GOOGLE-PATENTS. 2016. https://www.google.ch/patents/US3528216. Accessed: 05/01/2017.

GUPTA, A. K.; BEÉR, J. M.; LOUIS, J. F.; BUSNAINA, A. A.; LILlEY, D. G. Flow Aerodynamics Modeling of an MHD Swirl Combustor: Calculations and Experimental Verification. Journal of Fluids Engineering, v. 104, p. 385-391, 1982.

GUPTA, A. K.; LILLEY, D. G.; SYRED, N. Swirl Flows. Turnbridge Wells: Abacus Press, 1984.

HAASER, N. B.; SUllivan, J. A. Real Analysis. New York: Dover, 1991.

HAGHIGHI, M.; HAWBOLDT; A., K.; ABDI, M. A. Supersonic gas separators: Review of latest developments. Journal of Natural Gas Science and Engineering, 2015 .

HALL, M.; CACUCI, D. Physical interpretation of the adjoint functions for sensitivity analysis of atmospheric models. Journal of Atmospheric Sciences, Vol. 40 p. 2537 to $2546,1983$.

HAYASHI, M.; CEZE, M.; VOLPE, E. Characteristics-based boundary conditions for the Euler adjoint problem. International Journal for Numerical Methods in Fluids Vol. 71, No. 10 p. 1297 to 1321, 42013.

HAYASHI, M.; CEZE, M.; VOLPE, E. On the Use of the Continuous Adjoint Method to Compute Non-Geometric Sensitivities: Non-Geometric Sensitivities Using The Adjoint Method. International Journal for Numerical Methods in Fluids, 102017.

HAYASHI, M.; LIMA, J.; CHIEREGATTI, B.; VOLPE, E. Non-geometric sensitivities using the adjoint method. In: ICAAA2016. [S.l.: s.n.], 2016. v. 10, p. $155-163$.

HAYASHI, M. T. Cálculo de Sensibilidades Não-Geométricas pelas Equações de Euler Compressiveis Utilizando o Método Adjunto. Thesis (PhD) - University of São Paulo, 2016.

HICKS, R. M.; HENNE, P. A. Wing design by numerical optimization. Journal of Aircraft, v. 15, n. 7, p. 407-412, July 1978.

HODGE, B. K.; KOENIG, K. Compressible Fluid Dynamics with personal computer applications. Chennai: PearsonIN, 2016. 
HU, D. e. a. Numerical simulation of supersonic separator with axial or tangential outlet in reflow channel. Chemical Engineering and Processing: Process Intensification, 124, p. 109 to 121, 2018.

IMAEV, S. Z.; BAGIROV, L. A. e. a. New low temperature process of $\mathrm{CO}_{2}$ recovery from natural gases. In: Rio Oil \& Gas Conference. [S.l.]: Society of Petroleum Engineers Oil \& gas Conference, 2014.

INCE, E. L. Ordinary Differential Equations. London: Longman, Green and Co., 1956.

IONESCU-BUJOR, M.; JIN, X.; CACUCI, D. G. Deterministic local sensitivity analysis of augmented systems. ii: Applications to the quench-04 experiment using the relap5/mod3.2 code system. Nuclear Science and Engineering V. 151 p. 67 to $81,2005$.

JAMESON, A. Aerodynamic design via control theory. In: 12th IMACS World Congress on Scientific Computation, MAE Report 1824, Paris, pp. 1 to 40. [S.l.: s.n.], 1988.

JAMESON, A. Optimum aerodynamic design using cfd and control theory. In: AIAA 95-1729-CP. [S.1.: s.n.], 1995.

JAMESON, A.; MARTINELLI, L. An adjoint method for design optimization of ship hulls. In: 9th International Conference on Numerical Ship Hydrodynamics. [S.l.: s.n.], 2007.

JAMESON, A.; PIERCE, N.; MARTINELLI, L. Optimum aerodynamic design using the Navier-Stokes equations. In: 35th Aerospace Sciences Meeting \&6 Exhibit. [S.l.: s.n.], 1997.

JAMESON, A.; PIERCE, N.; MARTINELLI, L. Optimum aerodynamic design using the Navier-Stokes equations. Theoretical and Computational Fluid Dynamics, v. 1, p. 213-237, 1998.

JAMESON, A.; SCHIMIDT, W.; TURKEL, E. Numerical solution of the euler equations by finite volume methods using runge-kutta time-stepping schemes. AIAA Journal, 1981.

JAMESON, A.; SRIRAM, A.; MARTINELLI, L. A continuous adjoint method for unstructured grids. In: AIAA Computational Fluid Dynamics Conference. [S.1.]: AIAA 2003-3955, 2003.

KAHANER, F. N.; MOLER, C.; NASH, S. Numerical Methods and Software. Upper Saddle River, NJ: Prentice-Hall, 1989.

KARIMI, A.; ABEDINZADEGAN, A. Selective dehydration of high-pressure natural gas using supersonic nozzles. Chemical Engineering and Processing, v. 48,2009 .

KORNHUBER, K.; HOPPE, R.; PÉRIAUX, J.; PIRONNEAU, O.; WINDLUND, O.; XU, J. Domain Decomposition Methods in Sciences and Engineering. Berlin: Springer-Verlag, 2005.

KREYSZIG, E. Introductory Functional Analysis with Applications. New York: Wiley Classics Library Edition, 1989. 
KULFAN, B. M. A Universal Parametric Geometry Representation Method - "CST". In: 45th AIAA Aerospace Sciences Meeting and Exhibit. Reno, NV: [s.n.], 2007.

KULFAN, B. M.; BUSSOLETTI, J. E. Fundamental parametric geometry representations for aircraft component shapes. In: 11th AIAA/ISSMO Multidisciplinary Analysis and Optimization Conference. Portsmouth, VA: [s.n.], 2006.

LIBERZON, D. Calculus of Variations and Optimal Control Theory - A Concise Introduction. Princeton: Princeton University Press, 2012.

LIGHTHILL, M. J. A technique for rendering approximate solutions to physical problems uniformly valid. Philosophical Magazine, v. 40, p. 1179-1201, 1949.

LIONS, J. L. Optimal Control of Systems Governed by Partial Differential Equations. 1st. ed. Berlin: Springer-Verlag, 1971. (Die Grundelehren der mathematischen Wissenschaften, $170=$ ).

LUCHINI, P.; BOTTARO, A. Adjoint equations in stability analysis. Annual Review of Fluid Mechanics, Vol. 46 p. 493 to 512, 2014.

LUENBERGER, D. G. Optimization by Vector Space Methods. New York: John Wiley and Sons, 1969.

LUSTERNICK, L.; SOBOLEV, V. Elements of Functional Analysis. Delhi: Hindustan Pub. Co., 1961.

MADDAHIAN, R.; KEBRIAEE, A.; FARHANIEH, B.; FIROOZABADI, B. Analytical investigation of boundary layer growth and swirl intensity decay rate in a pipe. Archive of Applied Mechanics, v. 81(4), p. 489-501, 2011.

MARTINS, J. R.; HWANG, J. T. Review and unification of methods for computing derivatives of multidisciplinary computational models. AIAA Journal, Vol. 51, 2013 p. 2582 to 2599, 2013.

MAVRIPLIS, D. J. Unstructured Grid Techniques. Annual Review of Fluid Mechanicsl, v. 29, p. 473-514, 1997.

MELO, D. C.; GRAVA, W. M. e. a. Breakthrough on $\mathrm{CO}_{2}$ supersonic separation technology. In: Rio Oil $\&$ Gas Conference. [S.l.]: Society of Petroleum Engineers Oil \& gas Conference, 2014.

MENTER, F. R. Two Equation Eddy-Viscosity Turbulence Models for Engineering Applications. AIAA Journal, v. 32, p. 1598-1605, 1994.

MENTER, F. R. Review of the shear-stress transport turbulence model experience from an industrial perspective. International Journal of Computational Fluid Dynamicsl, v. 23, p. 305-316, 2009.

MOHAMADI, B.; PIRONNEAU, O. Applied shape optimization for fluids. Oxford: Oxford Press, 2000.

MONFORTE, J. C. Geometric, Control and Numerical Aspects of Nonholonomic Systems. Berlin: Springer-Verlag, 2002. 
MORSE, P. M.; FESHBACH, H. Methods of Theoretical Physics, Vol. 1. New York: McGraw-Hill, 1953.

ORBITALATK. 2015. www.orbitalatk. com. Accessed: 27/03/2018.

PALACIOS, F.; ECONOMON, T. D. e. a. Stanford University Unstructured $\left(\mathrm{SU}^{2}\right)$ : An open-source integrated computational environment for multi-physics simulation and design, AIAA Paper 2013-0287. In: 51st AIAA Aerospace Sciences Meeting and Exhibit. January 7th - 10th, 2013. Grapevine, Texas, USA. [S.l.]: AIAA, 2013.

PALACIOS, F.; ECONOMON, T. D. e. a. Stanford University Unstructured (SU2): Open-source analysis and design technology for turbulent flows, AIAA Paper 2014-0243. In: AIAA Science and Technology Forum and Exposition 2014: 52nd Aerospace Sciences Meeting, National Harbor, MD, January 13-17, 2014. [S.l.]: AIAA, 2014.

PARMETIS. 2020. http://glaros.dtc.umn.edu/gkhome/. Accessed: $01 / 08 / 2020$.

PIRONneAU, O. On Optimal Profiles in Stokes Flow. Cambridge: Cambridge Press, 1973.

PIRONneAU, O. On Optimal Designs in Fluid Dynamics. Cambridge: Cambridge Press, 1974.

PIRONNEAU, O. Optimal Shape Design for Elliptic Systems. New York: Springer-Verlag, 1983. (Springer Series in Computational Physics).

RESTREPO, J. e. a. Operational behavior of supersonic separators for real gas mixtures of methane and carbon dioxide, from the homogeneous nucleation point of view. Internal Report - RCGI repository. 2019.

SEDERBERG, T.; PARRY, S. Free-form deformation of solid geometric models. ACM SIGGRAPH Computer Graphics 20(4), v. 20, p. 151-160, 1986.

SHEEN, H. J.; CHEN, W. J.; JENG, S. Y.; HUANG, T. L. Correlation of Swirl Number for a Radial-type Swirl Generator. Experimental Thermal and Fluid Science, v. 12, p. 444-451, 1996.

SHIMA, E.; KEIICHI, K.; KEIICHIRO, F. New gradient calculation method for muscl type cfd schemes in arbitrary polyhedra. 48th AIAA Aerospace Sciences Meeting Including the New Horizons Forum and Aerospace Exposition, 2010.

SHIMA, E.; KITAMURA, K.; HAGA, T. Green-gauss/weighted-least-squares hybrid gradient reconstruction for arbitrary polyhedra unstructured grids. IAA Journal, AIAA Journal, Vol. 51, No. 11, DOI: 10.2514/1.J052095, 2013.

SMIRNOV, P. E.; MENTER, F. R. Sensitization of the SST Turbulence Model to Rotation and Curvature by Applying the Spalart-Shur Correction Term. ASME Journal of Turbomachinery, v. 131, 2009.

SUZUKI, M. Adsorption Engineering. New York: Elsevier, 1990.

SYRED, N.; BEÉR, J. M. Combustion Swirling Flows. Combustion and Flames, v. 23, p. 143-201, 1974. 
TWISTERBV. 2016. www.twisterbv .com. Accessed: 05/08/2017.

VAINBERG, M. M. Variational Methods for the Study of Nonlinear Operators. [S.1.]: Holden-Day, 1964. Translation from the 1956 Russian edition.

VOLPE, E.; SANTOS, L. D. C. Boundary and internal conditions for Euler adjoint fluid-flow problem. Journal of Engineering Mathematics. 65, p. 1-24, 2009 .

VOLPE, E. V. A11 - Inverse Aerodynamic Design Module. [S.1.], 2004.

VOLPE, E. V. A3 - Inverse Aerodynamic Design Applications. [S.l.], 2005.

VOLPE, E. V. Introduction to the Adjoint Method. Support library. 2016.

VOLPE, E. V.; OLIVEIRA, G. L.; SANTOS, L. C. C.; HAYASHI, M. T.; CEZE, M. A. B. Inverse aerodynamic design applications usign the mgm hybrid formulation. In: Inverse Problems Design and Optimization Symposium. Miami, FL: [s.n.], 2007.

WEN, C.; CAO, X. e. a. Swirling effects on the performance of supersonic separators for natural gas separation. Chemical Engineering and Technology, v. 34,2011 .

WEN, C.; CAO, X. e. a. Prediction of mass flow rate in supersonic natural gas processing. Oil \& Gas Science and Technology Rev. IFP Energies nouvelles, 2013.

WEN, C.; XUEWEN, C.; YANG, Y.; WENLONG, L. An unconventional supersonic liquefied technology for natural gas. Energy Education Science and Technology Part A: Energy Science and Research, 30(1): 651-660, 2012.

WIDMAnN, J. F.; CHARAGUNDLA, S. R.; PRESSER, C. Aerodynamic study of a vane-cascade swirl generator. Chemical Engineering Science, v. 55, p. 5311-5320, 2000.

WILCOX, D. C. Reassessment of the scale-determining equation for advanced turbulence model. AIAA Journal, Vol. 26, No. 11 p. 1299 to 1310, 1988.

WILCOX, D. C. Turbulence Modeling for CFD. La Cañada, USA: DCW Industries, 2006.

YANG, Y.; WEN, C.; WANG, S.; FENG, Y. Numerical simulation of real gas flows in natural gas supersonic separation processing. Journal of Natural Gas Science and Engineering, 2014.

ZHOU, R. Swirl Number for Non-Reacting and Reacting conditions of Cambridge Stratified Swirl Burner. 2012. \{https://www.repository.cam.ac. uk/bitstream/handle/1810/243259/DSpace_velocity_SwirlNumber_CSB_ LDA.pdf\}. Accessed: 12/18/2019.

ZHOU, R.; BALUSAMYA, S.; SWEENEY, M. S.; BARLOW, R. S.; HOCHGREB, S. Flow field measurements of a series of turbulent premixed and stratified methane/air flames. Combustion and Flame, v. 160, p. 2017-2028, 2013. 
ZINGG, D. W.; NEMEC, M.; PULLIAM, T. H. A comparative evaluation of genetic and gradient-based algorithms applied to aerodynamic optimization. European Journal of Computational Mechanics, Taylor and Francis, v. 17:1-2, p. 103-126, 2008. 
Appendices 


\section{Governing equations}

This appendix describes, briefly, the governing equations used in the open source code SU2, (sometimes it is written as $S U^{2}$ ), (PALACIOS; ECONOMON, 2013, 2014) for the scope of this project: Those are compressible Euler equations, compressible Navier-Stokes equations and Menter SST turbulence modeling.

\section{Compressible Euler}

In the differential form, the compressible Euler equations can be expressed as:

$$
\mathcal{R}(U)=\frac{\partial U}{\partial t}+\nabla \cdot \bar{F}^{c}(U)-S=0
$$

where $S$ is a generic source term, $U$ is the vector of conservative variables:

$$
U=\{\rho, \quad \rho \bar{u}, \quad \rho E\}^{\top}
$$

and the convective flux is:

$$
\bar{F}^{c}=\left\{\begin{array}{c}
\rho \bar{u} \\
\rho \bar{u} \otimes \bar{u}+\overline{\bar{I}} p \\
\rho E \bar{u}+p \bar{u}
\end{array}\right\}
$$

Considering an ideal gas, the static pressure expression is:

$$
p=(\gamma-1) \rho\left[E-\frac{1}{2}(\bar{u} \cdot \bar{u})\right]
$$

and the temperature is:

$$
T=p /\left(\rho R_{\text {gas }}\right)
$$

$\bar{u} \in \mathbb{R}^{3}$ is the flow velocity using Cartesian reference:

$$
\bar{u}=\{u, \quad v, w\}^{\top}
$$

The remaining symbols in the above equations are:

$R_{\text {gas }}$ is the gas constant; $\gamma$ is the ratio of specific heats $\left(\gamma=C_{p} / C_{v}\right)$, and $E$ 
is the total energy per unit mass.

\section{Compressible Navier-Stokes}

In the differential form, the compressible Navier-Stokes equations can be expressed as:

$$
\mathcal{R}(U)=\frac{\partial U}{\partial t}+\nabla \cdot \bar{F}^{c}(U)-\nabla \cdot \bar{F}^{v}(U, \nabla U)-S=0
$$

where $S$ is a generic source term, $U$ is the vector of conservative variables:

$$
U=\left\{\begin{array}{lll}
\rho, & \rho \bar{u}, & \rho E
\end{array}\right\}^{\top}
$$

the convective flux is:

$$
\bar{F}^{c}=\left\{\begin{array}{c}
\rho \bar{u} \\
\rho \bar{u} \otimes \bar{u}+\overline{\bar{I}} p \\
\rho E \bar{u}+p \bar{u}
\end{array}\right\}
$$

and the viscous flux is:

$$
\bar{F}^{v}=\left\{\begin{array}{c}
\cdot \\
\overline{\bar{\tau}} \\
\overline{\bar{\tau}} \cdot \bar{u}+k \nabla T
\end{array}\right\}
$$

Considering an ideal gas, the static pressure expression is:

$$
p=(\gamma-1) \rho\left[E-\frac{1}{2}(\bar{u} \cdot \bar{u})\right]
$$

and the temperature is:

$$
T=p /\left(\rho R_{\text {gas }}\right)
$$

$\bar{u} \in \mathbb{R}^{3}$ is the flow velocity using Cartesian reference:

$$
\bar{u}=\{u, \quad v, w\}^{\top}
$$

The viscous stress tensor is: 


$$
\overline{\bar{\tau}}=\mu\left(\nabla \bar{u}+\nabla \bar{u}^{\top}\right)-\mu \frac{2}{3} \overline{\bar{I}}(\nabla \cdot \bar{u})
$$

The remaining symbols in the above equations are:

$R_{\text {gas }}$ is the gas constant; $\gamma$ is the ratio of specific heats $\left(\gamma=C_{p} / C_{v}\right), E$ is the total energy per unit mass and $\mu$ is the viscosity. The thermal conductivity can be a constant, or expressed by $k=\mu C_{p} / \operatorname{Pr}$ where $\operatorname{Pr}$ is the Prandtl number.

\section{Menter's Shear-Stress Transport Model}

In the original article (MENTER, 1994), Lagrangian derivatives are used. The equations are written in conservation form here.

$$
\begin{gathered}
\frac{\partial(\rho \kappa)}{\partial t}+\frac{\partial\left(\rho u_{j} \kappa\right)}{\partial x_{j}}=P-\beta^{*} \rho \omega \kappa+\frac{\partial}{\partial x_{j}}\left[\left(\mu+\sigma_{\kappa} \mu_{t}\right) \frac{\partial \kappa}{\partial x_{j}}\right] \\
\frac{\partial(\rho \omega)}{\partial t}+\frac{\partial\left(\rho u_{j} \omega\right)}{\partial x_{j}}=\frac{\gamma}{\nu_{t}} P-\beta \rho \omega^{2}+\frac{\partial}{\partial x_{j}}\left[\left(\mu+\sigma_{\omega} \mu_{t}\right) \frac{\partial \omega}{\partial x_{j}}\right]+2\left(1-F_{1}\right) \rho \sigma_{\omega 2} \frac{1}{\omega} \frac{\partial \kappa}{\partial x_{j}} \frac{\partial \omega}{\partial x_{j}} \\
P=\tau_{i j} \frac{\partial u_{i}}{\partial x_{j}} \\
\tau_{i j}=\mu_{t}\left(2 S_{i j}-\frac{2}{3} \frac{\partial u_{\kappa}}{\partial x_{\kappa}} \delta_{i j}\right)-\frac{2}{3} \rho \kappa \delta_{i j} \\
S_{i j}=\frac{1}{2}\left(\frac{\partial u_{i}}{\partial x_{j}}+\frac{\partial u_{j}}{\partial x_{i}}\right) \\
\mu_{t}=\frac{\rho a_{1} \kappa}{\max \left(a_{1} \omega, \Omega F_{2}\right)}
\end{gathered}
$$

The equation (21) yields the blended value of each constant: The constants of the inner set (WILCOX, 1988), have the subscript 1 and the constants of the outer set (those from the standard $\kappa-\epsilon$ model) have the subscript 2. Equation (21) will provide the new blended value. For example, $\gamma=F_{1} \gamma_{1}+\left(1-F_{1}\right) \gamma_{2}$.

$$
\phi=F_{1} \phi_{1}+\left(1-F_{1}\right) \phi_{2}
$$




$$
\begin{gathered}
F_{1}=\tanh \left(\arg _{1}^{4}\right) \\
\left.\arg g_{1}=\min \left[\max \left(\frac{\sqrt{\kappa}}{\beta^{*} \omega d}, \frac{500 \nu}{d^{2} \omega}\right), \frac{4 \rho \sigma_{\omega 2} \kappa}{C D_{\kappa \omega} d^{2}}\right)\right] \\
C D_{\kappa \omega}=\max \left(2 \rho \sigma_{\omega 2} \frac{1}{\omega} \frac{\partial \kappa}{\partial x_{j}} \frac{\partial \omega}{\partial x_{j}}, 10^{-20}\right) \\
F_{2}=\tanh \left(\arg { }^{2}\right) \\
\arg _{2}=\max \left(\frac{2 \sqrt{\kappa}}{\beta^{*} \omega d}, \frac{500 \nu}{d^{2} \omega}\right) \\
\nu_{t}=\mu_{t} / \rho \\
\Omega=\frac{1}{2}\left(\frac{\partial u_{i}}{\partial x_{j}}-\frac{\partial u_{j}}{\partial x_{i}}\right) \\
\sqrt{2 W_{i j} W_{i j}}
\end{gathered}
$$

The constants which must be used in the above equations are:

$$
\begin{aligned}
& \gamma_{1}=\frac{\beta_{1}}{\beta^{*}}-\frac{\sigma_{\omega_{1}} \kappa^{2}}{\sqrt{\beta^{*}}} \\
& \gamma_{2}=\frac{\beta_{2}}{\beta^{*}}-\frac{\sigma_{\omega_{2}} \kappa^{2}}{\sqrt{\beta^{*}}} \\
& \beta^{*}=0.09 ; \\
& \beta_{1}=0.0750 \\
& \beta_{2}=0.0828 \\
& \sigma_{\kappa 1}=0.85 \text {; } \\
& \sigma_{\kappa 2}=1.0 \text {; } \\
& \sigma_{\omega 1}=0.5 \text {; } \\
& \kappa=0.41 ; \\
& a_{1}=0.31
\end{aligned}
$$$$
\sigma_{\omega 2}=0.856
$$ 